ZRC SAZU, UMETNOSTNOZGODOVINSKI INŠTITUT FRANCETA STELETA

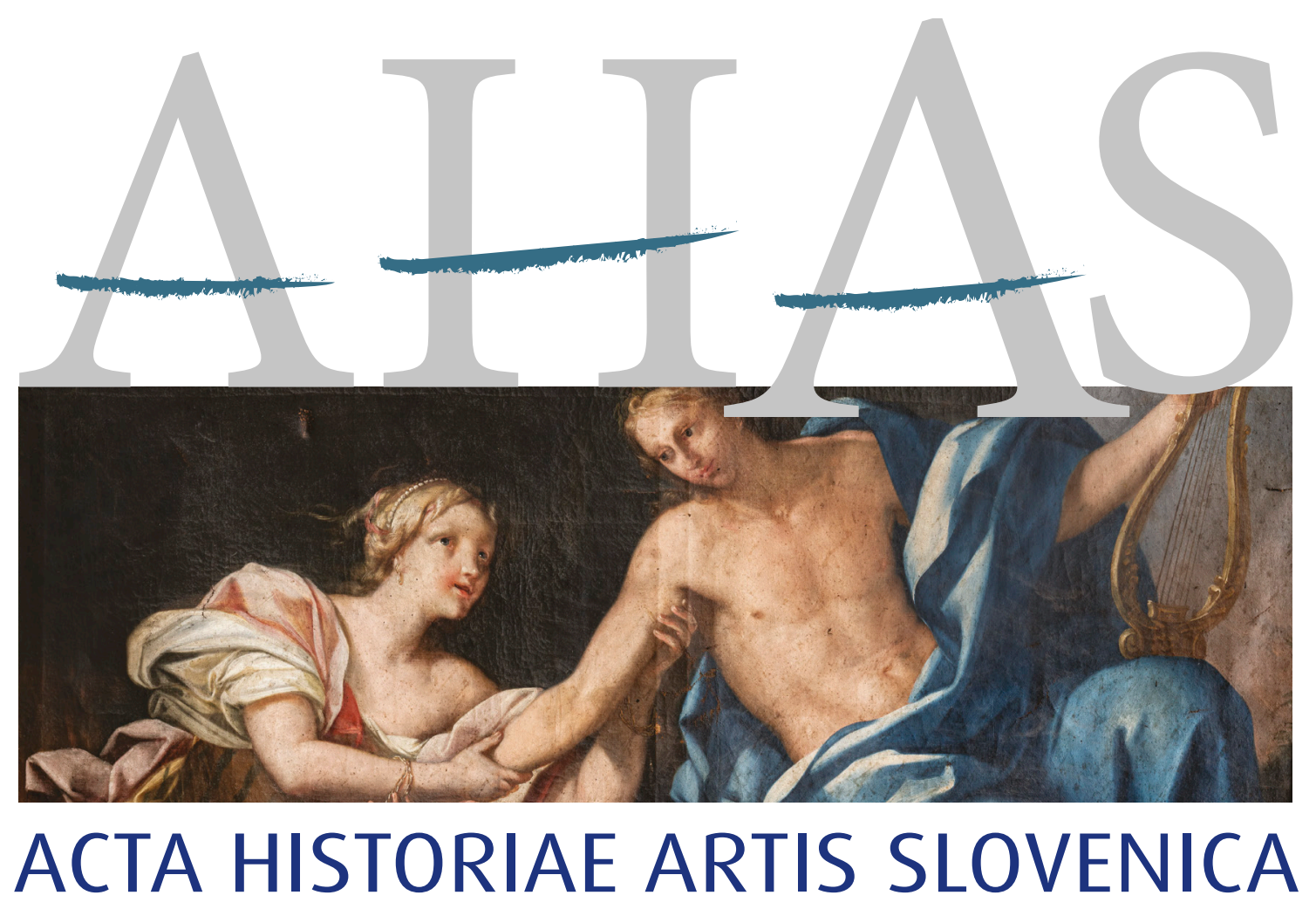

Frančišek Karel Remb in slikarstvo

v habsburških dednih deželah okrog leta 1700

Franz Carl Remp and Painting in the Habsburg Hereditary Lands around 1700

Franz Carl Remp und die Malerei in den habsburgischen Erblanden um 1700

$$
26 \mid 2 \cdot 2021
$$




\section{ACTA HISTORIAE ARTIS SLOVENICA $26 \mid 2 \cdot 2021$}

Frančišek Karel Remb in slikarstvo v habsburških dednih deželah okrog leta 1700

Franz Carl Remp and Painting in the Habsburg Hereditary Lands around 1700

Franz Carl Remp und die Malerei in den habsburgischen Erblanden um 1700 
Acta historiae artis Slovenica, 26/2, 2021

Frančišek Karel Remb in slikarstvo v habsburških dednih deželah okrog leta 1700

Franz Carl Remp and Painting in the Habsburg Hereditary Lands around 1700

Franz Carl Remp und die Malerei in den habsburgischen Erblanden um 1700

Znanstvena revija za umetnostno zgodovino / Scholarly Journal for Art History

ISSN 1408-0419 (tiskana izdaja / print edition) ISSN 2536-4200 (spletna izdaja / web edition)

ISBN 978-961-05-0568-6

Izdajatelj / Issued by

ZRC SAZU, Umetnostnozgodovinski inštitut Franceta Steleta /

ZRC SAZU, France Stele Institute of Art History

Založnik / Publisher

Založba ZRC

Urednika / Edited by

Edgar Lein, Polona Vidmar

Uredniški odbor / Editorial board

Renata Komić Marn, Tina Košak, Katarina Mohar, Mija Oter Gorenčič, Blaž Resman, Helena Seražin

Mednarodni svetovalni odbor / International advisory board

Günter Brucher (Salzburg), Ana María Fernández García (Oviedo), Hellmut Lorenz (Wien),

Milan Pelc (Zagreb), Sergio Tavano (Gorizia-Trieste), Barbara Wisch (New York)

Lektoriranje / Language editing

Oliver Currie, Manuela Dajnko, Andrea Leskovec

Prevodi / Translations

Alan Harvey Cook, Blaž Resman, Nika Vaupotič, Polona Vidmar

Celostni strokovni in jezikovni pregled / Expert and language editing

Blaž Resman

Oblikovna zasnova in prelom / Design and layout

Andrej Furlan

Naslov uredništva / Editorial office address

Acta historiae artis Slovenica

Novi trg 2, p. p. 306, SI -1001 Ljubljana, Slovenija

ahas@zrc-sazu.si; https://ojs.zrc-sazu.si/ahas

Revija je indeksirana v / Journal is indexed in

Scopus, ERIH PLUS, EBSCO Publishing, IBZ, BHA

Letna naročnina / Annual subscription: $35 €$

Posamezna enojna številka / Single issue: $25 €$

Letna naročnina za študente in dijake: $25 €$

Letna naročnina za tujino in ustanove / Annual subscription outside Slovenia, institutions: $48 €$

Naročila sprejema / For orders contact

Založba ZRC

Novi trg 2, p. p. 306, SI-1001, Slovenija

E-pošta / E-mail: zalozba@zrc-sazu.si

AHAS izhaja s podporo Javne agencije za raziskovalno dejavnost Republike Slovenije.

AHAS is published with the support of the Slovenian Research Agency.

(c) 2021, ZRC SAZU, Umetnostnozgodovinski inštitut Franceta Steleta, Založba ZRC, Ljubljana Tisk / Printed by Collegium Graphicum d.o.o., Ljubljana

Naklada / Print run: 400 


\section{VSEBINA \\ Contents}

Edgar Lein, Polona Vidmar

Frančišek Karel Remb in slikarstvo v habsburških dednih deželah okrog leta 1700. Predgovor ...........................5

Franz Carl Remp and Painting in the Habsburg Hereditary Lands around 1700. Preface .....................................7

Franz Carl Remp und die Malerei in den habsburgischen Erblanden um 1700. Vorwort .....................................9

\section{DISSERTATIONES}

Karin Požin

Remp's Ceiling Paintings in the Palais Attems in Graz. From Reproductive Prints to Frescoes

Rembove stropne poslikave v graški palači Attems. Od grafičnih predlog do fresk ...13

Georg Lechner

Franz Carl Remp zwischen Graz und Wien 31

Frančišek Karel Remb med Gradcem in Dunajem 48

Edgar Lein

Preis und Wert der Malerei um 1700. Zu den Kosten von Gemälden in der Steiermark 51

Cena in vrednost slik okrog leta 1700. O stroških za slike na Štajerskem

Renata Komić Marn

Zaplemba - prenos - distribucija. Slike grofa Attemsa iz gradu Slovenska Bistrica $v$ slovenskih javnih zbirkah

Confiscation - Transfer - Distribution. Count Attems' Paintings from

Slovenska Bistrica Castle in Slovenian Public Collections

Polona Vidmar

Emblematische Gratulationsschriften, Stammbäume und Porträts

von Dominik Franz Calin von Marienberg für das Haus Habsburg.

Emblematična voščila, rodovniki in portreti Dominika Frančiška Kalina

von Marienberga za Habsburžane

Ulrich Becker

Weltgeschichte im Wimmelbild. Stephan Kessler und der Entsatz von Wien 1683.

Svetovna zgodovina na »mrgoleči sliki«. Stephan Kessler in Rešitev Dunaja leta 1683 
Andreas Gamerith

Zeit des Experiments. Die Galleria maior des Stiftes Zwettl als Beispiel

für seicenteske Wandmalerei in Niederösterreich.

Čas eksperimentiranja. Galleria maior v samostanu Zwettl

kot primer stenskega slikarstva 17. stoletja v Spodnji Avstriji

\section{Martin Mádl}

The Patterns of the Transformation in Central European Ceiling Painting

around 1700 and Franz Carl Remp in Brežice Castle.

Vzorci transformacije v srednjeevropskem stropnem slikarstvu okrog leta 1700

in Frančišek Karel Remb v brežiškem gradu 


\section{Predgovor}

\section{FranČIŠEK KAREL REMB IN SLIKARSTVO V HABSBURŠKIH DEDNIH DEŽELAH OKROG LETA 1700}

Kljub razmeroma številnim slikam je ostal opus v Radovljici rojenega ter v Gradcu in na Dunaju delujočega slikarja Frančiška Karla Remba (1675-1718) široki javnosti doslej večinoma neznan. Prva in zaenkrat edina razstava Rembovih del je bila od 26. oktobra 1973 do 19. maja 1974 na ogled v Spodnjem Belvederu na Dunaju ter junija 1974 v vogalni sobi Stare galerije muzeja Joanneum v graški Neutorgasse. Razstavni katalog z naslovom Der Barockmaler Franz Carl Remp 1674-1718 vsebuje sedem strani obsegajoč uvod v umetnikovo življenje in delo, kataložni del z dvajsetimi enotami, časovnico in seznam literature.

Georg Lechner se je s Frančiškom Karlom Rembom ukvarjal v okviru svoje leta 2010 na Dunaju obranjene doktorske disertacije. Ko je spomladi 2018 Lechner opozoril, da se jeseni bliža tristota obletnica Rembove smrti, vendar ni niti na Dunaju niti v Gradcu načrtovana kakšna razstava slikarjevih del, smo se odločili za organizacijo simpozija, ki je pod naslovom Slikarji in naročniki. Frančišek Karel Remb in slikarstvo na Štajerskem okrog 1700 potekal 23. novembra 2018 v Laterneng'wölb dvorca Eggenberg. Naslednji dan so si udeleženci pod vodstvom Georga Lechnerja ogledali palačo Attems in pod vodstvom Paula Schusterja reprezentativne prostore dvorca Eggenberg. Simpozij so podprli univerzi v Gradcu in Mariboru ter Znanstvenoraziskovalni center Slovenske akademije znanosti in umetnosti, Umetnostnozgodovinski inštitut Franceta Steleta. Bil je del bilateralnega projekta BI SLO-AT/16-17-18: Umetnostni naročniki kot nosilci deželne identitete. Vloga in pomen naročnikov za gradnjo in opremo plemiških rezidenc in romarskih središč na Štajerskem, ki sta ga financirala Javna agencija za raziskovalno dejavnost Republike Slovenije in Österreichischer Austauschdienst, ter temeljnega raziskovalnega projekta J6-7410: Umetnostna reprezentacija plemstva. Naročništvo na Štajerskem $v$ zgodnjem novem veku (2016-2018), ki ga je financirala Javna agencija za raziskovalno dejavnost Republike Slovenije.

Simpozij so otvorili Georg Lechner s temeljnim prispevkom o Frančišku Karlu Rembu med Gradcem in Dunajem (Franz Carl Remp zwischen Graz und Wien), Christine Rabensteiner, ki je predstavila dela priseljenih in na Štajerskem rojenih baročnih slikarjev v depojih graške Stare galerije (Werke immigrierter und gebürtiger steirischer Barockmaler. Ein Blick in das Depot der Alten Galerie), ter Karin Požin s študijo o Rembovih stropnih poslikavah v palači Attems v Gradcu in likovnih virih zanje (Case Study of Remp's Ceiling Paintings in Palais Attems in Graz. From Reproductive Prints to Frescoes). V drugem delu je Edgar Lein predstavil ceno in vrednost slikarskih del okrog 1700 (Preis und Wert der Malerei um 1700), Tina Košak pa je na podlagi virov v mestnem arhivu v Antwerpnu raziskala trgovce $\mathrm{z}$ umetninami iz družine Forchondt in njihove štajerske stranke (The Forchondt Art Dealers and their Styrian Clients. Excerpts from the Antwerp City Archives). Renata Komić Marn je analizirala portrete Eleonore Marije Rozalije kneginje Eggenberg (The Portraits of Eleonora Maria Rosalia Princess of Eggenberg), Polona Vidmar pa je predstavila slikane genealogije štajerskega plemstva okrog leta 1700 (Gemalte Genealogien des steirischen Adels um 1700). Meje historične Štajerske so s svojimi referati presegli Ulrich Becker, ki je Stephanu Kesslerju pripisal upodobitvi Rešitve 
Dunaja leta 1683 (Weltgeschichte als Wimmelbild. Stephan Kessler und der Entsatz von Wien 1683), Andreas Gamerith, ki se je ukvarjal s stropnimi poslikavami pred Trogerjem oziroma okrog leta $1700 \mathrm{v}$ samostanih Zwettl in Altenburg (Vor Troger. Aspekte der Wandmalerei um 1700 am Beispiel der Klöster Zwettl und Altenburg), ter Martin Mádl z izčrpnim predavanjem o češkem stropnem slikarstvu okoli 1700 („So ist nun ... der Pracht im Bauen so hoch gestiegen ..... Profane Ceiling Painting in Bohemia around 1700).

Udeleženci simpozija so svoje referate pripravili za tisk ali pa so prispevali nova raziskovalna spoznanja, ki jih v Acta historiae artis Slovenica objavljamo pod naslovom Frančišek Karel Remb in slikarstvo v habsburških dednih deželah okrog leta 1700. Prispevka Karin Požin in Georga Lechnerja poglabljata vedenje o Rembovih stenskih poslikavah v palači Attems in o delih, ki jih je ustvaril po selitvi na Dunaj. Nekatere Rembove oljne slike so obravnavane tudi v prispevkih Edgarja Leina, ki se je posvetil stroškom za slike na Štajerskem, ter Renate Komić Marn, ki je raziskala slike iz Attemsove zbirke v Slovenski Bistrici v slovenskih javnih zbirkah. Slikarstvo zadnjih desetletij 17. stoletja je tema prispevkov Polone Vidmar, ki se je posvetila delom Dominika Frančiška Kalina von Marienberga za Habsburžane, in Ulricha Beckerja, ki je upodobitvi Rešitve Dunaja atribuiral tirolskemu slikarju Stephanu Kesslerju. Andreas Gamerith je Gallerio maior v samostanu Zwettl predstavil kot eksperiment v stropnem slikarstvu poznega 17. stoletja v Spodnji Avstriji, zvezek pa zaključuje prispevek Martina Mádla, ki se je posvetil transformaciji srednjeevropskega slikarstva okrog leta 1700 in pomembnim zgledom zanjo.

Upava, da bodo raznoliki prispevki in številne upodobitve spodbudili nadaljnje raziskovanje baročnega slikarstva. 


\section{Preface}

\section{Franz Carl Remp and Painting in THE HABSbURg Hereditary LANDS AROUND 1700}

The oeuvre of Radovljica born painter Franz Carl Remp (1675-1718) who worked in Graz and Vienna is little-known to the wider public despite his relatively numerous paintings. The first and only exhibition of Remp's works up to now was held from 26 October 1973 to 19 May 1974 at the Lower Belvedere in Vienna, and in the corner room of the present-day Universalmuseum Joanneum's Alte Galerie in Neutorgasse in Graz in June 1974. The exhibition catalogue entitled Der Barockmaler Franz Carl Remp 1674-1718 includes a seven-page introduction to the artist's life and work, a catalogue comprising twenty units, a chronology, and list of sources.

Georg Lechner researched Franz Carl Remp in his PhD thesis, which he defended 2010 in Vienna. In the spring of 2018, Lechner drew attention to the fact that the $300^{\text {th }}$ anniversary of the painter's death would occur in the autumn of the same year, and that neither Vienna nor Graz planned to commemorate the anniversary with an exhibition of the Baroque painter's works. We therefore decided to organize a conference entitled Painters and Patrons. Franz Carl Remp and Painting in Styria around 1700 that was held on 23 November 2018 at the Laterneng'wölb in the Eggenberg Castle. The following day the participants went on a tour of the Palais Attems, guided by Georg Lechner, as well as a tour of Eggenberg Castle's monumental rooms guided by Paul Schuster. The conference was supported by the Universities of Graz and Maribor, and the Research Centre of the Slovenian Academy of Sciences and Arts, the France Stele Institute of Art History. It formed part of the bilateral project BI SLO-AT/16-17-18: Art Patrons as Carriers of Province's Identity. The Role and Significance of Commissioners of Architectures and Furnishings of Aristocratic Residences and Pilgrimage Sites in Styria, which was financed by the Slovenian Research Agency and the Österreichischer Austauschdienst, and the research project J6-7410: Visual Representations of the Nobility. Early Modern Art Patronage in the Styria Province (2016-2018), financed by the Slovenian Research Agency.

The conference opened with Georg Lechner's general and foundational contribution - Franz Carl Remp between Graz and Vienna (Franz Carl Remp zwischen Graz und Wien) - followed by Christine Rabensteiner, who presented the works of immigrant and Styria-born Baroque painters in storage in the Alte Galerie in Graz (Werke immigrierter und gebürtiger steirischer Barockmaler. Ein Blick in das Depot der Alten Galerie), and Karin Požin with her study of Remp's ceiling paintings in Palais Attems in Graz and their sources (Case Study of Remp's Ceiling Paintings in Palais Attems in Graz. From Reproductive Prints to Frescoes). In the second part of the conference there were papers on the wider context and Styrian art of the period. Edgar Lein gave a spech on the cost and value of paintings around 1700 (Preis und Wert der Malerei um 1700). Tina Košak presented a study of the art dealers from the Forchondt family and their Styrian clients based on sources in the Antwerp city archives (The Forchondt Art Dealers and their Styrian Clients. Excerpts from the Antwerp City Archives). Renata Komić Marn analysed the portraits of Eleonora Maria Rosalia Princess of Eggenberg (The Portraits of Eleonora Maria Rosalia Princess of Eggenberg), and Polona Vidmar presented the painted genealogies of Styrian nobility around 1700 (Gemalte Genealogien des steirischen Adels um 
1700). The final section of the conference went beyond the borders of historical Styria: Ulrich Becker attributed the depictions of the Liberation of Vienna in 1683 to Stephan Kessler (Weltgeschichte als Wimmelbild. Stephan Kessler und der Entsatz von Wien 1683); Andreas Gamerith dealt with ceiling paintings in the Zwettl and Altenburg monasteries before Troger (Vor Troger. Aspekte der Wandmalerei um 1700 am Beispiel der Klöster Zwettl und Altenburg), and Martin Mádl gave a detailed paper on Czech ceiling painting around 1700 („So ist nun ... der Pracht im Bauen so hoch gestiegen .... Profane Ceiling Painting in Bohemia around 1700).

The conference participants prepared their papers for publication, or contributed new research findings, which are now being published in the Acta historiae artis Slovenica under the title Franz Carl Remp and Painting in the Habsburg Hereditary Lands around 1700. The contributions by Karin Požin and Georg Lechner deepen our knowledge of Remp's ceiling paintings in the Palais Attems, as well of the works he created after moving to Vienna. Some of Remp's oil paintings are also treated in the papers by Edgar Lein, who focuses on the cost of paintings in Styria, and by Renata Komić Marn, who discusses the paintings from the Attems collection in Slovenska Bistrica in Slovenian public collections. The topic of the papers by Polona Vidmar, who focuses on Dominik Franz Kalin von Marienberg's works for the Habsburg family, and Ulrich Becker, who attributes the depictions of the Liberation of Vienna to Tyrolian painter Stephan Kessler, is the painting of the last decades of the $17^{\text {th }}$ century. Andreas Gamerith discusses the Galleria maior in the Zwettl monastery as an experiment in ceiling painting in late $17^{\text {th }}$ century Lower Austria. The volume is concluded by Martin Mádl's contribution, which focuses on the transformation of Central European painting around 1700 and the models that were important for this transformation.

We hope that the diverse contributions and the numerous depictions will encourage further research in Baroque painting. 


\section{VORWORT}

\section{Franz CARl Remp UNd die MAlerei IN DEN HABSBURGISCHEN ERBLANDEN \\ UM 1700}

Trotz einer relativ großen Anzahl von Gemälden ist das CEuvre des in Radovljica in Slowenien geborenen und in Graz sowie Wien tätigen Malers Franz Carl Remp (1675-1718) einer breiten Öffentlichkeit bislang weitgehend unbekannt geblieben. Die erste und bislang einzige Ausstellung mit Werken des Malers wurde vom 26. Oktober 1973 bis zum 19. Mai 1974 im Unteren Belvedere in Wien und im Juni 1974 im Ecksaal der Alten Galerie des Joanneums in der Grazer Neutorgasse gezeigt. Das Katalogbändchen mit dem Titel Der Barockmaler Franz Carl Remp 1674-1718 enthält eine sieben Seiten umfassende Einführung zu Leben und Werk des Künstlers, einen Katalogteil mit zwanzig Einträgen, eine Zeittafel und ein Literaturverzeichnis.

Georg Lechner hat sich im Rahmen seiner 2010 in Wien abgeschlossenen Dissertation umfassend mit Franz Carl Remp befasst. Als Lechner im Frühjahr 2018 darauf hinwies, dass sich der 300. Todestag des Malers im Herbst nähere, aber weder in Wien noch in Graz eine Ausstellung mit Werken des Barockmalers geplant sei, beschlossen die Herausgeber, eine Tagung zu organisieren, die am 23. November 2018 unter dem Titel Maler und Auftraggeber. Franz Carl Remp und die Malerei in der Steiermark um 1700 im Laterneng'wölb von Schloss Eggenberg abgehalten wurde. Ergänzend dazu gab es am darauffolgenden Tag eine Besichtigung des Palais Attems unter der Leitung von Georg Lechner sowie eine Führung von Paul Schuster durch die Prunkräume von Schloss Eggenberg. Die von den Universitäten in Graz und Maribor sowie dem France Stele Institut für Kunstgeschichte am Forschungszentrum der Slowenischen Akademie der Wissenschaften und Künste unterstützte Veranstaltung war Teil des von der Slowenischen Forschungsagentur und dem Österreichischen Austauschdienst finanzierten bilateralen Projekts BI SLO-AT/16-17-18: Art Patrons as Carriers of Province's Identity. The Role and Significance of Commissioners of Architectures and Furnishings of Aristocratic Residences and Pilgrimage Sites in Styria sowie des von der Slowenischen Forschungsagentur finanzierten Forschungsprojekts J6-7410: Visual Representations of the Nobility. Early Modern Art Patronage in the Styria Province (2016-2018).

Den Anfang der Tagung machten Georg Lechner mit einem grundlegenden Vortrag über Franz Carl Remp zwischen Graz und Wien und Christine Rabensteiner mit Werke immigrierter und gebürtiger steirischer Barockmaler. Ein Blick in das Depot der Alten Galerie sowie Karin Požin mit einer Case Study of Remp's Ceiling Paintings in Palais Attems in Graz. From Reproductive Prints to Frescoes. Im zweiten Teil untersuchten Edgar Lein Preis und Wert der Malerei um 1700 und Tina Košak The Forchondt Art Dealers and their Styrian Clients. Excerpts from the Antwerp City Archives. Renata Komić Marn analysierte The Portraits of Eleonora Maria Rosalia Princess of Eggenberg und Polona Vidmar präsentierte Gemalte Genealogien des steirischen Adels um 1700. Den Blick über die Steiermark hinaus weiteten Ulrich Becker mit seinem Vortrag Weltgeschichte als Wimmelbild. Stephan Kessler und der Entsatz von Wien 1683, Andreas Gamerith mit einem Blick auf die Malerei Vor Troger. Aspekte der Wandmalerei um 1700 am Beispiel der Klöster Zwettl und Altenburg und Martin Mádl mit einem umfassenden Vortrag zum Thema „So ist nun ... der Pracht im Bauen so hoch gestiegen ..... Profane Ceiling Painting in Bohemia around 1700. 
Die Referenten und Referentinnen überarbeiteten ihre Vorträge für die Drucklegung oder präsentierten neue Forschungsergebnisse, die wir in den Acta historiae artis Slovenica unter dem Titel Franz Carl Remp und die Malerei in den habsburgischen Erblanden um 1700 veröffentlichen. Die Beiträge von Karin Požin und Georg Lechner erweitern das Wissen über Remps Wandmalereien im Palais Attems und über sein nach der Übersiedlung nach Wien geschaffenes Werk. Einige Ölgemälde Remps werden auch in den Beiträgen von Edgar Lein, der sich den Kosten für Gemälde in der Steiermark widmet, und Renata Komić Marn, die die Gemälde der ursprünglich in Schloss Slovenska Bistrica befindlichen Sammlung Attems in slowenischen öffentlichen Sammlungen untersucht, behandelt. Die Malerei in den letzten Jahrzehnten des 17. Jahrhunderts ist das Thema der Beiträge von Polona Vidmar, die die Werke Dominik Franz Calins von Marienberg für das Haus Habsburg präsentiert, und Ulrich Becker, der zwei Darstellungen des Entsatzes von Wien dem Tiroler Maler Stephan Kessler zuschreibt. Andreas Gamerith thematisiert die Galleria maior in Stift Zwettl als ein Experiment der Deckenmalerei des späten 17. Jahrhunderts in Niederösterreich. Der Band endet mit dem Beitrag von Martin Mádl, der sich der Transformation der mitteleuropäischen Wandmalerei um 1700 und ihren bedeutenden Vorbildern widmet.

Wir hoffen, dass die vielfältigen Beiträge und die zahlreichen Abbildungen zu einer weiteren Beschäftigung mit der Barockmalerei anregen werden.

Edgar Lein, Polona Vidmar 


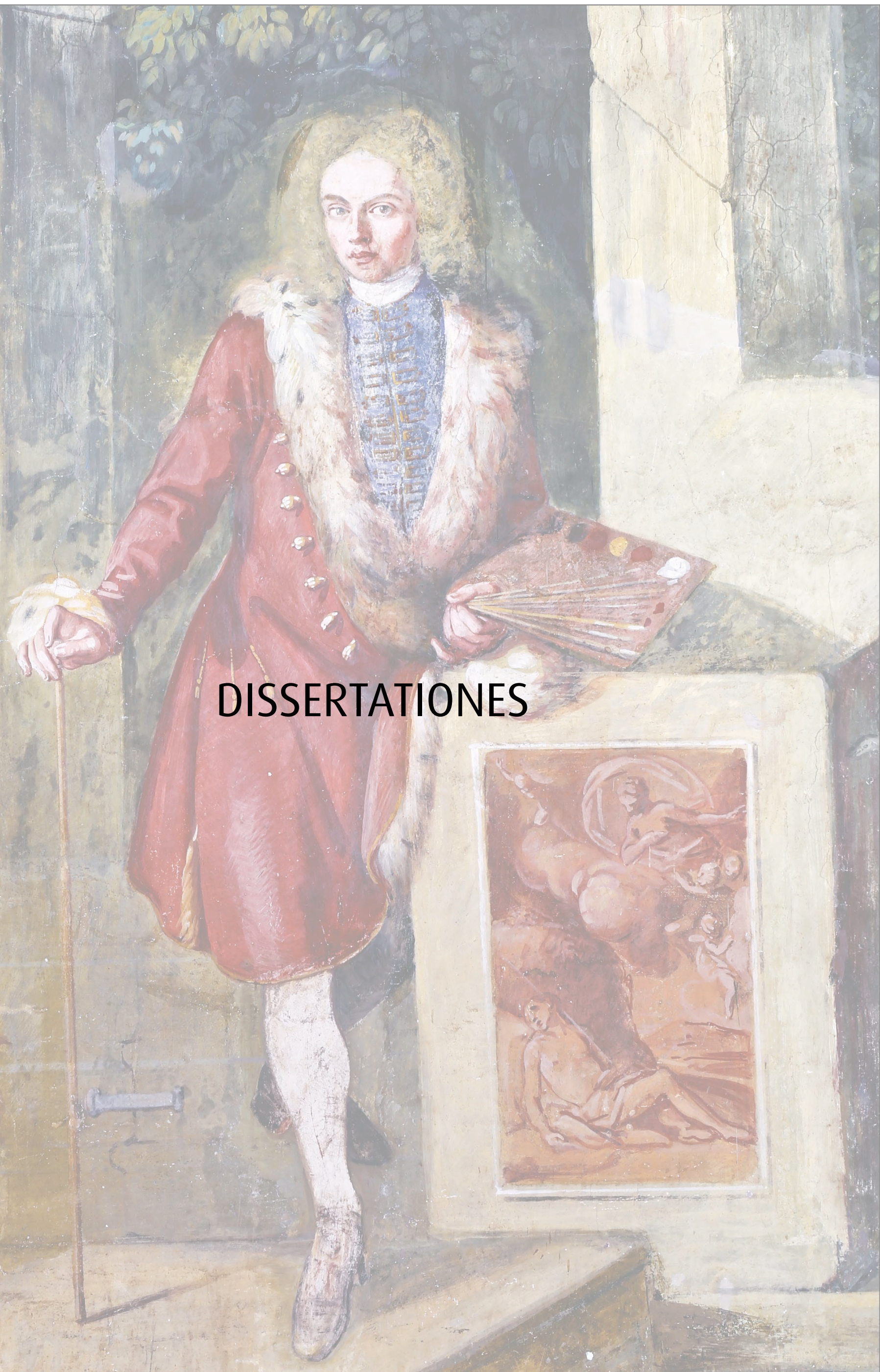




\title{
Emblematische Gratulationsschriften, Stammbäume und Porträts von Dominik Franz Calin von Marienberg für das Haus Habsburg
}

\author{
Polona Vidmar \\ Dr. Polona Vidmar, Univerza v Mariboru, Filozofska fakulteta, Oddelek za umetnostno zgodovino,
} Koroška cesta 160, 2000 Maribor, polona.vidmar@um.si

Izvleček:

Emblematična voščila, rodovniki in portreti Dominika Frančiška Kalina von Marienberga za Habsburžane

1.01 Izvirni znanstveni članek

V prispevku so obravnavani emblematični slavilni spisi in rodovniki, ki jih je Dominik Frančǐ̌ek Kalin von Marienberg (1624-1683) ustvaril za cesarja Leopolda I. Učeni in likovno nadarjeni Kalin je kot poet, libretist, historiograf, genealog, risar in slikar pisal panegirične spise in genealoške študije za bavarskega volilnega kneza, cesarja Leopolda I. in dunajsko dvorno plemstvo ter jih deloma tudi sam ilustriral. Prvič je obravnavan rokopis Corona Immortalis Gloriae s Kalinovim besedilom in emblemi njegove soproge Marije Ane Sibile Kalin. Pomemben in doslej skoraj spregledan pa je tudi Kalinov prispevek k vizualizaciji genealoških podatkov. Leta 1666 je Kalin zasnoval in naslikal reprezentančen rodovnik, na katerem je izvor Habsburžanov izpeljal iz frankovskega kralja Faramunda iz Troje in zaključil s portretoma cesarja Leopolda I. in Margarete Terezije. Istega leta je za cesarja naslikal tudi reprezentančno upodobitev s portreti cesarjev Svetega rimskega cesarstva od Karla Velikega do Leopolda I., rimskih in bizantinskih cesarjev ter osmanskih sultanov.

Ključne besede: Dominik Frančišek Kalin von Marienberg (1624-1683), Marija Ana Sibila Kalin, Habsburžani, genealogija, rodovnik, emblem, umetnostno naročništvo

\author{
Abstract: \\ Dominik Franz Calin von Marienberg's Emblematic Congratulatory Writings, Family Trees and Portraits \\ for the Habsburg Family
}

1.01 Original scientific article

The paper discusses the emblematic congratulatory writings and family trees which Dominik Franz Calin von Marienberg (1624-1683) created for Emperor Leopold I. As a poet, librettist, historiographer, genealogist, draughtsman, and painter, the educated and artistically talented Calin wrote panegyric essays and genealogical studies for the Bavarian prince-elector, Emperor Leopold I, and the Viennese court nobility, which he also partly illustrated. The manuscript Corona Immortalis Gloriae with Calin's text and the emblems of Calin's wife Maria Anna Sibylla Calin are analysed for the first time. Also important and practically overlooked is Calin's contribution to the visualization of genealogical data. In 1666, Calin designed and painted a grand family tree, where he traced the origin of the Habsburg family to the Frankish King Pharamond of Troy, and concluded with portraits of Emperor Leopold I and Margaret Theresa of Spain. In the same year he also painted for the emperor a monumental painting including the portraits of emperors of the Holy Roman Empire from Charles the Great to Leopold I, Roman and Byzantine emperors, and the Ottoman sultans.

Keywords: Dominik Franz Calin von Marienberg (1624-1683), Maria Anna Sibylla Calin, the Habsburgs, genealogy, family tree, emblem, art patronage 
Einige Jahrzehnte vor Franz Carl Remp wirkte Dominik Franz Calin (1624-1683) aus Vipavski Križ (Sveti Križ/Heiligenkreuz) in der ehemaligen Grafschaft Görz in Wien. ${ }^{1}$ Dass er erfolgreich war, entnehmen wir seinen ,illustren Kunden“,' denn er schuf Werke für Kaiser Leopold I., den Kurfürsten Ferdinand Maria von Bayern, den Erzbischof von Salzburg Maximilian Gandoph Graf von Kuenburg sowie für Familien des Hofadels. ${ }^{3}$ Peter von Radics war der Meinung, dass „der Historiograph von Kaiser Leopold in München“" wegen seiner Gemälde und Zeichnungen einen guten Ruf hatte, ${ }^{4}$ doch zeigt der von Friedrich W. Leitner erstellte Werkkatalog, ${ }^{5}$ dass Calins Erfolg vor allem auf seinen umfangreichen genealogischen Studien und der höfischen Panegyrik gründete, beziehungsweise dass der Schwerpunkt seiner Arbeit auf dem Wort und weniger auf dem Bild lag. Im vorliegenden Beitrag werden die Werke Calins, die er für das Haus Habsburg anfertigte, vorgestellt, wobei zuerst die verschiedenen, mit Gelegenheitszeichnungen versehenen, geschichtlichen und panegyrischen Werke in Zusammenhang mit den biographischen Daten Calins behandelt werden, während seinen emblematischen Gratulationsschriften und Stammbäumen gesonderte Kapitel gewidmet werden. Zum ersten Mal wird auch eine Handschrift behandelt, die eine gemeinsame Arbeit von Dominik Franz und seiner Gemahlin Maria Anna Sibylla Calin ist, ${ }^{6}$ und die beweist, dass nicht nur Dominik Franz als Maler und Zeichner „dilletierte“, ${ }^{\text {" }}$ sondern auch Maria Anna Sibylla als Malerin tätig war.

\section{Die Werke Dominik Franz Calins}

Calins Werk fand wenig Forschungsinteresse und wurde meist nur in lexikalischen Beiträgen reflektiert. ${ }^{8} 1982$ verfasste Ljubomir Andrej Lisac einen Beitrag, in dem er Calin als Polyhistor,

1 Zur Biographie von Dominik Franz Calin siehe vor allem Ljubomir Andrej LISAC, Kalin (Kalyn, Kalynus, Calin) Dominik Frančišek, Primorski slovenski biografski leksikon, 2/8 (Hrsg. Martin Jevnikar), Gorica 1982, S. 12-13; Friedrich W. LEITNER, Zur Genealogie des fürstlichen Hauses Portia, Archiv für Diplomatik, Schriftgeschichte, Siegel- und Wappenkunde, 35, 1989, S. 519-630.

2 Christoph BRANDHUBER, Trias colossea. Max Gandolphs Familie, Fürsterzbischof Maximilian Gandolph Graf von Kuenburg. Regisseur auf vielen Bühnen 1668-1687 (Hrsg. Christoph Brandhuber, Reinhard Gratz), Salzburg 2018, S. 20.

3 Siehe LEITNER 1989 (Anm. 1), S. 625-630; zu den im Auftrag des Hofadels gefertigten Werken auch Polona VIDMAR, Theatrum genealogicum. Die Stammbäume der Grafen Herberstein und Dietrichstein als Mittel adeliger Repräsentation, Acta historiae artis Slovenica, 24/2, 2019, S. 49-62.

4 Peter RADICS, Umeteljnost in umeteljna obrtnost Slovencev. Kulturno-zgodovinska študija, Letopis Matice slovenske za leto 1880 (Hrsg. Janez Bleiweis), Ljubljana 1880, S. 23.

5 LEITNER 1989 (Anm. 1), S. 625-630.

6 Maria Anna Sibylla CALIN, Corona Immortalis Gloriae in Leopoldi Augusti Caesaris Praeclaris Virtutibus effigiata; Eiusdemque Sacratissimae Maiestati Humillimo Calamo consecrata â Maria Anna Sibylla Calina. Anno Chr. MDCLXXI, Österreichische Nationalbibliothek (ÖNB), Sammlung von Handschriften und alten Drucken (HAD), Cod. 10176; siehe auch Elisabeth KOVÁCS, Otto MAZAL, Maria Anna Sibylla Calina, Corona immortalis gloriae /.../, Welt des Barock. Katalog, Augustiner-Chorherrenstift St. Florian, Linz 1986, S. 80, Kat. Nr. 3.06.

7 France STELE, Kalin (Calin, Kalynus), Dominik Franz, Allgemeines Lexikon der bildenden Künstler von der Antike bis zur Gegenwart, 19 (Hrsg. Hans Vollmer), Leipzig 1926, S. 467.

8 Ivan KUKULJEVIĆ SAKCINSKI, Leben südslawischer Künstler, Agram 1868, S. 29-30; August DIMITZ, Geschichte Krains von der ältesten Zeit bis auf das Jahr 1814, 4, Laibach 1876, S. 124; RADICS 1880 (Anm. 4), S. 23; Stanko STANIČ, Dominik Franc Kalin, Čas. Znanstvena revija Leonove družbe, 9, 1915, S. 280-283; STELE 1926 (Anm. 7), S. 467; Anna CORETH, Österreichische Geschichtsschreibung in der Barockzeit (1620-1740), Wien 1950 (Veröffentlichungen der Kommission für Neuere Geschichte Österreichs, 37), S. 40. 
Kupferstecher und Musiker charakterisierte und ohne Angabe der Quellen behauptete, dass Calin am 4. August 1624 in einer bäuerlichen Familie in Heiligenkreuz geboren wurde, von 1639 bis 1644 das Gymnasium in Gorizia (Görz) und von 1644 bis 1647 das philosophische Triennium in Graz ${ }^{9}$ besuchte sowie von 1648 bis 1653 Hauslehrer bei den Familien Herberstein und Dietrichstein war. ${ }^{10}$ Obwohl diese Daten nicht überprüft werden konnten, lassen die genauen Jahresangaben und die Tatsache, dass Lisac Archivar war, darauf schließen, dass seine Angaben auf schriftlichen Quellen beruhen. Eine Ausbildung bei den Jesuiten wird durch Calins historische Kenntnisse und sein Geschick im „emblematischen Denken und Kombinieren“, das von den Jesuiten gefördert wurde, ${ }^{11}$ bezeugt und führte sogar zur Behauptung, dass Calin ein Jesuit gewesen sei. ${ }^{12}$ Nach Lisac hatte der Kurfürst Ferdinand Maria von Bayern Calin nach München berufen, wo er als kurfürstlicher Bibliothekar, Hofsekretär und Hofrat tätig war, bis ihn Kaiser Leopold I. 1670 nach Wien berief. ${ }^{13}$ Lisac zufolge erhob Kaiser Leopold I. Calin zum Pfalzgrafen mit dem Prädikat von Marienberg und ernannte ihn zum Hofhistoriographen; Calin sollte am 1. September 1683, während der osmanischen Belagerung Wiens angeblich an der Pest gestorben sein. ${ }^{14}$ Der vielfach begabte Calin soll sich nicht nur mit Geschichte und Genealogie beschäftigt haben, sondern auch mit Literatur und Musik. Außerdem soll er Zeichnungen und Kupferstiche angefertigt haben. ${ }^{15}$

Am ausführlichsten hat sich Friedrich W. Leitner mit der Biographie und dem Schaffen Calins befasst. ${ }^{16}$ Leitner vermutete, dass Calin aus einer vermögenden und geachteten Familie stammte, seine Studien in Gorizia, Cividale und wohl auch in Italien betrieb und sich unter anderem auch in Venedig aufhielt. ${ }^{17}$ Durch seine umfangreichen archivalischen Forschungen der Bestände des Niederösterreichischen Landesarchivs und des Hofkammerarchivs in Wien sowie durch die Beachtung der Titel, die den Arbeiten Calins beigefügt sind, bereicherte Leitner die Erforschung von Calins Leben und Werk wesentlich. ${ }^{18}$ Aufgrund fehlender Aktenbelege schlussfolgerte Leitner, dass die Titel „kurfürstlicher Bibliothekar“ und „kaiserlicher Hofhistoriograph“" nur Ehrentitel waren,

9 In den von Johann Andritsch publizierten Matrikeln der Universität Graz kommt Dominik Franz Calin nicht vor, wohl aber sein Bruder Johann Calin, der sich am 18. Januar 1652 in die Klasse der Logici inskribierte; siehe Johann ANDRITSCH, Die Matrikeln der Universität Graz 1630-1662, 6/2, Graz 1980, S. 88. Zur Angabe, dass Johann Calin ein Bruder von Dominik Franz Calin war, siehe LEITNER 1989 (Anm. 1), S. 528.

10 LISAC 1982 (Anm. 1), S. 12.

11 Zur Förderung des emblematischen Denkens und Kombinierens an jesuitischen Kollegien siehe Karel PORTEMAN, Emblematic Exhibitions (affixiones) at the Brussels Jesuit College (1630-1685), Brussels-Turnhout 1996; Friedrich POLLEROSS, Architektur und Panegyrik. Eine Allegorie der Jesuiten zur Geburt von Erzherzog Leopold Joseph (1682), Barock in Mitteleuropa. Werke, Phänomene, Analysen. Hellmut Lorenz zum 65. Geburtstag (Hrsg. Martin Engel), Wien 2007 (= Wiener Jahrbuch für Kunstgeschichte, 55/56, 2006/2007), S. 376.

12 Milan PELC, Theatrum humanum. Ilustrirani letci i grafika 17. stoljeća kao zrcalo vremena. Primjeri iz Valvasorove grafične zbirke Nadbiskupije zagrebačke, Zagreb 2013, S. 115.

13 LISAC 1982 (Anm. 1), S. 12.

14 LISAC 1982 (Anm. 1), S. 12.

15 LISAC 1982 (Anm. 1), S. 12.

16 LEITNER 1989 (Anm. 1), S. 519-630; Friedrich W. LEITNER, Ein Kartenwerk des Hofhistorikers Domenicus Franciscus Calin von Marienberg über das Herzogtum Kärnten, Bericht über den dreizehnten österreichischen Historikertag in Klagenfurt, veranstaltet vom Verband Österreichischer Geschichtsvereine in der Zeit vom 18. bis 21. Mai 1976, Wien 1977 (Veröffentlichungen des Verbandes Österreichischer Geschichtsvereine, 21), S. 239-248. Da Leitner den Beitrag von Ljubomir Andrej Lisac nicht kannte, fehlen die genauen Angaben über Ausbildung und Frühwerk Calins; vgl. LEITNER 1989 (Anm. 1), S. 527-530.

17 LEITNER 1977 (Anm. 16), S. 242-243; LEITNER 1989 (Anm. 1), S. 528-530.

18 LEITNER 1977 (Anm. 16), S. 239-248; LEITNER 1989 (Anm. 1), S. 524-525. 
die mit keiner besoldeten Planstelle verbunden waren. ${ }^{19}$ Somit darf man Calin zu den mehr als 30 Gelehrten rechnen, die nach den Angaben von Arno Strohmayer während der Regierungszeit Leopolds I. entweder den Titel eines Hofhistoriographen trugen oder unter Einfluss des Wiener Hofes historiographische Werke verfassten. ${ }^{20} \mathrm{Da}$ auch die Verleihung einer Pfalzgrafenwürde mit dem Prädikat von Marienberg, die Calin seit 1675 verwendete, nicht archivalisch belegt ist, vermutete Leitner, dass es sich um ein sogenanntes kleines Palatinat gehandelt haben muss, das Calin von einem Träger eines großen Palatinates verliehen wurde, vermutlich von einer Familie, für die Calin genealogische Arbeiten verfasste. ${ }^{21}$

Leitner zufolge war Calin von ungefähr 1660, als seine erste Arbeit bekannt wurde, bis 1665/1666 in München tätig und übersiedelte dann nach Wien. ${ }^{22}$ Calins älteste bekannte Handschrift Corona Austriacorum Caesarum ist jedoch 1657 datiert und dem (zukünftigen) Kaiser Leopold I. gewidmet. ${ }^{23}$ Corona Austriacorum Caesarum umfasst ein Widmungsgedicht an Leopold I. und drei Gedichtserien: eine Habsburger Kaiserserie von Rudolf I. bis König Ferdinand IV., eine Serie der ungarischen Könige vom Heiligen Stephan bis König Leopold sowie eine Serie der böhmischen Fürsten und Könige von Cechius bis König Leopold. ${ }^{24}$ Das älteste bekannte Werk Calins war somit eine der poetischen Habsburgergenealogien, die als „poetische Stammbäume bzw. poetische Gegenstücke zu Kaiserchroniken zu verstehen sind. “"25 Johannes Amann-Bubenik stellte jedoch fest, dass Calin zahlreiche Gedichte von Heinrich Meibom und ganze Vergilverse nur leicht verändert übernahm, ohne den Autor zu nennen. ${ }^{26}$

Während seines mutmaßlichen Aufenthalts in München in den Jahren 1660 bis ungefähr 1665/1666 publizierte Calin zwei emblematische Festschriften, auf die im weiteren Verlauf des vorliegenden Beitrags eingegangen werden soll, ein Elogium vitae nach dem Ableben von Erzherzog Leopold Wilhelm und betätigte sich als Übersetzer von lateinischen und italienischen Texten ins Deutsche. ${ }^{27}$

19 LEITNER 1977 (Anm. 16), S. 241; LEITNER 1989 (Anm. 1), S. 527.

20 Siehe Arno STROHMEYER, Höfische und ständische Geschichtsschreibung, Quellenkunde der Habsburgermonarchie (16.-18. Jahrhundert). Ein exemplarisches Handbuch (Hrsg. Josef Pauser, Martin Scheutz, Thomas Winkelbauer), Wien-München 2004 (= Mitteilungen des Instituts für Österreichische Geschichtsforschung, 44), S. 882.

${ }^{21}$ Leitner nennt in diesem Zusammenhang die Familien Lamberg, Weissenwolff, Dietrichstein, Sinzendorff, Neuburg, Portia, Montecuccoli und Proskau; siehe LEITNER 1977 (Anm. 16), S. 241; LEITNER 1989 (Anm. 1), S. 526-527.

22 LEITNER 1977 (Anm. 16), S. 243; LEITNER 1989 (Anm. 1), S. 531.

23 Dominicus Franciscus CALIN VON MARIENBERG, Corona Austriacorum Caesarum, nec non Ungariae, Boemiaeque Regum elogia. Annexo panegyrico, et luctu Austriae, ob tristissimum obitum Divi Ferdinandi Tertii, Caesaris Augusti, justi, pii s. Serenissimo ac potentissimo Principi, Domino, Domino Leopoldo, Ungariae, Boemiaeque Regi s. Archiduci Austriae, Duci Burgundiae, Styriae, Carinthiae, Carnioliae etc. Comiti Habspurgi, Tyrolis, et Goritiae etc. Domino, Domino clementissimo, humillime submisissimeque dedicata a Dominico Kalyno ex comitatu Goritiensi, 1657, ÖNB, HAD, Cod. 10210.

${ }^{24} \mathrm{Zu}$ Calins Corona Austriacorum Caesarum siehe Johannes AMANN-BUBENIK, Kaiserserien und HabsburgerGenealogien. Die Entwicklung einer Gattung poetischer Habsburgerpanegyrik vom 16. bis zum 18. Jahrhundert, Wien 2013 (ungedruckte Dissertation), S. 154, 280-281.

25 Sonja REISNER, Die poetische Habsburg-Panegyrik in lateinischer Sprache als historische Quelle, Quellenkunde der Habsburgermonarchie 2004 (Anm. 20), S. 905.

26 AMMAN-BUBENIK 2013 (Anm. 24), S. 280-281.

27 LEITNER 1989 (Anm. 1), S. 625-626, Nr. 1-6. 
In den Jahren 1667 bis 1669, 1671 und 1673 bis 1677 wurden Calin von der Hoffinanzkammer finanzielle Zuwendungen für seine vorgelegten Arbeiten angewiesen; nach den Forschungen Leitners insgesamt 7375 Gulden. ${ }^{28}$ Für diese beträchtliche Summe entwarf und malte Calin mindestens vier Stammbäume der Habsburger, die in der Albertina erhalten sind, ${ }^{29}$ verfertigte das Ehrenwerk Thesaurus Genealogicus mit 152 Stammtafeln der königlichen und fürstlichen Familien ${ }^{30}$ sowie ein unvollendetes Werk mit einer genealogischen Tafel, das Leopold I. betrifft und in der Universitätsbibliothek in München verwahrt wird. ${ }^{31}$ Die Hoffinanzkammer bezahlte wahrscheinlich auch die 1666 in Wien publizierte Gratulationsschrift anlässlich der Hochzeit von Leopold I. und Margarita Teresa $^{32}$ sowie den Entwurf eines Stammbaumes der Habsburger, der von Johann Martin Lerch anlässlich der Geburt von Erzherzog Ferdinand Wenzel Joseph 1667 in Kupfer gestochen wurde. ${ }^{33}$ Eine Überarbeitung dieses Stammbaumes, die im Landesmuseum Kärnten verwahrt wird, erfolgte 1673 anlässlich der Hochzeit Leopolds I. mit Claudia Felicitas. ${ }^{34}$ Die Gratulationsschrift und die Stammbäume werden im Folgenden behandelt.

Nicht erhalten ist nach Friedrich W. Leitner ein "gewisses Ehrenwerk“, das Calin anlässlich des kaiserlichen Geburtstags im Juni 1677 Leopold I. offerierte und wofür er 1500 Gulden erhielt. ${ }^{35}$ Möglich wäre, dass damit das genealogische Werk über die Familie Pfalz-Neuburg gemeint ist, aus der die dritte Gemahlin des Kaisers stammte. ${ }^{36}$ Nicht zur Ausführung gelangte vermutlich Calins ambitionierter Plan für ein Genealogisches Ehrenwerk, über das Calin dem Kaiser eine detaillierte, jedoch

28 LEITNER 1989 (Anm. 1), S. 527.

29 LEITNER 1989 (Anm. 1), S. 626-627, Nr. 7-8, 10, 12.

30 Dominicus Franciscus CALIN VON MARIENBERG, Thesaurus Genealogicus Omnium totius Europaei Orbis Regum et Principum Consanguinitates demonstrans. Authore Serenissimi Bauar: Elec: Bibliothecario Dominico Francis: Calin de Sancta Cruce /.../, 1671, ÖNB, HAD, Cod. 9229; siehe auch LEITNER 1989 (Anm. 1), S. 627, Nr. 11.

31 LEITNER 1989 (Anm. 1), S. 627, Nr. 13.

32 Dominicus Franciscus CALIN VON MARIENBERG, In optatissimo Natalis Diei recursu Augustissimi, potentissimi ac invictissimi Romanorum Imperatoris Leopoldi, Germaniae, Hungariae, Bohoemiae Regis; Archiducis Austriae; Ducis Burgundiae, Styriae, Carinthiae, Carniolae; \& c. \& c. Comitis Habspurgi, Tyrolis \& Goritiae \& c. Eidem Sacrat. mae Majestati, nec non Pro communi totius Patriae applausu \& congratulatione, inclytis utr. Austriae statibus ac deputatis; humillimo et devotissimo animo dedicata â Serenissimi Bavariae Electoris Bibliothecario \&̂c. Dominico Francisco Calin, de Sancta Cruce ex Comitatu Goritiae, Viennae 1666.

33 PELC 2013 (Anm. 12), S. 115, 117-118. Wie im Folgenden ersichtlich wird, hat Calin öfter mit dem Kupferstecher Johann Martin Lerch zusammengearbeitet. Nach Meinung von Friedrich Polleroß entwickelte sich der Kupferstecher Lerch zum »inoffiziellen Hofberichterstatter«; siehe Friedrich POLLEROSS, »Pro decore Majestatis«. Zur Repräsentation Kaiser Leopolds I. in Architektur, Bildender und Angewandter Kunst, Jahrbuch des Kunsthistorischen Museums Wien, 4/5, 2003, S. 273.

34 LEITNER 1989 (Anm. 1), S. 627, Nr. 14.

35 LEITNER 1989 (Anm. 1), S. 532.

36 Dominicus Franciscus CALIN VON MARIENBERG, Gentilitius Honos Serenissimae Neoburgicae Prosapiae Duodecim Regiis Coronis Exornatus. Hoc est Opus Genealogico-Historicum In quo per succedentes Generationes stemmatographicé repraesentantur, qualiter Augustissima Neo-Imperatrix Eleonora Magdalena Theresia, Leopoldi Ter Justi, Ter Pii, Terque Magni Caes. Tertia Conjunx, Nata Com: Palatina Rheni in Neuburg, Ducissa Bavariae, Juliaci, Cliviae, Montium etc. /.../ Inter festivos Germaniae Applausus publicae luci expositus A Domino Francisco Calin de Marienberg, Equite Aurato, Comite Palatino \& Historiographo Caesareo. Anno, quo a VstrIACA DoMVs a VGVsta PROLE BEABITVR, Viennae (1677); siehe auch LEITNER 1989 (Anm. 1), S. 628-629, Nr. 23. Auf die Genealogie der Familie Neuburg dürfte sich jedoch auch ein Ansuchen Calins um Honorierung seiner Auflagen beziehen, das im April 1677 mit der Auszahlung von 300 Gulden positiv beantwortet wurde; siehe LEITNER 1989 (Anm. 1), S. 527, 523. 
undatierte Spezifikation vorlegte. ${ }^{37}$ Leitner war der Meinung, dass die Spezifikation vor 1670 entstanden ist. ${ }^{38}$ Im ersten Teil - dem Österreichischen Ehrenwerk - wollte Calin alle Markgrafen, Herzöge, Kaiser und Erzherzöge des Landes Österreich mit bildnussen sambt ihren Elogijs unnd Symbolis darstellen, außerdem alle Bistümer, Abteien und Prälaturen sowie alle Städte der kaiserlichen Erbländer mit Beschreibungen, Veduten und Wappen anführen, alle gräflichen und freiherrlichen Familien der kaiserlichen Erbländer mit ihren Wappen vorstellen sowie alle Erbländer Cosmographicè in grundt gelegt und beschreiben. Ebenso wollte Calin auch den zweiten (Ungarisches Ehrenwerk) und dritten Teil (Böhmisches Ehrenwerk) in fünf Kapitel einteilen, während der vierte - Römisches Ehrenwerk - in acht Kapiteln alle römischen Kaiser von Julius Caesar bis Leopold I., geistliche und weltliche Kurfürsten, geistliche Fürstentümer, weltliche fürstliche Familien, Reichsstädte, Reichsabteien und Prälaturen, Reichsgrafen und Freiherren sowie alle Fürstentümer des Heiligen Römischen Reichs vorstellen sollte.

Nach Leitner scheint seit 1677 Calins Verbindung zur kaiserlichen Hoffinanzkammer abgebrochen zu sein, ${ }^{39}$ obwohl auch später noch dem Kaiser gewidmete Werke entstanden, wie z.B. eine Gratulationsschrift zur Geburt von Erzherzog Leopold Joseph und zum Geburtstag des Kaisers am 9. Juni $1682 .{ }^{40} \mathrm{Nach}$ dem Ende der Zuwendungen durch die Hoffinanzkammer entstanden auch drei Werke Calins, die im Codex 10109 in der Österreichischen Nationalbibliothek zusammengebunden sind. ${ }^{41}$ Auf den 26. September 1680 ist ein polemischer, in Linz entstandener Brief datiert, in dem Calin dem kaiserlichen Bibliothekar Daniel Nessel vorwarf, dass er die Abstammung der Habsburger von den Trojanern, Sicambrern und Merowingern als Fabel bezeichne und dass er die Pflicht habe, seine These, die Habsburger entstammten der Familie der römischen Pierleonen, mit guten und sicheren Proben zu belegen ${ }^{42}$ Aufgrund der kalligraphischen Ausführung ist anzunehmen, dass der Brief für den Kaiser und nicht für seinen Bibliothekar Nessel bestimmt war; bemerkenswert ist auch die Anführung Calins, dass er die Schrift dabam Lincij ex angustißimo Musceolo, ${ }^{43}$ was auf einen Aufenthalt Calins in Linz schließen lässt. Die zweite Schrift im Codex 10109 ist ein Szenarium für ein „Huldigungsturnier“ (Gran Torneo à Cavallo, Famosissimo Torneo) mit dem Titel Trionfo riportato dall'Invidia, das 1680 datiert und Kaiser Leopold I. gewidmet ist. ${ }^{44}$

37 Dominicus Franciscus CALIN VON MARIENBERG, Specification der Genealogischen Ehrnwerkh, welche, sofern Ihro Kä̈s: Mä̈s: allergnädigist beliebig wäre, khundten in Vier sonderliche Theil, der nachkhomenden Posteritet zu einem angedenkhen, forderist aber Zu Ihr Kä̈s: Maÿs: immerwehrender Ehr, Von mir Dominico Francisco Calin gemacht und aufgesezt werden, ÖNB, HAD, Cod. 4014. Zur Spezifikation siehe Joseph CHMEL, Die Handschriften in der k. $k$. Hofbibliothek in Wien, 1, Wien 1840, S. 441-445, Nr. 49; CORETH 1950 (Anm. 8), S. 40; LEITNER 1989 (Anm. 1), S. 522-523.

38 LEITNER 1989 (Anm. 1), S. 523.

39 LEITNER 1989 (Anm. 1), S. 532.

40 LEITNER 1989 (Anm. 1), S. 629, Nr. 28.

41 LEITNER 1989 (Anm. 1), S. 628-629, Nr. 19-21, 26-27.

42 Dominicus Franciscus CALIN VON MARIENBERG, Provocatio Humanissima Dominici Francisci Calin de Marienberg, Historiographi Caesarei etc. Scripta ad Danielem Nesselium Caesareum Bibliothecarium etc. XXVI. Septembris, Anno Salutis MDCLXXX. Concernens primam Serenissimae Habspurgo-Austriae Gentis originem, ÖNB, HAD, Cod. 10109, Fol. 26r-26v. Zu der Schrift siehe CORETH 1950 (Anm. 8), S. 40; LEITNER 1989 (Anm. 1), S. 532-533.

43 CALIN VON MARIENBERG 1680 (Anm. 42), Fol. 26v.

44 Dominicus Franciscus CALIN VON MARIENBERG, Trionfo riportato dall'Invidia. Rappresentatione d'un Gran Torneo à Cavallo, introdotto da Dodieci superbissime Comparse sopra tanti Carri Trionfanti, per solennizzare le Gran Glorie dell'Augustissima Casa d'Austria. Inventione semplicissima Humillißim. Dedicata à Sua Sacra Cesarea 


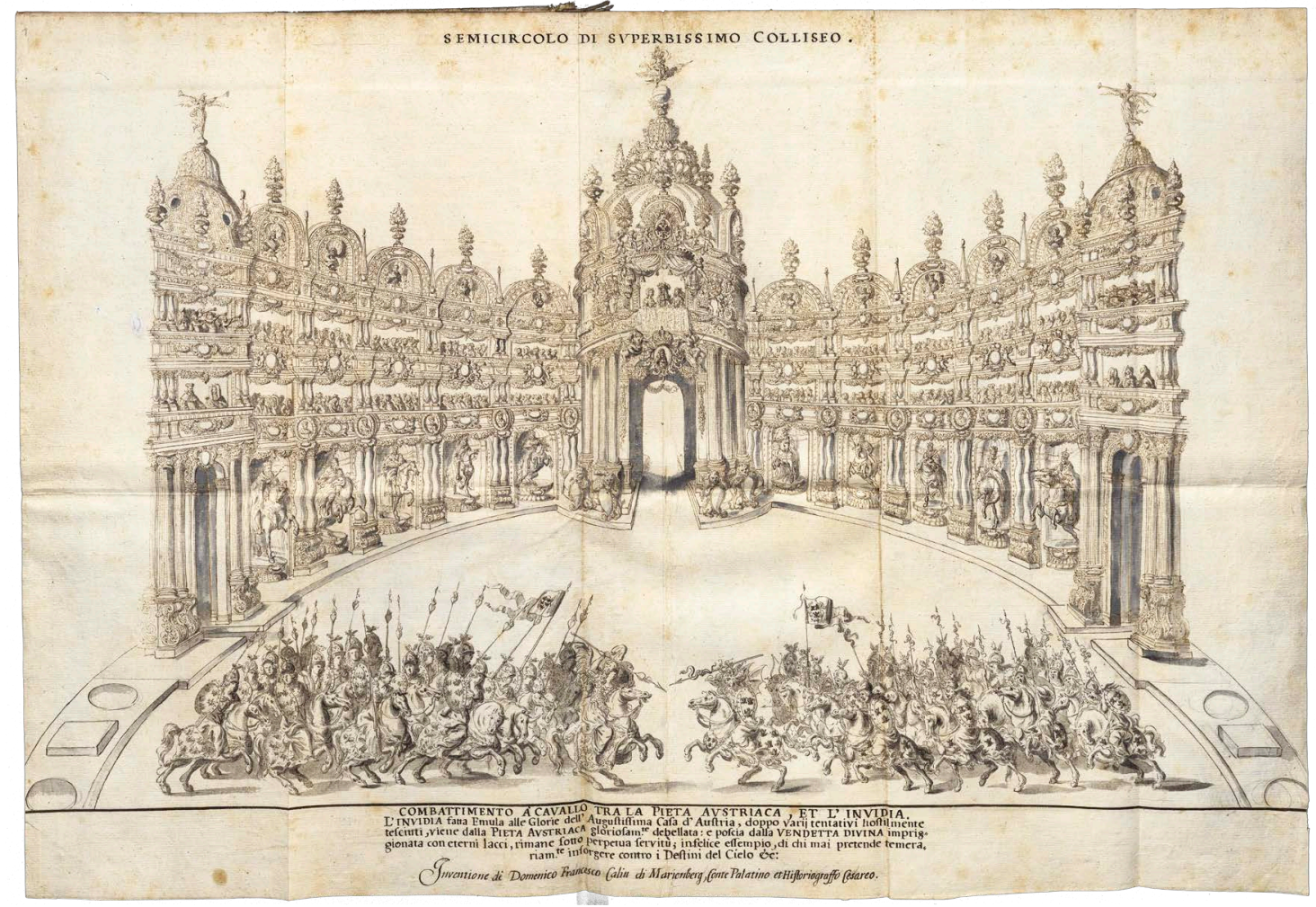

1. Dominik Franz Calin: Semicircolo di superbissimo Colliseo, 1680, Österreichische Nationalbibliothek, HAD, Cod. 10109, Fol. 1 r

Für das Werk verfertigte Calin eine Semicircolo di svPerbissimo Colliseo betitelte Zeichnung (Abb. 1). Die Inschrift unter der Darstellung ist zugleich eine Zusammenfassung des Szenariums, das einen Kampf zu Pferd beinhaltet: Combattimento à cavallo tra la Pieta Avstriaca, et L'Invidia. L'Invidia fatta Emula alle Glorie dell'Augustissima Casa d'Austria, doppo varij tentativi hostilmente tesciuti, viene dalla PIETa Avstriaca gloriosam..$^{\text {te }}$ debellata: e poscia dalla VendetTa DIVINa impriggionata con eterni lacci, rimane sotto perpetua servitù; infelice essempio, di chi mai pretende temerariam. ${ }^{\text {te }}$ insorgere contro i Destini del Cielo \& $c$ : Inventione di Domenico Francesco Calin di Marienberg, Conte Palatino et Historiograffo Cesareo. Auf der Zeichnung ist die prachtvolle Szene zu sehen, die von vergoldeten Statuen der Fürsten, Könige und Kaiser umgeben sein sollte, und die Calin im Text beschrieben hat. Da die Personifikation des Neides l'occulto mistero die Buchstaben A. E. I. O. U. nicht verstehen konnte und ihr auch die Furien dabei nicht helfen konnten, wird dem Neid als Divino Oracolo erklärt: A.ustriacorum. E.rit. I.imperium. O.rbis. V.niversi $!^{45}$

Real Maesta di Leopoldo Imperatore de Romani \& c. Da Domenico Fran: Calin di Marienberg \&́c. L’Anno 1680, ÖNB, HAD, Cod. 10109, Fol. 1r-8v.

45 Calins Interpretation der Buchstaben A. E. I. O. U. unterscheidet sich von der üblicheren Austria erit in orbe ultima, die auf Daniels Prophezeiung anspielt, Österreich würde als Vierte Weltmonarchie bis zum Ende der Welt bestehen bleiben; siehe dazu Elisabeth KOVÁCS, Die Apotheose des Hauses Österreich. Repräsentation und politischer Anspruch, Welt des Barock (Hrsg. Rupert Feuchtmüller, Elisabeth Kovács), Wien-Freiburg-Basel 1986, S. 75. $\mathrm{Zu}$ den verschiedenen Interpretationen der Buchstaben siehe Alphons LHOTSKY, Die „Devise“ Kaiser Friedrichs III. und sein Notizbuch, Mitteilungen des Instituts für Österreichische Geschichtsforschung, 60, 1952, S. 155-193; Karl VOCELKA, Lynne HELLER, Die Lebenswelt der Habsburger. Kultur- und Mentalitätsgeschichte 
An der Handlung nehmen auch antike Götter und Personifikationen der Tugenden und Laster teil, bis unter Jupiters Kommando die Vendetta Divina und die Austriaca Pietà erscheinen und sich die Spiriti Celestiali mit Invidia, Ambitione, Discordia und Perfidia in einen Kampf verwickeln. Nach dem Sieg befiehlt Jupiter all'Eternità, zwölf Erbländer und vier Kontinente ins Kolosseum zu rufen. Sie kommen auf prächtigen Triumphwagen und con il più superbo Sequito, che la mente humana potesse mai imaginarsi und huldigen dem Genio Immortale dell'August. Casa. Die Handlung endet mit dem großen Turnier der Erbländer. Auf der Zeichnung ist nicht das Turnier, sondern der Kampf dargestellt. Spiriti Celestiali werden von Pietas Austriaca geleitet und sind mit Lanzen bewaffnet, die mit brennenden Herzen versehen sind. Auf den Helmen sind Adler dargestellt, während Fahne, Pferdedecken und Schilde bemerkenswerterweise nur das Wappen von Niederösterreich tragen. Das feindliche Heer ist mit schlangenumwundenen Lanzen und Bögen bewaffnet, die Helme sind mit Fledermäusen versehen, auf der Fahne, den Pferdedecken und Schilden ist das Wappen mit drei Fröschen dargestellt. Obwohl im Text nicht angedeutet, kann die Invidia anhand des Wappens mit Frankreich verbunden beziehungsweise als französischer Neid identifiziert werden, da drei Frösche im Wappen des legendären Frankenkönigs und des mutmaßlichen ersten französischen Königs Pharamundus (von Troja) vorkommen. ${ }^{46}$ Das Kolosseum ist als prächtige halbkreisförmige Architektur dargestellt. Die Seitenflügel, auf denen sich in zwei Etagen die Balkone für das Publikum befinden, sind mit zehn Reiterdenkmälern und zahlreichen Porträts in Ovalrahmen und Porträtbüsten verziert, die als Habsburgische Ahnenreihe den Huldigungscharakter des Werkes betonen. In der Mitte befindet sich ein Rundtempel mit nur einer Loge, in der Kaiser Leopold I., seine dritte Gemahlin Eleonora Magdalena Theresia und die Kaiserinwitwe Eleonora Gonzaga dargestellt sind. Der Tempel wird von vier wappentragenden Löwen behütet. Unter der Kaiserloge befindet sich das gekrönte Porträt des Kaisers, während die Loge von dem Reichswappen und den Wappen von Ungarn und Böhmen umgeben ist. Als Bekrönung der prächtigen Kuppel dient die Weltkugel, die von einer Binde, die an den österreichischen Bindenschild erinnert, umfasst wird. Ein Adler, Attribut des oben dargestellten Jupiters und zugleich Reichssymbol, setzt seinen Fuß auf den Globus, der als Verdeutlichung von weltumspannenden Herrschaftsansprüchen gedeutet werden kann. ${ }^{47}$

Die zweite Zeichnung Calins im Codex 10109 (Abb. 2) ist wahrscheinlich nicht als Illustration zur Trionfo riportato dall'Invidia entstanden, wie France Stele vermutete, ${ }^{48}$ sondern zum Libretto des Dramma Musicale mit dem Titel Copia della Semplicissima Inventione sopra le Quattro Monarchie del Mondo. ${ }^{49}$ Das Original soll nach Calin bereits 1675 entstanden sein, die erhaltene Kopie

einer Familie, Graz-Wien-Köln 1997, S. 219-221; vgl. Jutta SCHUMANN, Die andere Sonne. Kaiserbild und Medienstrategien im Zeitalter Leopolds I., Augsburg 2003 (Colloquia Augustana, 17), S. 250, 265, 269.

46 Dazu siehe den Stammbaum Calins von 1666, der den Ursprung der Habsburger von den Frankenkönigen bzw. Pharamundus von Troia ableitet und in der Fortsetzung des Beitrags behandelt wird.

47 Siehe SCHUMANN 2003 (Anm. 45), S. 269. Zur Feststellung, dass der Globus in seiner sinnbildlichen Form als Reichsapfel schon Ausdruck der Weltherrschaft der antiken Kaiser gewesen ist und dass er durch die Entdeckungen der Neuen Welt eine neue realpolitische Dimension erhielt, siehe Friedrich POLLEROSS, „Sol Austriacus“ und „Roi Soleil“. Amerika in den Auseinandersetzungen der europäischen Mächte, Federschmuck und Kaiserkrone. Das barocke Amerikabild in den habsburgischen Ländern (Hrsg. Friedrich Polleroß, Andrea Sommer-Mathis, Christopher F. Laferl), Schloßhof im Marchfeld 1992, S. 54. Zum Globus als Herrschaftssymbol der Habsburger siehe Friedrich POLLEROSS, „Austrie est imperare orbi universo“. Der Globus als Herrschaftssymbol der Habsburger, 1492-1992. Spanien, Österreich und Iberoamerika (Hrsg. Wolfram Krömer), Innsbruck 1993, S. 35-50.

48 STELE 1926 (Anm. 7), S. 467.

49 Dominicus Franciscus CALIN VON MARIENBERG, Copia della Semplicissima Inventione sopra le Quattro Monarchie del Mondo, Humillissim: ${ }^{\text {te }}$ Dedicata in Poesia e Musica con un Dissegno di Gran Amfiteatro, a Sua Sacra 


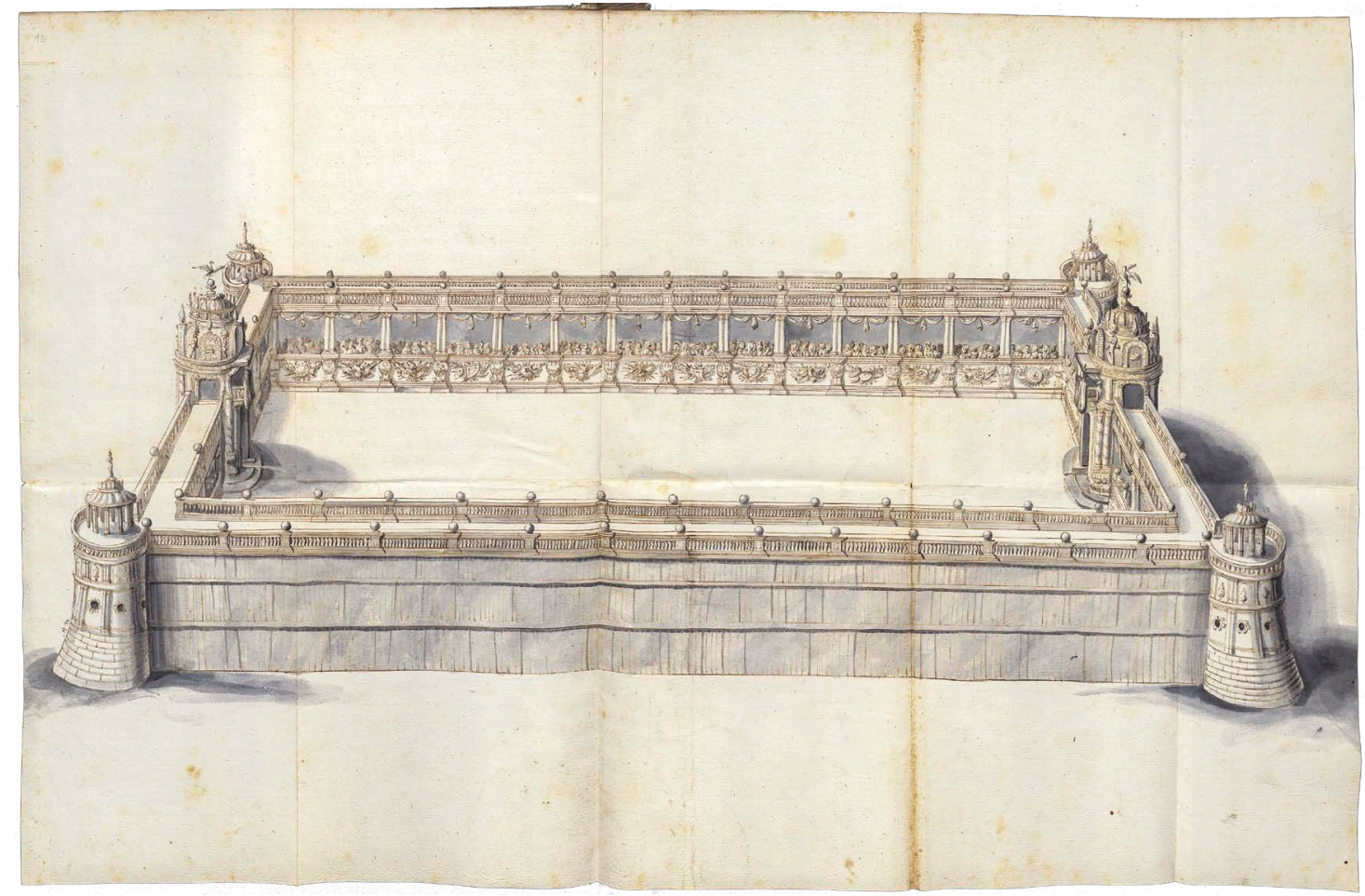

2. Dominik Franz Calin: Zuschauertribüne für das Dramma musicale Le Quattro Monarchie del Mondo, um 1678, Österreichische Nationalbibliothek, HAD, Cod. 10109, Fol. $12 r$

kann man aber sicherlich nach der Aufführung der Prunkoper La Monarchia latina trionfante, die 1678 im Theater auf der Kurtine der Wiener Hofburg stattfand und auf die sich Calin im Titel bezieht, datieren..$^{50}$ Um die Triumphe der österreichischen Erblande zu feiern und per festeggiare le Gran Glorie dell'Augustissima Casa d'Austria schlug Calin Festlichkeiten vor, die außerhalb der Stadt Wien stattfinden und aus drei solennissime Feste bestehen sollten: eines Dramma Musicale, einem Gran Torneo und einem Fuoco Articioso, aus dem ein Genius des Hauses Österreich come immortal Fenice risorge à nuovi Trofei e Glorie. ${ }^{51}$ Als Protagonisten des Dramma Musicale kommen die im Titel erwähnten Monarchien der Assyrer, Perser, Griechen und Römer vor, die von der Personifikation der Ewigkeit aus den Katakomben gerufen werden, die sie nur mit großer Mühe und bereits ganz blass verlassen können, sowie Jupiter, die vier Elemente, die vier Hauptwinde und die zwölf Tierkreis-Zeichen. Die österreichische Monarchie wird durch Felicità Austriaca personifiziert, die von den beiden Tugenden Conseglio und Industria begleitet wird, die der Devise Kaiser Leopolds I. (CONSILIO ET INDUSTRIA) entstammen. ${ }^{52}$ Vorgesehen war bereits das Ende der

Cesarea Real Maesta, L’Anno 1675. Domenico Francesco Calin etc. Dove si scuopre, che l'Opera essibita nel Gran Theatro, col Titolo La Monarchia Latina Trionfante per solenizzare la Gloriosissima Nascita del Serenissimo Arciduca Gioseppe etc. Sij stata tutta cavata da quella, ò al meno aplicata nel medemo tenore, ÖNB, HAD, Cod. 10109, Fol. 9r-11v, 13r-25r.

50 Zur Ausführung siehe Andrea SOMMER-MATHIS, Das Theater auf der Kurtine, Die Wiener Hofburg 1521-1705. Baugeschichte, Funktion und Etablierung als Kaiserresidenz (Hrsg. Herbert Karner), Wien 2014, S. 425.

51 CALIN VON MARIENBERG 1675 (Anm. 49), Fol. 10r.

52 Zur Darstellungen der Devise Leopolds I. siehe Sibylle APPUHN-RADTKE, Das Thesenblatt im Hochbarock. Studien 
Welt, doch nachdem die Götter das Auge Gottes gedreht hatten, bemerkten sie die Verdienste der Semidei Austriaci und beschlossen, die Fünfte Monarchie zu gründen, die von Augustissima Casa d'A ustria geleitet wird und ewig gedeihen soll. ${ }^{53}$ Der Kaiser wird als glorioso Atlante gepriesen, der das große Gewicht der Welt trägt, und als Doppelsonne (Anagramatico moto DVPLO SOLE, cioè LEOPOLDVS). ${ }^{54}$ Auf der Zeichnung sind jedoch nicht die Protagonisten des Dramma Musicale zu sehen, sondern eine ephemere Zuschauertribüne, die als rechteckige Befestigung mit runden Ecktürmen, einer durchgehenden Dachterrasse mit Balustraden und zwei als Rundtempel gestalteten und mit Balkonen für vornehmste Gäste versehenen Bauten dargestellt ist. Es gibt keinen Hinweis darauf, ob Calins Dramma Musicale jemals ausgeführt wurde. Die Nachschrift auf der Titelseite Dove si scuopre, che l'Opera essibita nel Gran Theatro, col Titolo La Monarchia latina trionfante per solenizzare la Gloriosissima Nascita del Serenissimo Arciduca Gioseppe etc. Sij stata tutta cavata da quella, ò al meno aplicata nel medemo tenore lässt darauf schließen, dass Calin mit der Kopie dem Kaiser bezeugen wollte, dass Nicolò Minato für das Libretto der Prunkoper La Monarchia latina trionfante seine drei Jahre ältere Idee kopiert hatte. ${ }^{55}$ Obwohl sich die beiden Texte der klassischen Möglichkeiten der Panegyrik, wie dem Vergleich des Kaisers mit antiken Göttergestalten oder dem Lob seiner Tugenden bedienten, ist die Handlung der Prunkoper viel komplexer konzipiert. Außerdem verweist Minato auf die besondere Berufung des Hauses Habsburg, das er in der Nachfolge der Römischen Monarchie sieht ${ }^{56}$ und nicht als Gründer einer „Fünften Monarchie“. Es ist anzunehmen, dass die Bezeichnung Dramma musicale und die Beischrift in Poesia e Musica die Forscher zu der falschen Annahme führte, Calin habe sich auch als Komponist betätigt. ${ }^{57}$

Die bisher bekannten biographischen Daten über Calin können durch eine Zeichnung seines Wiener Hauses vervollständigt werden, die in einer seiner Handschriften erhalten ist. ${ }^{58}$ Calin hat ein zweigeschossiges und siebenachsiges Haus mit vier Läden im Erdgeschoß gezeichnet; der Dachform ist zu entnehmen, dass es ein Eckhaus war (Abb. 3). Das Haus stand bei dem „Schönen Brunnen“, der sich and der Stelle des heutigen Tuchlaubenbrunnens (vor dem Haus Tuchlauben 8) befand. Die Verzierung der Fassade mit Emblemen und Beleuchtung wird im Folgenden behandelt. Anhand der Größe des Hauses darf man auf einen aufwendigen Lebensstil Calins schließen, der auch durch einen Hinweis der Niederösterreichischen Stände aus dem Jahr 1674 dokumentiert ist:

zu einer graphischen Gattung am Beispiel der Werke Bartholomäus Kilians, Weißenhorn 1988, S. 67-69; Sibylle APPUHN-RADTKE, Allegorie und Emblem, Quellenkunde der Habsburgermonarchie 2004 (Anm. 20), S. 993.

53 CALIN VON MARIENBERG 1675 (Anm. 49), Fol. 18v.

54 Zum Anagramm duplo sole siehe SCHUMANN 2003 (Anm. 45), S. 197, 327, 383; Sibylle APPUHN-RADTKE, Sol oder Phaeton? Invention und Imitation barocker Bildpropaganda in Wien und Paris, Kunst und Macht. Politik und Herrschaft im Medium der bildenden Kunst (Hrsg. Wilhelm Hofmann, Hans-Otto Mühleisen), Münster 2005 (Studien zur visuellen Politik, 2), S. 111-112; POLLEROSS 2007 (Anm. 11), S. 380.

55 Zur Prunkoper La Monarchia latina trionfante siehe Maria GOLOUBEVA, The Glorification of Emperor Leopold I in Image, Spectacle and Text, Mainz 2000 (Veröffentlichungen des Instituts für europäische Geschichte Mainz, 184), S. 105; SCHUMANN 2003 (Anm. 45), S. 256-258; zu dem Librettisten Graf Nicolò Minato und seiner Rolle am Hof GOLOUBEVA 2000 (Anm. 55), S. 49-51, 81, 88, 96-97, 157-158.

56 Vgl. SCHUMANN 2003 (Anm. 45), S. 257.

57 STELE 1926 (Anm. 7), S. 467; LISAC 1982 (Anm. 1), S. 12.

58 Dominicus Franciscus CALIN VON MARIENBERG, Congratulatoria Emblemata, et Luminaria ad Auspicatissimas Cunas Serenissimi Neogeniti Archiducis Leopoldi \&s. Inter Festivos Applausus Publice Repraesentata â Dominico Francisco Calin de Marienberg, Equite Aurato, Com. Palat., et Histor. Caesareo, Viennae Austriae, Anno Chr. MDCLXXXII, Mense Iunio, ÖNB, HAD, Cod. 8321, Fol. 13. Zur Gratulationsschrift siehe auch LEITNER 1989 (Anm. 1), S. 629, Nr. 28. 


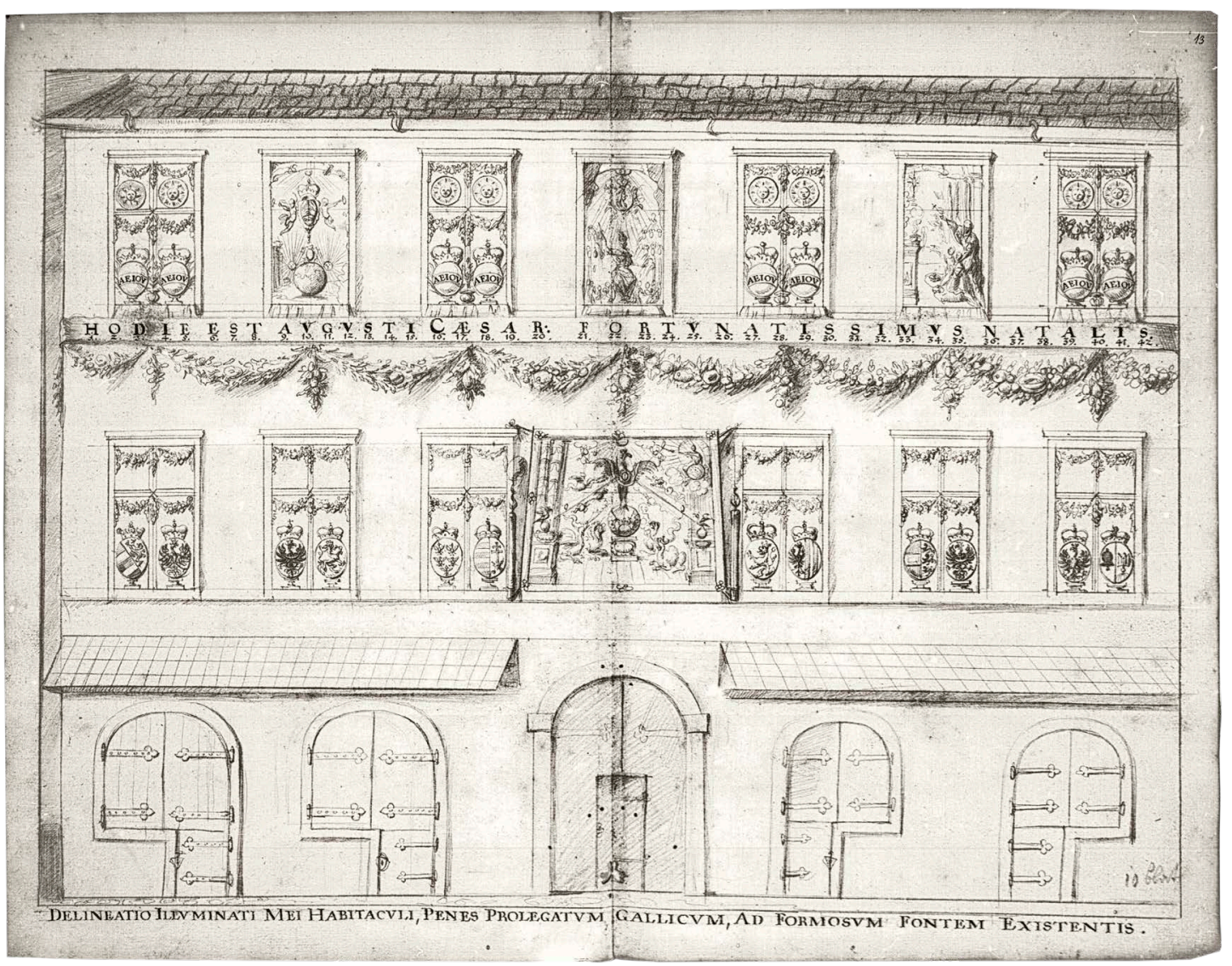

3. Dominik Franz Calin: Delineatio illuminati mei habitaculi, 1682, Österreichische Nationalbibliothek, HAD, Cod. 8321, Fol. $13 r$

„/.../ gesezt auch es möhten die Löbl. Ständ Ihme Calin für sein bemühung waß aussezen, so ist doch leiht zu erahten daß Er mit einem wenigen niht vergnügt sein wird, weilen Er die underhaltung auff sein völliges Haußwesen begehrt /.../. ${ }^{\text {“59 }}$

Wer zu Calins Haushalt gehörte, ist nicht überliefert. Man darf annehmen, dass in seinem Haus auch Maria Anna Sibylla Calin wohnte, die nach Meinung von Leitner entweder die Witwe des vor 1667 verstorbenen Johann Calin oder die Ehefrau von Dominik Franz Calin war. ${ }^{60}$ Aus der Korrespondenz mit der Hoffinanzkammer 1671 wird jedoch ersichtlich, dass Maria Anna Sibylla die Gemahlin von Dominik Franz Calin und nicht seine Schwägerin war. ${ }^{61}$ Vor dem 10. November 1671 ersuchte Frau Calin Kaiser Leopold I. um eine Abgeltung ihrer Schreibarbeiten, die sie im

59 Zitiert nach LEITNER 1989 (Anm. 1), S. 529.

60 Nach den Forschungen von Friedrich W. Leitner hat Johann Calin bereits um 1656 den Niederösterreichischen Ständen den Vorschlag unterbreitet, ein „Genealogisches Ehrenwerk“ herauszugeben, das er jedoch nicht vollendete. Seine Witwe überbrachte den Niederösterreichischen Ständen das unvollendete Werk und Dominik Franz Calin bekundete am 11. Oktober 1667 den Ständen sein Interesse, das unvollendet gebliebene Werk seines Bruders fortzuführen. Obwohl Dominik Franz von den Ständen dazu ermächtigt wurde, fand die Ausgabe eines auf Niederösterreich bezogenen genealogischen Ehrenwerks aber offensichtlich keine Verwirklichung; siehe CORETH 1950 (Anm. 8), S. 126; LEITNER 1989 (Anm. 1), S. 528-529.

${ }^{61}$ Vgl. LEITNER 1989 (Anm. 1), S. 528-529. 
Zusammenhang mit der Abfassung eines genealogischen Werkes geleistet hatte; ihr wurden zugleich mit Dominik Franz Calin, „/.../ wegen einer durch Ihn verfaßt und Ihrer Mays: offerierten Genealogia $300 \mathrm{fl}$. recompens /.../“ zugeteilt. ${ }^{62}$ Aus dem Bittgesuch kann man entnehmen, dass die Handschrift mit Emblemen illustriert war: „/.../ allerunderthenigst offerirt als auch Sie vor ohngefehr 10. Wochen ein von Ihr zusambengeschieben: und besagt Ihren Ehemann componirtmit Emblematibus geziertes opusculum diemietigist überraiht habe /.../.633 Mit dem von Dominik Franz Calin „komponierten“ und von Maria Anna Sibylla Calin ausgeführten Heft ist die 1671 datierte Handschrift Corona Immortalis Gloriae in Leopoldi Augusti Caesaris praeclaris virtutibus effigiata gemeint, die kalligraphisch in Antiqua in Goldschrift geschrieben ist. ${ }^{64}$ Dem Titelblatt folgen das Widmungsblatt und acht Blätter mit ovalen Darstellungen und Begleittexten. Sie folgen der für die Embleme charakteristischen dreiteiligen Bild-Text-Kombination mit Lemma, Ikon und erläuterndem Epigramm, ${ }^{65}$ wobei statt Lemma eine der habsburgischen Herrschertugenden Pietas, Clementia, Fortitudo, Prudentia, Iustitia, Religio, Pax und Felicitas eingefügt ist. ${ }^{66}$ In der Widmung an Kaiser Leopold I. erwähnt Maria Anna Sibylla Calin bescheiden ihre mangelnde Bildung und die Nichtbeherrschung der lateinischer Sprache, jedoch offeriert sie dem Kaiser das Büchlein mit propria syngrapha, woraus man entnehmen kann, dass sie die Darstellungen selbst gemalt hat. Sie erwähnt auch, dass sie, als ihr Ehemann dem Kaiser das Werk Glorice Coronam gewidmet habe, den Beschluss gefasst habe, ihm das Büchlein zu schenken ${ }^{67}$ Einen Hinweis für die Annahme, dass Maria Anna Sibylla trotz gebotener Bescheidenheit selbstbewusst ihre Fähigkeiten betonen wollte, ergibt sich aus ihrer Angabe, dass sie sich zur Schenkung auch deswegen berechtigt fühle, weil ihr die mysteriöse Natur des Schicksals den Namen Sibylla gegeben habe. ${ }^{68}$

Corona Pietatis wird durch eine Weltkugel veranschaulicht, die durch eine Binde mit den Buchstaben A. E. I. O. U., einem Kreuz, der Kollane des Ordens vom goldenen Vlies, der Kaiserkrone, zwei Zeptern und Palmen- und Lorbeerzweigen versehen ist (Abb. 4) ${ }^{69}$ Die Verbindung der Weltkugel mit der Formel A. E. I. O. U. kann zur Regierungszeit Leopolds I. als Verdeutlichung der weltumspannenden Herrschaftsansprüche der Habsburger gedeutet werden, da das Motto von dem kaiserlichen Bibliothekar Peter Lambeck als Kürzel für die Sätze Austriae est imperare orbi universo bzw. Alles Erdreich ist Oesterreich untertan entschlüsselt wurde. ${ }^{70}$ Hinter der Krone, auf der ein Adler sitzt, befinden sich Flammen (die brennende Frömmigkeit). Die Weltkugel steht in Wien auf dem Platz Am Hof und wird links von dem jesuitischen Professhaus flankiert, das zwischen 1660 und 1663 vom Hofarchitekten Filiberto Luchese mit einer neuen Fassade versehen wurde, die auch eine bühnenartige Terrassenanlage als Raum für die Inszenierung der kaiserlichen Frömmigkeit

62 LEITNER 1989 (Anm. 1), S. 529.

63 Zitiert nach LEITNER 1989 (Anm. 1), S. 529.

${ }^{64}$ CALIN 1671 (Anm. 6).

65 Zur idealen dreiteiligen Bild-Text-Kombination der Embleme siehe APPUHN-RADTKE 2004 (Anm. 52), S. 971.

66 Vgl. KOVÁCS, MAZAL 1986 (Anm. 6), S. 80, Kat. Nr. 3.06. Zu den Tugenden, die zur Repräsentation und Glorifizierung Leopolds I. vorkommen, siehe GOLOUBEVA 2000 (Anm. 55), S. 168-189.

67 CALIN 1671 (Anm. 6), Fol. 2r.

68 CALIN 1671 (Anm. 6), Fol. 2r.

69 Zur Pietas als Herrschertugend siehe Anna CORETH, Pietas Austriaca. Ursprung und Entwicklung barocker Frömmigkeit in Österreich, Wien 1959, S. 9-16.

70 Siehe dazu LHOTSKY 1952 (Anm. 45), S. 180; POLLEROSS 1993 (Anm. 47), S. 45-46; vgl. SCHUMANN 2003 (Anm. 45), S. 269. 


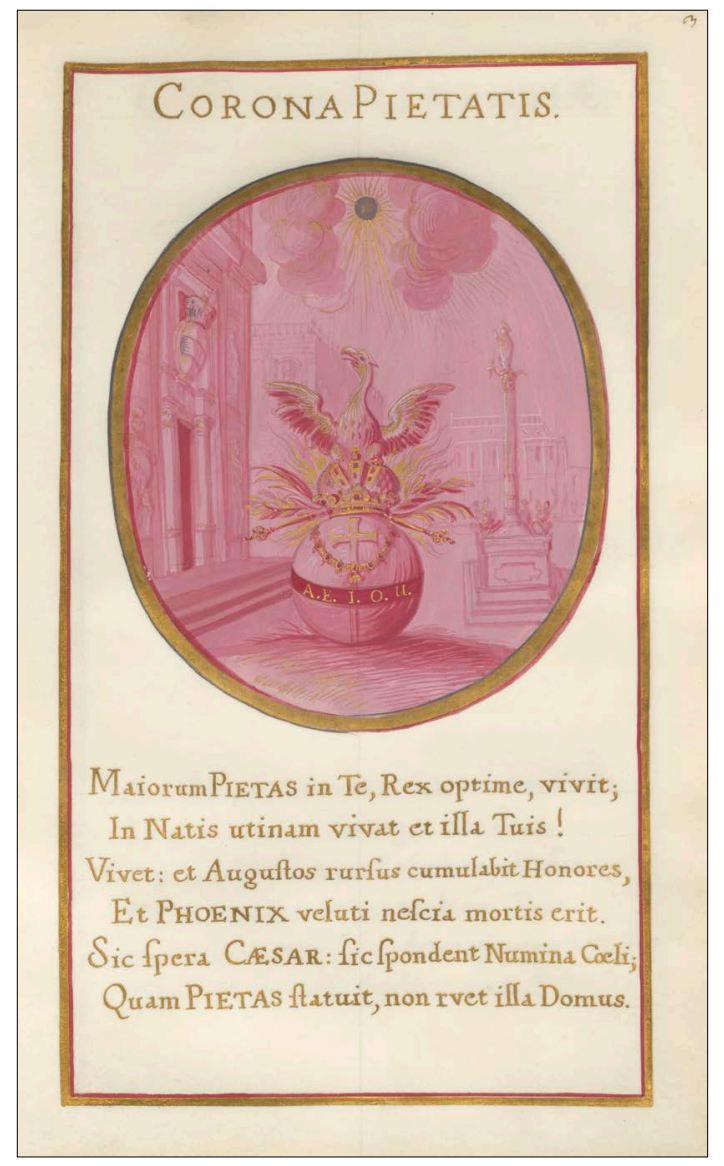

4. Maria Anna Sibylla Calin: Corona Pietatis, 1671, Österreichische Nationalbibliothek, HAD, Cod. 10176, Fol. $3 r$ miteinbezieht. ${ }^{71}$ Maria Anna Sibylla Calin stellte jedoch nicht die Terrassenanlage dar, sondern ein Gebäude mit dem Bindenschild über dem Hauptportal und Kaiserstatuen in den Nischen, die auf die Habsburger Ahnen Bezug nehmen. Rechts befindet sich die Mariensäule, mit der Maria Anna Sibylla sowohl auf die Marienfrömmigkeit als eine der beiden zentralen Formen der habsburgischen Frömmigkeit Bezug nimmt $^{72}$ als auch auf die zu diesem Zeitpunkt aktuelle Neuaufrichtung der Säule, als unter Kaiser Leopold die steinernen Skulpturen durch einen aufwendigen Metallguss ersetzt wurden; die Weihe erfolgte am 8. Dezember $1667 .^{73}$ Das Bild bezeugt, dass der Autorin (bzw. ihrem Ehemann) die Immaculata-Verehrung als Schwerpunkt des kaiserlichen Marienkultes bekannt war, vermutlich auch die Bedeutung der Statue für den Kaiser, der nach dem Vorbild der Bronzestatue von Jakob Herold für die Schatzkammer beim Augsburger Goldschmied Philipp Küsel eine $129 \mathrm{~cm}$ hohe Nachbildung aus vergoldetem Silber und Edelsteinen bestellte. ${ }^{74}$

In der Corona Clementiae wird Kaiser Leopold mit der Sonne verglichen und als gekröntes, mit einem Auge versehenes Herz, das Tag und Nacht wohltätig ist, dargestellt. ${ }^{75}$ In der Corona

Fortitudinis wird auf die Siege Leopolds Bezug genommen, dem Mars centum clara trophoea dedit (Abb. 5). Maria Anna Sibylla stellte einen mit Bindenschild und Fahnen versehenen Altar dar, auf dem eine gekrönte Kartusche mit der Initiale L für Leopold steht, die in der Himmelszone mit einem Lorbeerkranz gekrönt ist. Im Hintergrund vertreibt ein Löwe die flüchtenden Osmanen, womit wahrscheinlich auf die siegreiche Schlacht bei St. Gotthard im Jahre 1664 angespielt ist. Corona Prudentiae huldigt Leopold, der von Pallas Athena, Apollo und den Musen gesegnet ist, als Säule des Hauses Habsburg. Maria Anna Sibylla stellte einen auf Büchern stehenden Globus dar, auf dem ein gekrönter und mit zwei Schlangen umschlungener Spiegel steht. Rechts ist eine Tempelfassade mit zwei Säulen,

71 Herbert KARNER, Pietas Mariana und die Heilung der Städte. Sakralität des Herrschers im öffentlichen Raum, Sakralisierungen des Herrschers an europäischen Höfen. Bau - Bild - Ritual - Musik (1648-1740), Regensburg 2019, S. 141-142.

72 Zur Marienfrömmigkeit der Habsburger im 17. Jahrhundert siehe CORETH 1959 (Anm. 69), S. 43-59.

73 Zur Neuaufrichtung der Mariensäule und dem ikonographischen Programm siehe KARNER 2019 (Anm. 71), S. 139-153.

74 Siehe dazu Friedrich POLLEROSS, Die Immaculata, Kaiser Leopold I. und ein römisches Thesenblatt der Laibacher Franziskaner, Acta historiae artis Slovenica, 23/1, 2018, S. 93-95.

75 Abgebildet in KOVÁCS 1986 (Anm. 45), S. 71. 


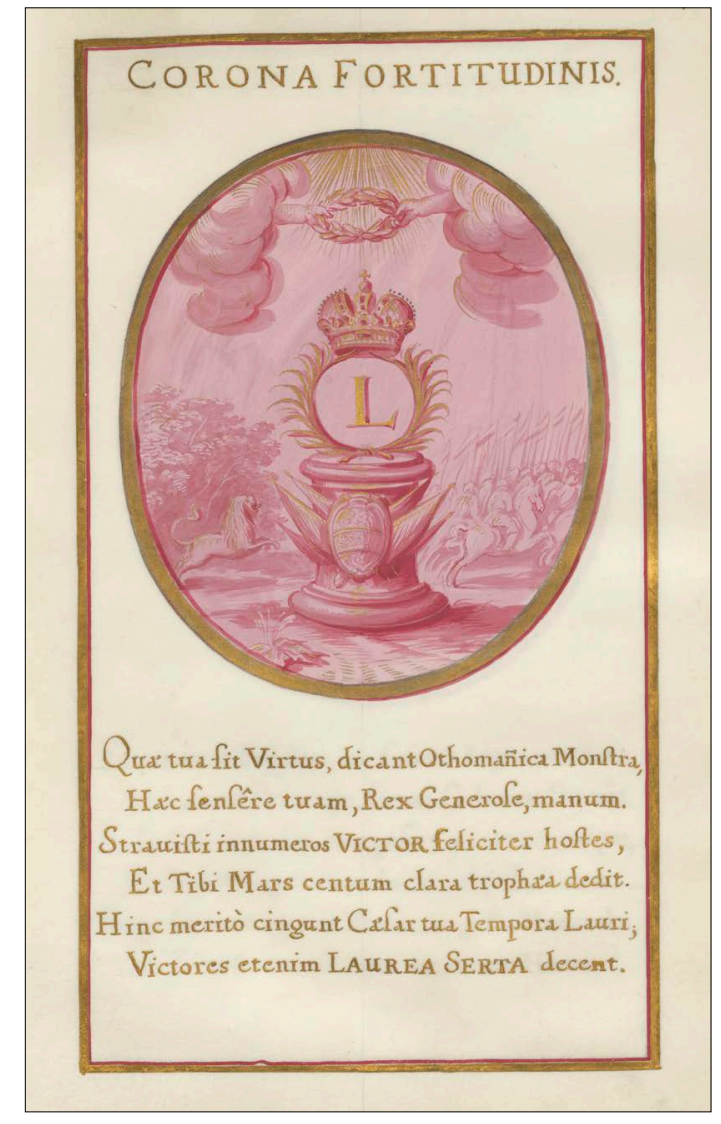

5. Maria Anna Sibylla Calin: Corona Fortitudinis, 1671, Österreichische Nationalbibliothek, HAD, Cod. 10176, Fol. 5 r

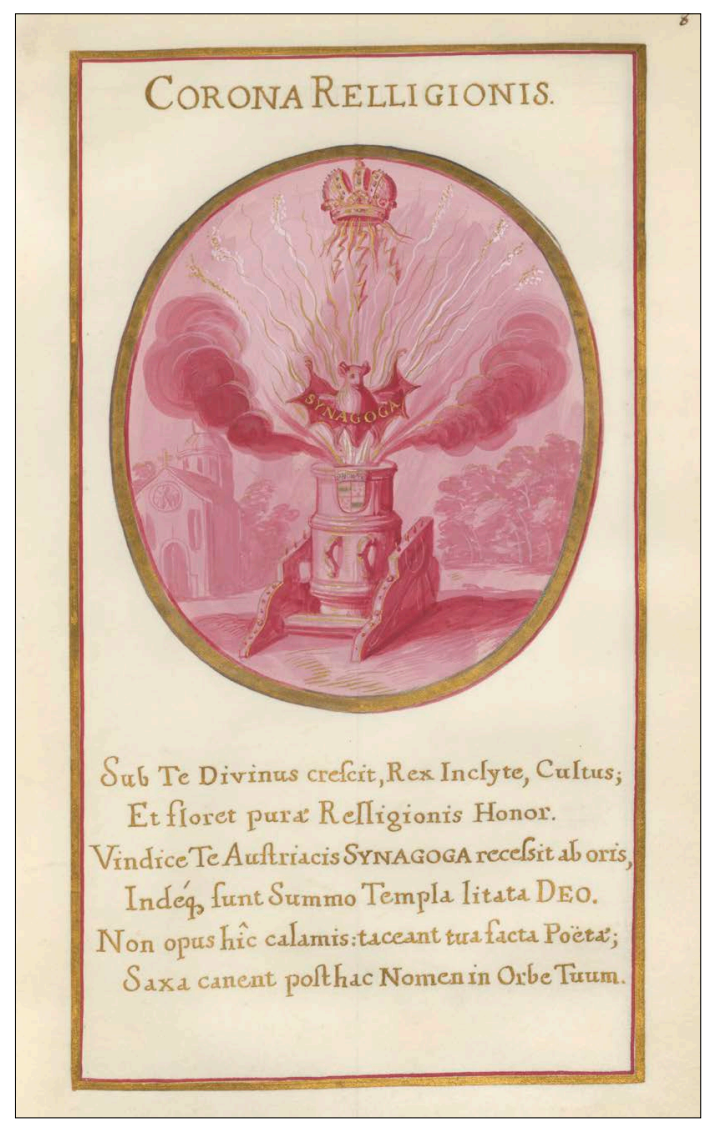

6. Maria Anna Sibylla Calin: Corona Relligionis, 1671, Österreichische Nationalbibliothek, HAD, Cod. 10176, Fol. 8 r

hinter der die Sonne aufgeht, links sieht man eine befestigte Stadt, wahrscheinlich Wien. Im erläuternden Epigramm der Corona Iustitiae vergleicht Calin Kaiser Leopold mit einer Palme, die von Maria Anna Sibylla in der Mitte der Darstellung wiedergegeben wurde. Die Palme ist mit einem Herzogshut neben den Wurzeln, einer Königskrone um den Stamm und einer Kaiserkrone über der Baumkrone geschmückt. ${ }^{76}$ Blitze gefährden die Palme, die von den Winden mit Pfeilen und Schlangen beschossen wird, was als Hinweis auf äußere Feinde (die Osmanen) und innere Feinde bzw. Rebellen, die im Text genannt werden, zu verstehen ist.

Corona Relligionis bezieht sich auf den Aufschwung des wahren Glaubens unter Leopold I. und das Verschwinden der Synagoga, womit auf die Vertreibung der Juden aus Wien 1670 angespielt wird, bei der aufgrund eines Gelöbnisses der Kaiserin Margarita Teresa die Bewohner des jüdischen Ghettos vertrieben, die ehemalige Judenstadt zur Leopoldstadt umbenannt und an der Stelle der zerstörten Synagoge die Leopoldskirche erbaut wurden. ${ }^{77}$ Maria Anna Sibylla stellte die Synagoga als eine Fledermaus dar, die aus einem Geschütz abgefeuert und von den Blitzen, die aus der Kaiserkrone

76 Abgebildet in KOVÁCS 1986 (Anm. 45), S. 71.

77 Brigitte HAMANN, Die Habsburger. Ein biographisches Lexikon, Wien 1988, S. 280; POLLEROSS 2003 (Anm. 33), S. 218. 


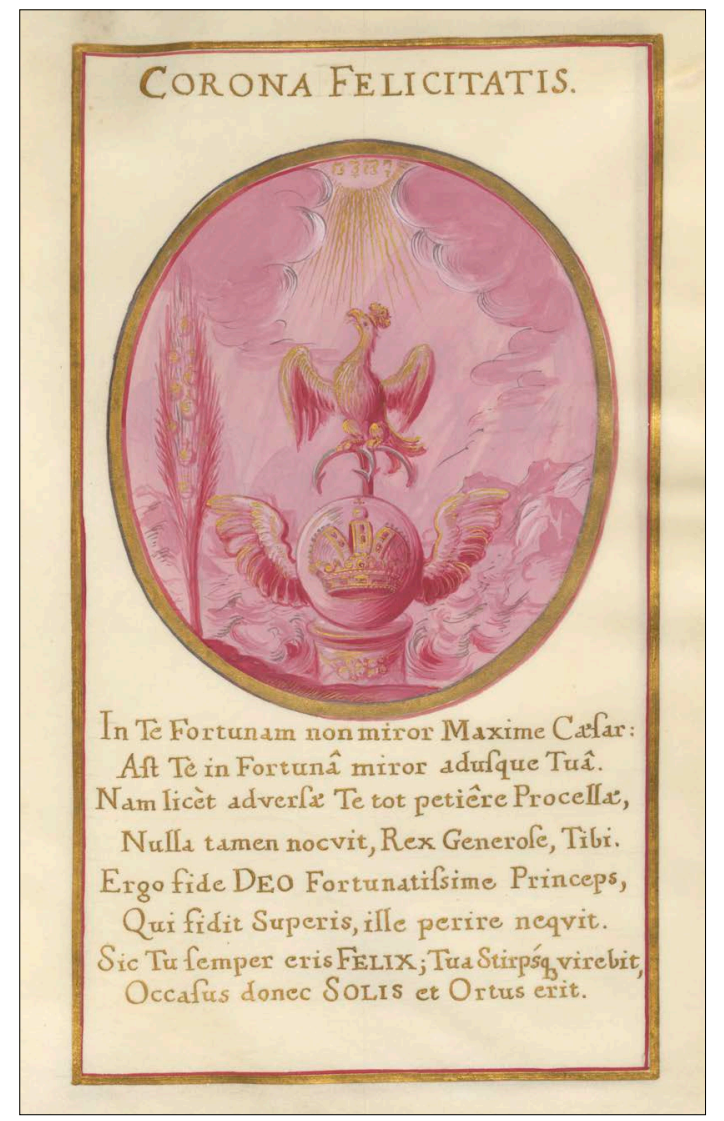

7. Maria Anna Sibylla Calin: Corona Felicitatis, 1671, Österreichische Nationalbibliothek, HAD, Cod. 10176, Fol. 10r kommen, vernichtet wird (Abb. 6). Dass sich seit der gewaltsamen Vertreibung der Andersgläubigen hier nur dem christlichen Gott geweihte Tempel befinden, wird durch eine Kirche im Hintergrund visualisiert. Corona Pacis preist Kaiser Leopold als Friedenskaiser und betont, dass sub nostro Regno gubernat Amor. ${ }^{78}$ Auf der von der Sonne bestrahlten Erde küssen sich zwei gekrönte Tauben, während in der Himmelszone zwei Hände ein Zepter halten. Das Zepter ist von Lorbeer umwunden, in der Mitte mit einer Königs- und oben mit der Kaiserkrone versehen. Die Huldigungsmotivik gipfelt in der Corona Felicitatis mit Glückwünschen an den Kaiser und sein Geschlecht und mit einer Anspielung auf Fortuna (Abb. 7). Auf einem Altar ist eine geflügelte Weltkugel als Attribut der Fortuna dargestellt. Die Kugel trägt außerdem die Kaiserkrone. Aus ihr wächst der Anker der Hoffnung, auf dem der Kaiseradler sitzt und der Sonne entgegenstrebt. Links ist eine Zypresse dargestellt, die Reichsäpfel als Früchte trägt.

Welche Teile des Manuskripts Maria Anna Sibylla Calin und welche Dominik Franz Calin zuzuschreiben sind, kann nicht eindeutig geklärt werden. Wie oben angeführt, war Dominik Franz Autor der Texte, während Maria

Anna Sibylla die Schrift in Goldfarbe und die Malereien mit Temperafarben und Muschelgoldtechnik ausführte. Der ikonographische Entwurf der Bilder dürfte seine Erfindung sein, da aus den Bildern eine gute Kenntnis des in den jesuitischen Schulen gepflegten emblematischen Denkens ersichtlich ist. Die im Manuskript Corona Immortalis Gloriae bezeugte Zusammenarbeit des Ehepaars lässt die Annahme zu, dass Maria Anna Sibylla auch bei der Ausführung anderer gemalter Werke, die nur von Calin signiert sind, beteiligt war.

\section{Die Geburten der Aurora und des Sol Oriens, die Hochzeit von Margarita und Duplo Sole sowie französische Sonne vs. österreichische Doppelsonne}

Im Folgenden werden vier Werke behandelt, die zu den emblematischen Festschriften gehören, die an einen bestimmten Anlass gebunden waren. ${ }^{79}$ Alle vier haben eine ähnliche Struktur mit Frontispiz, Titelblatt, Widmung, Vorwort und vollständigen Emblemen, die aus dem einführenden Lemma

78 Abgebildet in KOVÁCS 1986 (Anm. 45), S. 71.

$79 \mathrm{Zu}$ emblematischen Festschriften siehe APPUHN-RADTKE 2004 (Anm. 52), S. 986-988. 


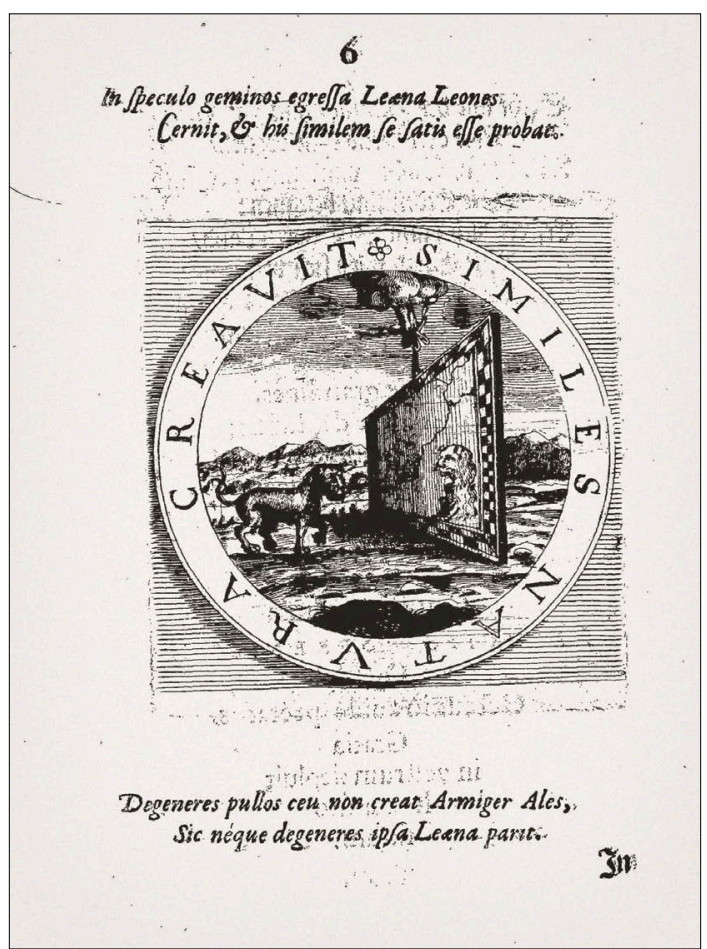

8. Similes natura creavit, in: Dominik Franz Calin, Aurora exorta, München 1660

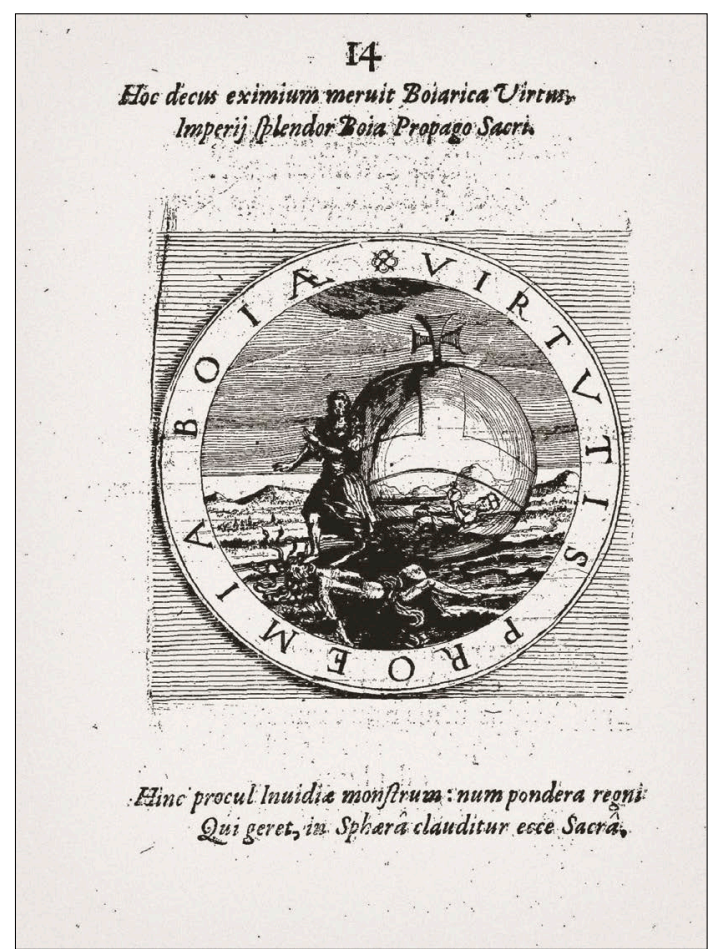

9. Virtutis proemia Boiae, in: Dominik Franz Calin, Aurora exorta, München 1660

(motto), dem bildlichen Ikon (pictura) und dem erläuternden Epigramm (subscriptio) bestehen. ${ }^{80}$ Während seines mutmaßlichen Aufenthalts in München publizierte Calin zwei Gratulationsschriften für das bayerische Kurfürstenpaar, ${ }^{81}$ bei denen er als Autor der Texte sowie Entwerfer und vielleicht Zeichner der Abbildungen tätig war, während die Kupferstiche wahrscheinlich von anderen Künstlern angefertigt wurden. Die Gratulationsschrift anlässlich der Geburt von Maria Anna, der ältesten Tochter von Kurfürst Ferdinand Maria, für die Calin die Metapher der Aurora verwendete, die hoffnungsvoll die Geburt der Sonne (des Thronfolgers) ankündet, ist mit acht nicht signierten Emblemen illustriert (Abb. 8) ${ }^{82}$ Leitners Behauptung, dass die Schrift „mit selbstverfertigten emblematischen Darstellungen in Kupferstich geschmückt worden " ${ }^{\text {sei }}{ }^{83}$ kann nicht bestätigt werden, da Calins Tätigkeit als Kupferstecher sonst nicht bezeugt ist. Es scheint, als seien die runden Bilder der Embleme von einem nicht besonders befähigten Künstler ausgeführt worden, worauf vor allem die figuralen Darstellungen schließen lassen (Abb. 9). Die Bilder der Embleme enthalten zahlreiche Hinweise auf das Haus Wittelsbach,

80 Siehe dazu APPUHN-RADTKE 2004 (Anm. 52), S. 971.

${ }^{81} \mathrm{Zu}$ den Gratulationsschriften siehe Lorenz SEELIG, Aspekte des Herrscherlobs - Max Emanuel in Bildnis und Allegorie, Kurfürst Max Emanuel. Bayern und Europa um 1700. 1: Zur Geschichte und Kunstgeschichte der MaxEmanuel-Zeit (Hrsg. Hubert Glaser), München 1976, S. 6, 24.

82 Dominicus Franciscus CALIN VON MARIENBERG, Aurora exorta. Hoc est Serenissima princeps Maria Anna Christina Iosepha Theresia Caietana Antonia Francisca Felix Hyacinta Victoria serenissimis Bavariae principibus Ferdinando Mariae et Adelaidae Henrietae anno quo GratIa De CoeLIs BoIas ManaVIt In oras felicissime progenita. Cuius Auspicatissimos Exortus Carmine atque Emblemate Dominicus Franciscus Calin de sancta Cruce ex Comitatu Goritiae repraesentavit, Monachii 1660.

83 LEITNER 1989 (Anm. 1), S. 530. 


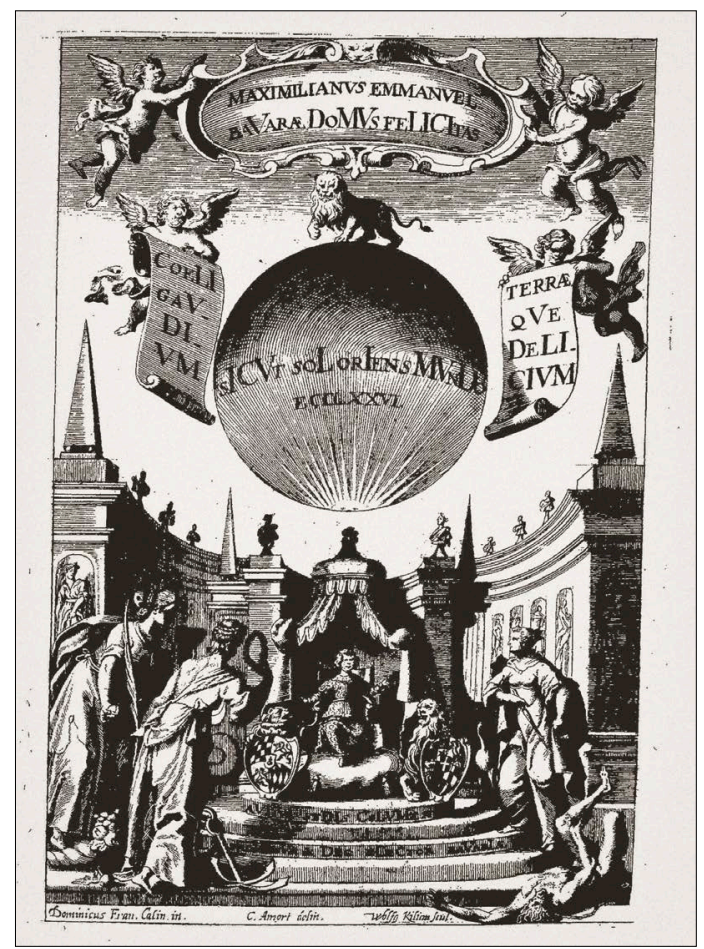

10. Dominik Franz Calin, Kaspar Amort,

Wolfgang Kilian; Frontispiz, in: Dominik Franz Calin, Sol Oriens, München 1662 wie das Wappen, den Kurfürstenhut und die heraldischen Löwen.

Calins Anteil an den Darstellungen ist besser in der Gratulationsschrift ersichtlich, die 1662, anlässlich der Geburt von Maximilian II. Emanuel oder Sol Oriens erschienen ist und zwölf komplexere Embleme sowie das Frontispiz enthält. ${ }^{84}$ Am unteren Rand des Frontispizes sind die Signaturen des Inventors Calin (Dominicus Fran. Calin in.), des Zeichners Kaspar Amort (C. Amort delin.) und des Stechers Wolfgang Kilian (Wolff. Kilian scul.) angebracht (Abb. 10). ${ }^{85}$ Calin entwarf eine Darstellung des jungen Prinzen auf einem Thron, der mit einem Baldachin überdacht und von wappentragenden Löwen bewacht wird. Der Thron steht in einer offenen Ruhmeshalle, die mit Obelisken, Büsten und Skulpturen der Tugenden ausgestattet ist. Die Personifikationen von Herrschaft (mit Weltkugel und Kurfürstenhut) und Ruhm (mit Palmenzweig und Lorbeerkranz) verbeugen sich vor Maximilian Emanuel und bringen Wohlstand (Füllhorn) und Hoffnung (Anker) ins

Land, während die Personifikation der herrscherlichen Wachsamkeit (Krone, Zepter und Kranich) einen nackten Feind besiegt. Zur Geburt von Maximilian II. Emanuel publizierten auch die Münchner und Kölner Jesuiten Gratulationsschriften, die ebenfalls emblematisch konzipiert sind, was Lorenz Seelig zu der Feststellung veranlasste, dass die drei illustrierten Publikationen die zunehmende Bedeutung der emblematischen Gelegenheitsliteratur im höfischen Bereich belegen. ${ }^{86}$ Allen dreien liegt zwar der Gedanke zugrunde, den Kurprinzen mit der über Bayern aufgehenden Sonne zu identifizieren, ${ }^{87}$ sie unterscheiden sich jedoch beträchtlich in dem Entwurf des Frontispizes. In der Schrift der Kölner Jesuiten ist der Kurprinz in der Wiege liegend dargestellt, die von seinen elf heiligen Namenspatronen umgeben ist, während die Münchner Jesuiten mit der Darstellung der

84 Dominicus Franciscus CALIN VON MARIENBERG, Sol Oriens. In Serenissimo Principe ac Domino, Domino Maximiliano Emmanuele Ludovico Maria Iosepho Caietano Antonio Nicolao Francisco Ignatio Felice, Serenissimi et Potentissimi Principis ac Domini, Domini Ferdinandi Mariae, Utr. Bauariae \& Sup. Palat. Ducis, Com. Pal. Rheni, S.R.I. Archidap. \& Electoris, Landgrauij Leichtenbergae, nec non Serenissimae Principis ac Dominae, Dominae Mariae Henrietae Adelaidae, Utriusq; Bauariae \& Sup. Palat. Ducis. Com. Pal. Rh. Electr. Landgrauiae Leichtenbergensis, Natae Regiae Principis Sabaudiae \& c. Dilectissimo Filio effigiatus â Dominico Francisco Calin, de Sancta Cruce ex Comitatu Goritiae, Monachij 1662. Zur Gratulationsschrift siehe auch LEITNER 1989 (Anm. 1), S. 530, 625-626.

85 In den Chronogrammen der Inschriften kommt das Geburtsjahr 1662 sechsmal vor: SICVT SOL ORIENS MVNDo; MAXIMILIANVS EMMANVEL Ba VAR DOMVS FELICITAS; CELI GaVDIVM / TERRAQVE DELICIVM; aVITE SEDIS COLVMEN; PROMIsSVS Â DEO ELECTOR BA VARIE.

86 SEELIG 1976 (Anm. 81), S. 6.

87 SEELIG 1976 (Anm. 81), S. 6. 
Erbauung eines Triumphbogens auf die künftigen Taten Max Emanuels anspielten. ${ }^{88}$ Der Kupferstich für die Münchner Jesuiten war ebenfalls von Kaspar Amort gezeichnet worden, wurde jedoch von Bartholomäus II. Kilian ausgeführt. ${ }^{89}$

In Calins Gratulationsschrift befinden sich zwölf Embleme, die von Wolfgang Kilian (Wolff. Kilian scul.) signiert sind. Hier bleibt die Kartusche mit sechs ovalen kleineren Emblemen, die eigene Motti tragen, immer gleich, nur die Darstellungen im zentralen Oval zeigen das jeweilige Motto. Wahrscheinlich wurden sie ebenfalls von Kaspar Amort gezeichnet und von Calin entworfen (Abb. 11). ${ }^{90}$ Die kleinen Embleme in den Rahmenkartuschen spielen mit der Darstellung eines großen und eines kleinen Löwen auf das Verhältnis von Vater und Sohn und die Erziehung des jungen Prinzen zum Herrscher (Sic decet tueri) an, die auf Pietate, Religione, Arcto foedere und Non luditur gründen soll. Das untere Rahmenemblem (Ex utroque) verweist auf seine künftige Herr-

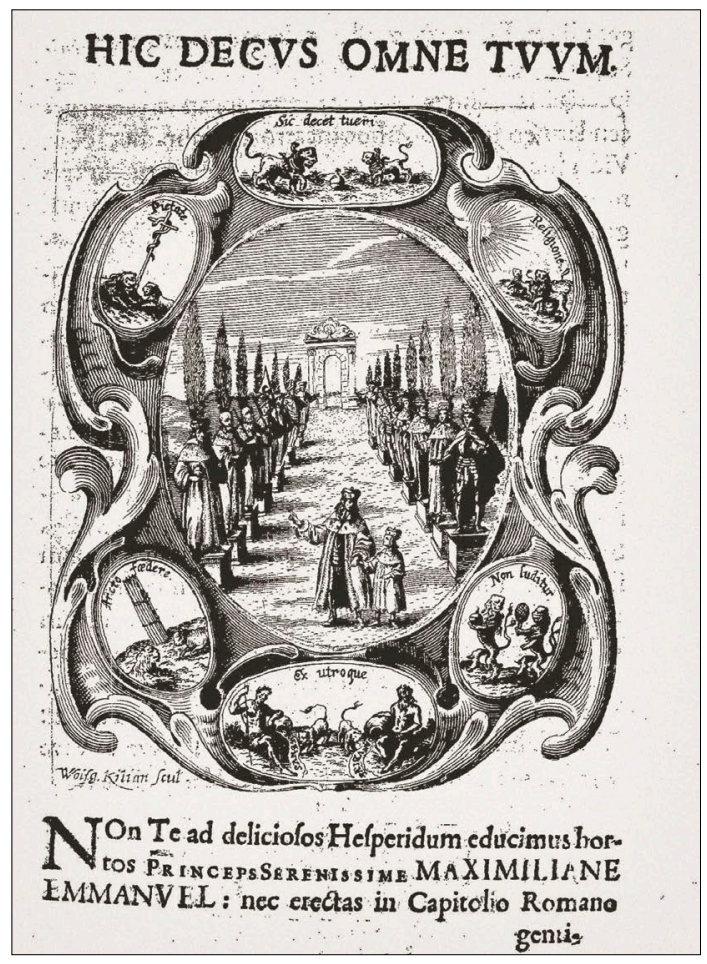

11. Wolfgang Kilian nach Dominik Franz Calin (?) und Kaspar Amort: Hic decus omne tuum, in: Dominik Franz Calin, Sol Oriens, München 1662 schaft im Rhein- und Donaugebiet bzw. auf den einstmals ungeteilten Besitz der Wittelsbacher, der die Pfalz und Bayern umfasste. ${ }^{91}$ Die Beziehung von Vater und Sohn wird besonders im zwölften Emblem (HIC DECVS OMNE TVVM) hervorgehoben, auf dem Ferdinand Maria seinem Sohn die Ahnen aus dem Haus Wittelsbach vorstellt, die auf Postamenten in einer Zypressenallee stehen, die mit einem Triumphbogen endet. Im erläuternden Epigramm nennt Calin Albrecht I. als Vorbild für Pietas, Albrecht II. für Sapientia, Wilhelm I. für Constantia, Albrecht III. für Magnanimitas, Wilhelm II. für Religio, Maximilian für Iustitia und Ferdinand Maria für Clementia.

Eine ähnliche Struktur wie die beiden Gratulationsschriften anlässlich der Geburten der ältesten Kinder des Kurfürsten Ferdinand Maria zeigt die 1666 in Wien publizierte Gratulationsschrift, die anlässlich der Hochzeit von Leopold I. und der Infantin Margarita Teresa erschien. ${ }^{22}$ Auf dem Frontispiz befindet sich die Signatur des Kupferstechers Johann Martin Lerch (Ioh. Mart. Lerch sc. Vienno), der wahrscheinlich auch die Kupferstiche der nicht signierten Embleme nach der

88 Lorenz SEELIG, Fama prognostica, Kurfürst Max Emanuel. Bayern und Europa um 1700. 2: Katalog der Ausstellung im Alten und Neuen Schloß Schleißheim (Hrsg. Hubert Glaser, Reinhold Baumstark, Annemarie Seling), München 1976, S. 5-6, Kat. Nr. 6; zu dem Frontispiz siehe auch POLLEROSS 2007, S. 385-386.

89 SEELIG 1976 (Anm. 88), S. 5.

90 Zu den Emblemen siehe Lorenz SEELIG, Emblematische Huldigung auf die Geburt Max Emanuels, Kurfürst Max Emanuel 1976 (Anm. 88), S. 6, Kat. Nr. 7.

91 SEELIG 1976 (Anm. 90), S. 6.

92 CALIN VON MARIENBERG 1666 (Anm. 32). 


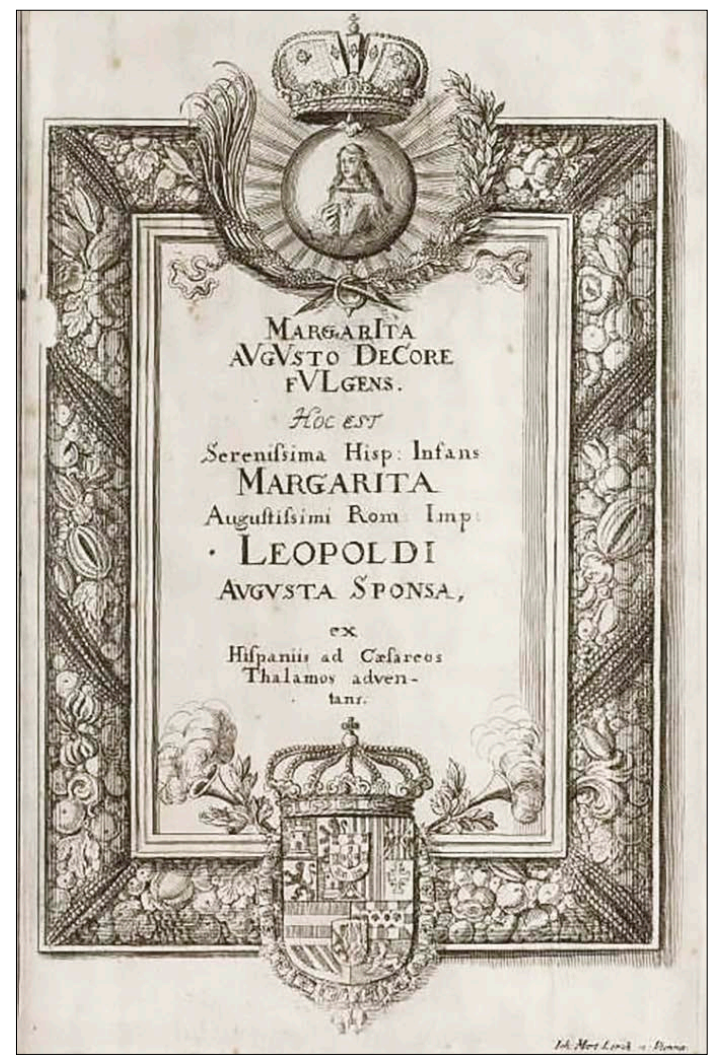

12. Johann Martin Lerch nach Dominik Franz Calin: Frontispiz, in: Dominik Franz Calin, In optatissimo Natalis Diei recursu, Wien 1666
Invention und der Zeichnung von Calin anfertigte. Die erste Eheschließung Leopolds löste eine Welle von Gratulationsschriften aus, von denen einige emblematisch angelegt waren. ${ }^{93}$ Wie die Grazer Jesuiten mit Genealogia Serenissimae Domus ${ }^{94}$ und der Hofkaplan Sebastian Glavinich (Glavinić de Glamoč; 1632-1697) mit Deplua charitum Aurora, ${ }^{95}$ deutete auch Calin in seiner Gratulationsschrift im panegyrischen Verfahren den Namen der Braut Margarita (Perle), der positive und politisch folgenreiche Assoziationen wachrufen sollte. ${ }^{96}$ Auf dem Frontispiz wird das Porträt der neuen Kaiserin auf einer vollkommen runden Perle in einer muschelartigen Umrahmung dargestellt, die von Palmen- und Lorbeerblättern umgeben und mit der Kaiserkrone bekrönt ist (Abb. 12). Als Vorlage für das Brustbildnis der (zukünftigen) Kaiserin diente das ganzfigurige Verlobungsporträt, das Gérard Duchâteau 1664 in Madrid gemalt hatte, 1665 nach Wien kam und in der Hofburg verwahrt wurde..$^{97}$ Im unteren Teil des Frontispizes ist das gekrönte spanische Wappen mit zwei lorbeerumgebenen Posaunen der Fama dargestellt. ${ }^{98}$ Die Bordüre des Frontispizes weist mit Perlenschnüren, Blüten und

Früchten auf den Wohlstand und die Fruchtbarkeit von Margarita Teresa hin, die den Fortbestand der Dynastie garantieren sollte, ${ }^{99}$ und wiederholt sich in der Umrahmung der fünf Embleme, während die anderen fünf mit Perlenschnüren und Muscheln umrahmt sind. Eine Perle ist

93 APPUHN-RADTKE 2004 (Anm. 52), S. 983.

94 Genealogia Serenissimae Domus Austriacae a Philippo Primo rege Hispaniarum, altero Austriacae magnitudinis fundatore ad augustissimos caesares Leopoldum, et Margaretham deducta, et eisdem augustissimis, dum felici, et toto orbe desiderato hymenaeo jungerentur. Submississime dedicata ab Archiducali Collegio Graecensi Societatis Jesu, Graecii 1666.

95 Sebastian GLAVINICH, Deplua charitum Aurora Augustissimi Phoebi Leopoldi Augusto Rore in Margaritam resoluta: Auspicatissimis Toris Augustissimi, Potentissimi, Invictissimi \& c. \& c. Leopoldi, et Augustissimae Margaritae affectu pio, et aeternum devoto oblata Ab humillimo subdito, ac Capellano Sebastiano Glavinich, Viennae 1666.

96 APPUHN-RADTKE 2004 (Anm. 52), S. 983.

97 Zum Porträt siehe Günther HEINZ, Karl SCHÜTZ, Porträtgalerie zur Geschichte Österreichs von 1400 bis 1800 , Wien 1976 (Führer durch das Kunsthistorische Museum, 23), S. 85; POLLEROSS 2003 (Anm. 33), S. 223-225.

98 Das Frontispiz enthält die Inschrift: MARgarIta aVGVsto DeCore FVLgENS. Hoc est Serenissima Hisp: Infans Margarita Augustissimi Rom: Imp: Leopoldi Avgvsta Sponsa, ex Hispaniis ad Caesareos Thalamos adventans. Das Chronogramm ergibt die Jahreszahl 1666.

99 Zur Verbindung von Perlen mit der Fruchtbarkeit der Fürstinnen siehe APPUHN-RADTKE 2004 (Anm. 52), S. 988; Milan PELC, Panegyric Emblem Books, Jesuits and the Habsburg Emperors: Some Examples Related to $17^{\text {th }}$-Century Croatia, Radovi Instituta za povijest umjetnosti, 43, 2019, S. 66. 


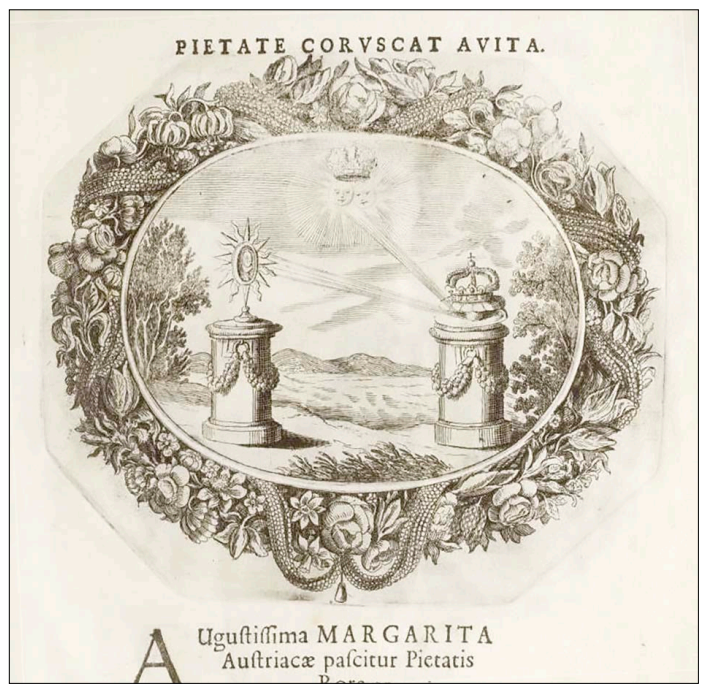

13. Johann Martin Lerch nach Dominik Franz Calin: Pietate coruscat avita, in: Dominik Franz Calin, In optatissimo Natalis Diei recursu, Wien 1666

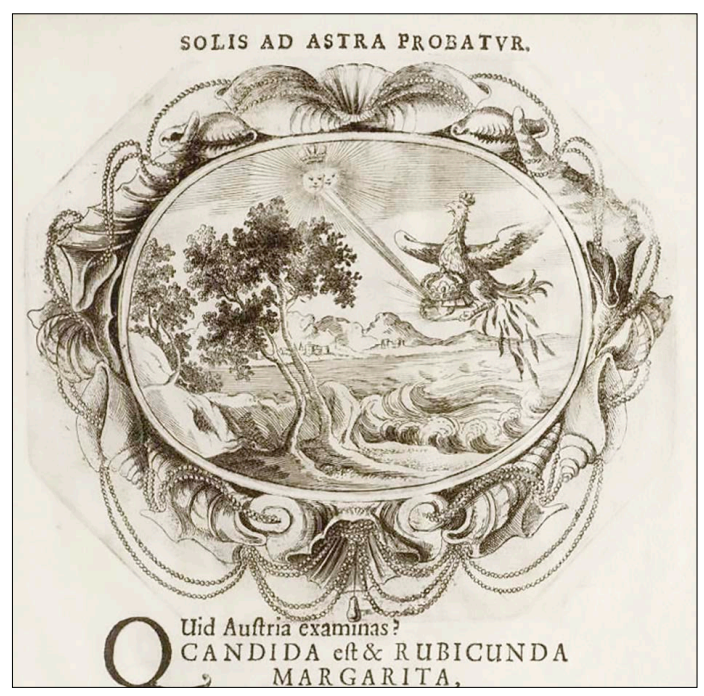

14. Johann Martin Lerch nach Dominik Franz Calin: Solis ad astra probatur, in: Dominik Franz Calin, In optatissimo Natalis Diei recursu, Wien 1666

in allen Bildern der Embleme, meistens in einer gekrönten Muschel, dargestellt (Abb. 13). Fast so konsequent war Calin mit der Darstellung einer Doppelsonne, die er als „LEOPOLDVS. Anagramma DVPLO SOLE“ erklärte und in sechs der zehn Embleme darstellte (Abb. 14). Damit war Calin einer der ersten, der das Anagramm duplo sole für Leopold I. verwendete. Sibylle Appuhn-Radtke stellte fest, dass nicht klar ist, wann genau das Anagramm in Leopolds Panegyrik aufgenommen wurde, spätestens jedoch $1668 .{ }^{100}$ Ein Vergleich mit den gleichzeitig erschienenen Gratulationsschriften der Grazer Jesuiten und von Sebastian Glavinich zeigt, dass sie nicht so konsequent auf die Metapher der Perle konzentriert waren. Der damalige Hofkaplan Sebastian Glavinich, der von 1669/70 bis 1690 Pfarrer in Slovenske Konjice (Gonobitz) und von 1690 bis 1697 Bischof von Senj (Zeng) und Modruš war, ${ }^{101}$ deutete die Namen des Kaisers und der Kaiserin mit Anagrammen, Chronogrammen und Akrostichen. ${ }^{102}$ Die ovalen Bilder der zehn Embleme, vor allem die mehrfiguralen Darstellungen mit mythologischen Gestalten, sind komplexer gestaltet als jene von Calin. Weil sie nicht umrahmt sind, ist der Eindruck jedoch schlichter. Die Stiche in der Gratulationsschrift von Glavinich sind nicht signiert. Milan Pelc stellte fest, dass Glavinich mit seiner panegyrischen Schrift seine Stelle am Hof festigen wollte und neue Begünstigungen anstrebte, was sich mit der späteren Ernennung zum Bischof auch verwirklichte. ${ }^{103}$ Die von den Grazer Jesuiten verfasste Gratulationsschrift Genealogia Serenissimae Domus wurde im Folio-Format gedruckt und

100 APPUHN-RADTKE 2005 (Anm. 54), S. 111.

${ }^{101}$ Zu Sebastian Glavinich und seinem Mäzenatentum siehe Ana LAVRIČ, Umetnostna dejavnost v konjiški župniji pod župnikom Sebastijanom Glavinićem de Glamoč, Kronika, 66/1, 2018, S. 43-68.

102 Zur Gratulationsschrift siehe GOLOUBEVA 2000 (Anm. 55), S. 95; Rostislav SMíŠEK, Deplua charitum Aurora. Leopold I. a Markéta Tereza Španělská v symbolické řeči gratulačního spisu Sebastiana Glaviniće k jejich sňatku roku 1666, Listy filologické/Folia philologica, 137/1-2, 2014, S. 41-71; PELC 2019 (Anm. 99), S. 64-70, Abb. 9, $11-20$.

${ }^{103}$ PELC 2019 (Anm. 99), S. 69-70. 
prachtvoller gestaltet als die Schriften von Calin und Glavinich. Sie enthält elf ganzseitige und prächtig umrahmte Embleme sowie das Frontispiz, das von dem Zeichner Albinus Patho und dem Augsburger Kupferstecher Philipp Kilian signiert ist; Kilian signierte auch acht der elf Embleme. ${ }^{104}$ Auf dem Frontispiz befinden sich unter der gekrönten und mit der Collane des Ordens vom goldenen Vlies umgebenen „kaiserlichen Sonne ${ }^{“ 105}$ die Personifikationen der Austria und Spania sowie Porträts der vier spanischen Könige und der fünf Kaiser von (Erzherzog) Philipp dem Schönen bis Ferdinand III. In den Emblemen, in denen Kaiser und spanische Könige alternieren, während die letzten beiden Embleme Kaiser Leopold und Margarita Teresa gewidmet sind, wurde auf die Devisen der Habsburger zurückgegriffen. ${ }^{106}$

Die vierte emblematische Festschrift Calins, die nach der Geburt von Erzherzog Leopold Joseph (2. 6. 1682-3. 4. 1684) entstand, wurde meines Wissens nicht publiziert. ${ }^{107}$ Nach der Geburt des Erzherzogs, der als zweiter Sohn Kaiser Leopolds I. ein Garant für die Sicherheit der Thronfolge zu sein schien, ${ }^{108}$ beging der Hof das Fest mit Feiern und Sinnbildern, die von ausländischen Gesandten vorgeführt wurden, wobei der französische Botschafter Marquis Bernardin Cadot Sébeville an seiner Residenz ein Emblem der Sonne mit dem französischen Wappen und dem Motto FULGET UBIQUE anbringen ließ ${ }^{109}$ Die Provokation, nämlich dass der französische Sonnenkönig überall, also auch im Habsburgerreich, strahlt, wurde nach Angaben von Jutta Schumann als Ausdruck der universalistischen Pläne des französischen Königs gewertet und in der Flugschriftenliteratur immer wieder erwähnt. ${ }^{110}$ Sie erregte Unmut bei diplomatischen Vertretern, in Regierungskreisen und sogar beim einfachen Volk und war so besorgniserregend, dass man auf Seiten der kaiserlichen Regierung rasch reagierte. ${ }^{111}$ In einem 1686 in Leipzig erschienenen Pamphlet wurde die Reaktion folgenderweise beschrieben: „Doch damit man dem gemeinen Volck ein anders vorbilden / und dem Frantzösischen Gesandten dieses gleichsam verweisen möchte / wurde etwan zwey Häuser davon in eines vornehmen Hofbedienten Fenstern unter andern Sinnbildern die Weltkugel / auf derselben die Sonne / und über dieser das Ertz=Hertzogliche Oesterreichische Wapen aufgestellet / mit der Uberschrifft: FULGET UBIQVE MAGIS. Die Nebenschrifft so durch das Wapen oder Sinnbild gieng / waren diese Buchstaben: A. E. I. O. U. mit der Unterschrift, Inferiora velut Sol inter sidera fulget, Austria sic felix fulget ubiqve magis. ${ }^{{ }^{112}}$ Die Buchstaben A. E. I. O. U. können zeitgemäß als Ausdruck der weitreichenden habsburgischen Herrschaftsansprüche gewertet werden, ${ }^{113}$ während

${ }^{104}$ Zur Gratulationsschrift siehe APPUHN-RADTKE 2004 (Anm. 52), S. 987-988; PELZ 2019 (Anm. 99), S. 65.

105 POLLEROSS 2003 (Anm. 33), S. 200.

${ }^{106} \mathrm{Zu}$ den Devisen siehe APPUHN-RADTKE 2004 (Anm. 52), S. 987, 992-994.

${ }^{107}$ CALIN VON MARIENBERG 1682 (Anm. 58). Siehe auch LEITNER 1989 (Anm. 1), S. 629, Nr. 28.

${ }^{108}$ POLLEROSS 2007 (Anm. 11), S. 378.

109 Zum Vorgehen des Botschafters siehe KOVÁCS 1986 (Anm. 45), S. 75; Friedrich POLLEROSS, Sonnenkönig und österreichische Sonne. Kunst und Wissenschaft als Fortsetzung des Krieges mit anderen Mitteln, Wiener Jahrbuch für Kunstgeschichte, 40, 1987, S. 251; SCHUMANN 2003 (Anm. 45), S. 264-265; POLLEROSS 2003 (Anm. 33), S. 289-290; APPUHN-RADTKE 2005 (Anm. 54), S. 108-109; POLLEROSS 2007 (Anm. 11), S. 381.

110 SCHUMANN 2003 (Anm. 45), S. 264-265. Zur Meinung, dass die Provokation 1682 nur fiktiv war und später erfunden wurde, siehe Hendrik ZIEGLER, Der Sonnenkönig und seine Feinde. Die Bildpropaganda Ludwigs XIV. in der Kritik, Petersberg 2010 (Studien zur internationalen Architektur- und Kunstgeschichte, 79), S. 55-61.

111 SCHUMANN 2003 (Anm. 45), S. 264-265.

${ }^{112}$ Franckreich / Die neuen Conjuncturen Werden dir den Compass gewaltig verrücken / Benebenst vielen remarqvablen Begebenheiten, Leipzig 1686, S. 64.

113 SCHUMANN 2003 (Anm. 45), S. 265. 
das Motto „scheint überall stärker“ und die Erklärung „Wie die Sonne unter den geringeren Sternen strahlt, so überstrahlt das glückliche Östrerreich alles" aussagen, dass der Kaiser die höchste Macht repräsentiert. ${ }^{114}$ Die Anbringung des provozierenden französischen Emblems und die Reaktion der Wiener sind auf einem Kupferstich von Johann Ulrich Kraus bildlich dokumentiert, der jedoch eine deutsche Stadt und nicht Wien darstellt. ${ }^{115}$ Kraus stellte die Residenz des französischen Gesandten mit dem Sonnenemblem über dem Hauptportal und mit Fackeln beleuchtet dar. Eines der gegenüberliegenden Häuser ist in ganzer Fassadenbreite mit dem Gegenemblem versehen, dessen Gestaltung mit der zitierten Beschreibung des Pamphlets identisch ist. Auch andere Häuser sind mit Emblemen geschmückt, wobei die aufwendigsten am Haus im Vordergrund rechts erscheinen und in pädagogisch anschaulicher Weise durch Personifikationen der Pietas, Sapientia, Justitia und Fortitudo auf die Erziehung des jungen Prinzen hinweisen (Votum viae crescat Leopoldus Josephus in Pietate, Sapienta, Iustitia et Fortitudine et populus dicat Amen).

Bisher blieb in der Forschung unbeachtet, dass sich auch Dominik Franz Calin am „Bilderkrieg" nach der Geburt von Erzherzog Leopold Joseph mit der Verfassung einer kurzen, mit sieben Zeichnungen versehenen Schrift, die dem Kaiser gewidmet war, beteiligte ${ }^{116} \mathrm{Im}$ Text beschrieb Calin, wie er in der Nacht zum zweiundvierzigsten Geburtstag des Kaisers (8./9. Juni 1682) sein Haus mit Emblemen geschmückt und beleuchtet habe. Er tat das als Reaktion auf die Überheblichkeit des arroganten französischen Botschafters, der während der Feierlichkeiten tausenden Wienern den französischen König als totius Mundi maximum darzustellen versuchte. ${ }^{117}$ Calin hat das heiß umstrittene Emblem mit der Unterschrift PRoLEgati GaLLICI EMbLEMA, SEV POTIVS SCOMMA versehen (Abb. 15). ${ }^{118}$ Die Zeichnung mit dem Motto FVLGET VBIQVE MAGIS und der Erklärung Inferiora Velvt SOL Inter Sydera FVlget, Avstria Sic Felix FVlget VbiQve Magis stimmt nicht völlig mit der Beschreibung im zitierten Pamphlet überein. ${ }^{119}$ Sie zeigt zwar den österreichischen Bindenschild als Strahlkörper, anstelle der Weltkugel ist jedoch Invidia dargestellt (Abb. 16). Calin deutete in seinem Text die Tat des Botschafters als Gallica Invidia, die durch die Freude der Bevölkerung anlässlich der Geburt des Erzherzogs verursacht worden sei. Der personifizierte französische Neid sitzt auf einer Terrasse, deren Balustrade mit gekrönten Weltkugeln geziert ist. Auf den Postamenten stehen zwei gekrönte Adler und verstärken mit Spiegeln die verheerende Wirkung der vom leuchtenden Bindenschild ausgehenden Strahlen auf den französischen Neid. Der Bindenschild ist mit einer Kaiserkrone gekrönt und mit der Collane des Ordens vom Goldenen Vlies umgeben, an der jedoch kein Vlies, sondern eine strahlende heilige Hostie mit dem Kreuzzeichen hängt. Zwei Sternenkreise umgeben den Bindenschild; sechs innere Sterne sind mit einem Mond und Tierkreis-Zeichen versehen.

${ }^{114}$ Vgl. KOVÁCS 1986 (Anm. 45), S. 75; ZIEGLER 2010 (Anm. 110), S. 59.

115 Johann Ulrich Kraus, Abbiltung der Jenigen nach dencklichen Sinbilter, so Zu Ehren des neu gebornen Kay. Printzens, in Wien vorgestellet worden. Ein Exemplar ist im Germanischen Nationalmuseum, Inv. Nr. HB 15573 erhalten. Siehe SCHUMANN 2003 (Anm. 45), S. 563, Abb. 30; The New Hollstein German Engravings, Etchings and Woodcuts 1400-1700. Johann Ulrich Kraus, 5 (Bearb. Jörg Diefenbacher; Hrsg. Eckhard Leuschner), Ouderkerk aan den Ijssel 2019, S. 216-217, Kat. Nr. 1418.

${ }^{116}$ CALIN VON MARIENBERG 1682 (Anm. 58). Siehe auch LEITNER 1989 (Anm. 1), S. 629, Nr. 28.

117 CALIN VON MARIENBERG 1682 (Anm. 58), Fol. 2. Den im Pamphlet und von dem Botschafter Sébeville genannten hohen Hofbeamten kann man mit Dominik Franz Calin identifizieren, den „Place de Schöneborn“ aber mir dem Platz am Schönen Brunnen, vgl. Abb. 3 und ZIEGLER 2010 (Anm. 110), S. 219.

${ }^{118}$ CALIN VON MARIENBERG 1682 (Anm. 58), Fol. 5.

${ }^{119}$ Vgl. Franckreich / Die neuen Conjuncturen 1686 (Anm. 112), S. 63-64. 


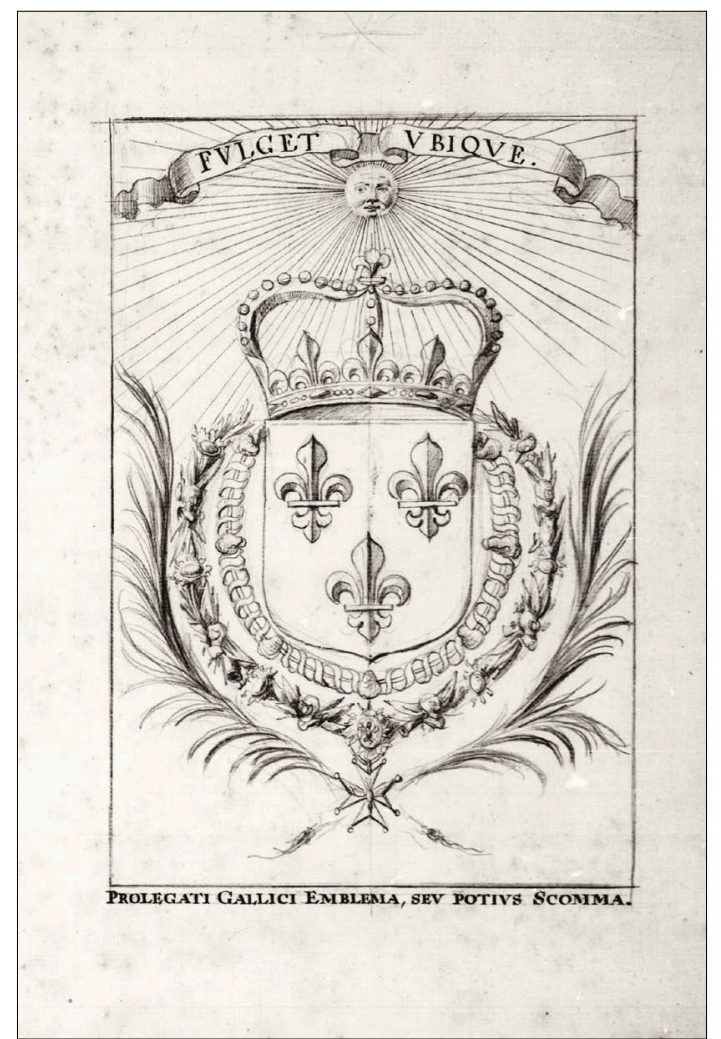

15. Dominik Franz Calin: Fulget ubique,

1682, Österreichische Nationalbibliothek, HAD,

Cod. 8321, Fol. $5 r$

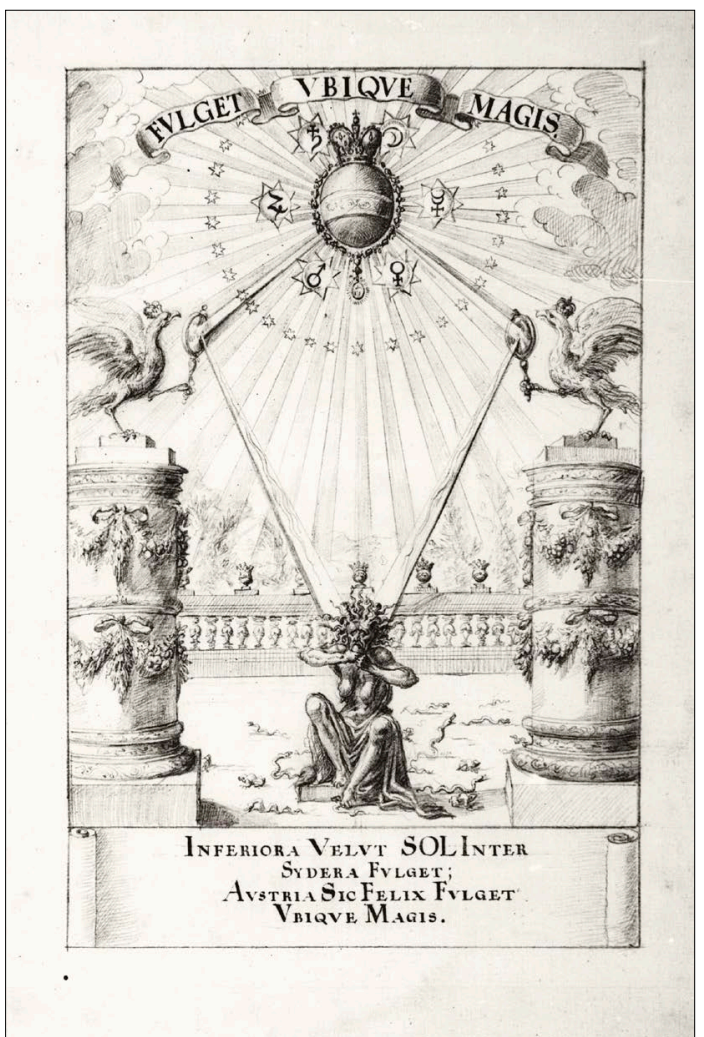

16. Dominik Franz Calin: Fulget ubique magis, 1682, Österreichische Nationalbibliothek, HAD, Cod. 8321, Fol. 6 r

Wie aus der Zeichnung von Calins Haus (Abb. 3) ersichtlich ist, wurden jedoch die Embleme FVLGET VBIQVE und FVLGET VBIQVE MAGIS nicht an der Fassade angebracht. Vier Fenster des zweiten Geschosses waren mit auf Postamenten stehenden Bindenschildern mit der Inschrift A. E. I. O. V., den Erzherzogshüten und Fruchtgirlanden geschmückt. Zwei Sonnenmedaillons in jedem Fenster stellten das Anagramm duplo sole dar. Sechs Fenster des ersten Geschosses, die sich unterhalb der Inschrift HODIE EST AVGUSTI CAESAR: FORTVNATISSIMVS NATALIS und der 42 Zahlen für jedes Lebensjahr des Kaisers befinden, sind ebenfalls einheitlich dekoriert, jedoch sind statt der Inschrift A. E. I. O. V. Länderwappen mit entsprechenden Kronen dargestellt. Links von dem mit Fackeln beleuchteten Hauptmotiv folgen die Wappen des Königreichs Ungarn sowie der Herzogtümer Österreich unter der Enns, Steiermark, Krain, Tirol und Görz, und rechts die Wappen des Königreichs Böhmen und der Herzogtümer Österreich ob der Enns, Kärnten, Mähren und Schlesien sowie ein gespaltener Schild mit den Wappen der Windischen Mark und der Herrschaft Pordenone (Portenau). ${ }^{120}$

Drei Fenster des zweiten Geschosses und die Mitte des ersten Geschosses über dem Portal wurden mit vier komplexeren Emblemen geziert, die Calin auch einzeln gezeichnet hat. Das Emblem mit dem Motto SINE FINE MANET, das auf dem linken Fenster im zweiten Geschoss angebracht

${ }^{120}$ Wegen des kleinen Formats der Zeichnung sind die Adlerwappen (Krain, Tirol, Mähren und Schlesien) nicht eindeutig bestimmbar. 


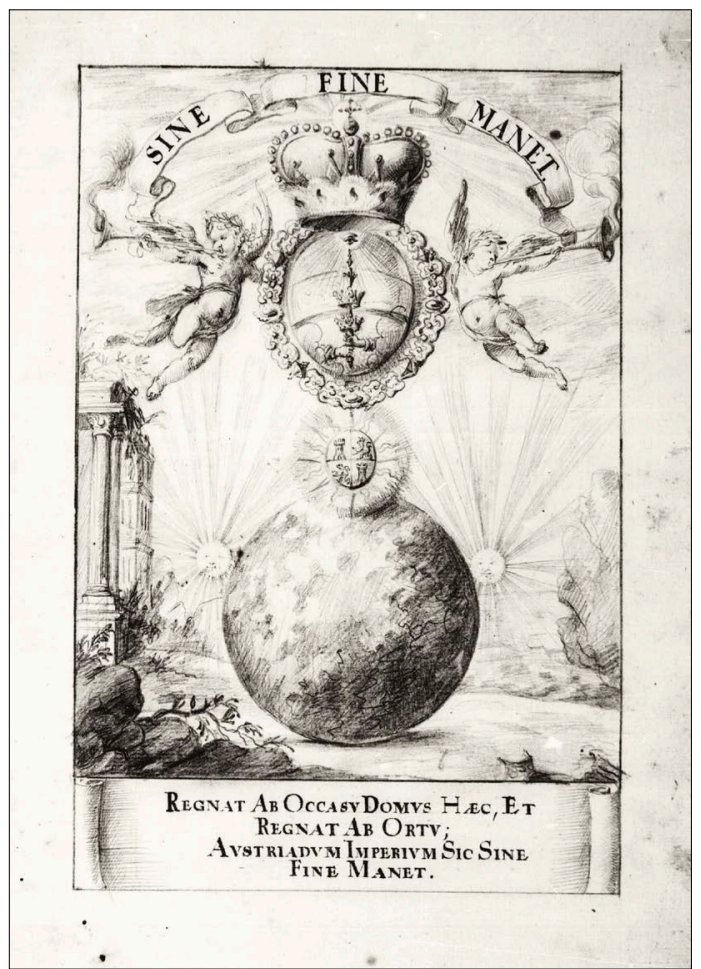

17. Dominik Franz Calin: Sine fine manet,

1682, Österreichische Nationalbibliothek, HAD,

Cod. 8321, Fol. $7 r$

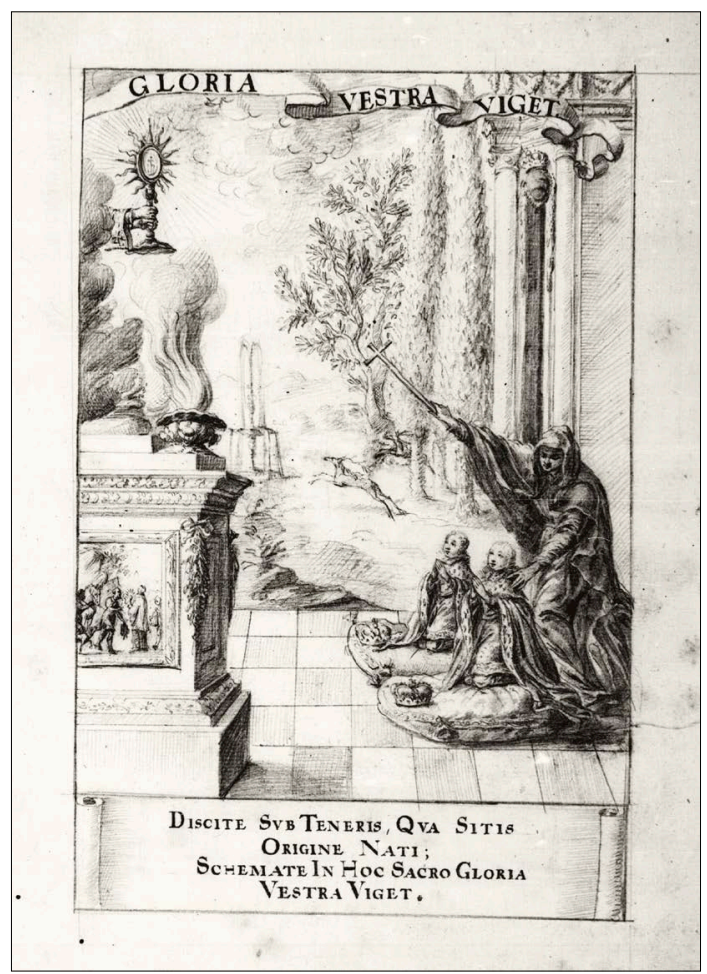

18. Dominik Franz Calin: Gloria vestra viget, 1682, Österreichische Nationalbibliothek, HAD, Cod. 8321, Fol. 8 r

war, stimmt teilweise mit der zitierten Beschreibung im Pamphlet überein, ${ }^{121}$ da auf der Weltkugel die Sonne und der Bindenschild mit dem Erzherzogshut dargestellt sind, die Erklärung ist jedoch eine andere: Regnat Aв OcCasv Domvs Hac, Et Regnat Aв Ortv; Avstria DVM Imperivm SiC SiNe FINE MANet (Abb. 17). Die Weltkugel steht an einer Küste und wird links von einem bewachsenen Tempel und einem Palais und rechts von einem Felsen flankiert. Die Weltkugel wird in der irdischen Zone von zwei Sonnen beleuchtet, die als der Kaiser und der Thronfolger ${ }^{122}$ oder als die Erzherzöge Joseph und Leopold Joseph gedeutet werden können. In der himmlischen Zone halten zwei lorbeerbekrönte und posaunenblasende Putti den Bindenschild mit dem Erzherzogshut. Auf dem Bindenschild stellte Calin ein von zwei Händen gehaltenes Zepter dar, das von zwei Kronen umgeben und mit einem strahlenden Auge bekrönt ist, was an die Devise von Leopolds älterem Bruder Ferdinand IV. PRO DEO ET POPULO erinnert. Mit der Darstellung der beiden Kronen wird vermutlich die Hoffnung auf das spanische Erbe versinnbildlicht, das der jüngere Erzherzog antreten soll. Der Bindenschild ist mit der Collane des Ordens vom Goldenen Vlies umgeben, an der jedoch wiederum kein Vlies hängt, sondern eine strahlende Sonne mit dem Wappen des Königreichs Kastilien-León, was ebenfalls als Hoffnung darauf gedeutet werden kann, dass Leopold Joseph im Königreich Spanien regieren wird.

${ }^{121}$ Vgl. Franckreich / Die neuen Conjuncturen 1686 (Anm. 112), S. 63-64.

${ }^{122}$ Nach der Geburt des Thronfolgers Joseph 1678 nahm das Anagramm duplo sole eine zusätzliche Bedeutung an und bezeichnete den Kaiser und seinen Kronprinzen; siehe APPUHN-RADTKE 2005 (Anm. 54), S. 112. 


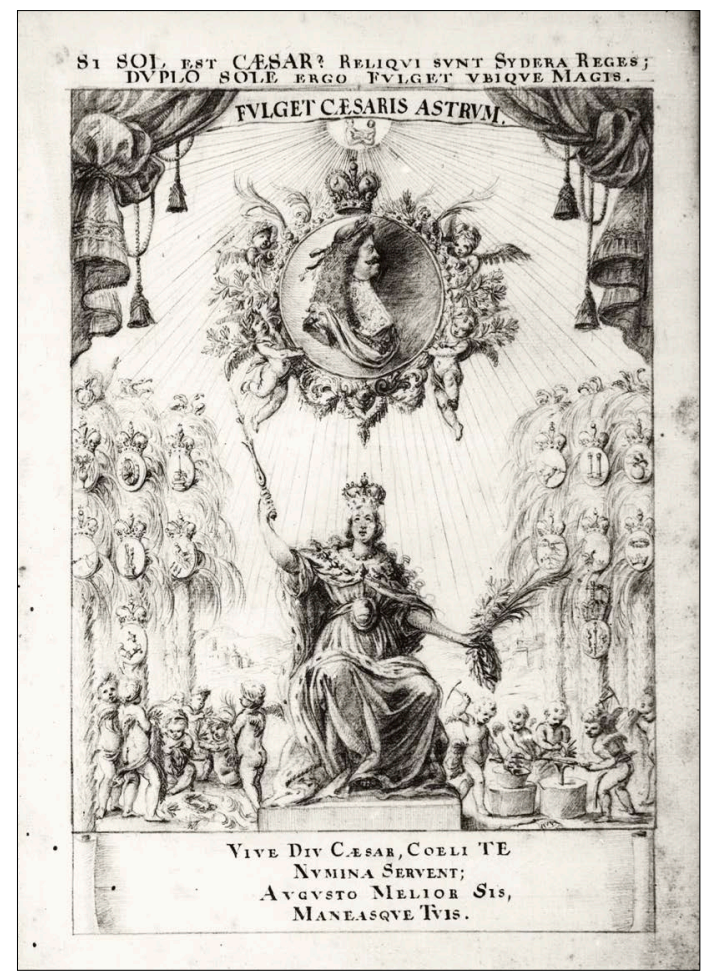

19. Dominik Franz Calin: Fulget caesaris astrum, 1682, Österreichische Nationalbibliothek, HAD, Cod. 8321, Fol. 9 r
Auf dem rechten Fenster im zweiten Geschoss befand sich das Emblem mit dem Motto GLORIA VESTRA VIGET und der Inschrift Discite SVb Teneris, Qva Sitis Origine Nati; Schemate In Hoc SaCro Gloria Vestra Viget (Abb. 18). Die beiden Erzherzöge Joseph und Leopold Joseph beten kniend auf einer offenen Terrasse. Sie werden von der Personifikation der Pietas Austriaca begleitet, die ihre linke Hand schützend auf Josephs Schulter gelegt hat und mit dem Kreuz auf die heilige Hostie im linken oberen Eck verweist. Links ist ein Altar dargestellt, dessen Seite mit einem Relief verziert ist, das Rudolf I. von Habsburg zeigt, wie er vom Pferd steigt, um es dem Priester zu übergeben, damit er den Bach überqueren und einem Sterbenden zur Hilfe eilen kann. Die Flammen in der Opferschale auf dem Altar lodern auf zur Monstranz. Damit bezieht sich Calin auf die Anbetung des Allerheiligsten Sakraments als eine der beiden zentralen Formen der habsburgischen Frömmigkeit. ${ }^{123}$ Im Hintergrund ist rechts ein monumentaler tempelartiger Bau dargestellt; ein Kapitell ist durch den gekrönten Bindenschild ausgewechselt. Mit Hilfe von zwei Hirschen, die im Hintergrund zu einem Springbrunnen laufen, stellt Calin in Anlehnung an Psalm 42,2 die Sehnsucht der jungen Prinzen nach Gott dar: „Wie der Hirsch lechzt nach frischem Wasser, so lechzt meine Seele nach dir, Gott.“

Das im mittleren Fenster des zweiten Geschosses angebrachte Emblem war dem Kaiser gewidmet: FVLGET CÆSARIS ASTRVM (Abb. 19). Die Inschrift über dem Lemma bezieht sich unmittelbar auf den von dem französischen Botschafter verursachten Aufruhr hinsichtlich der Sonnenembleme und betont, dass die Doppelsonne (Leopold) überall stärker scheine: SI SOL EST CAESAR? RELIQVi SVNT Sydera Reges; DVPLO SOLE eRGo FVLGET VBIQVE MAGis. Unter dem Bild befindet sich der Glückwunsch: Vive Div Casar, Coeli TE Nvmina Servent; Avgvsto Melior SIS, MANEASQVE TVIS. In der Mitte der irdischen Zone sitzt mit erhobenem Zepter, Palmenblättern und einem Lorbeerkranz die gekrönte Personifikation der Austria und hebt den Blick zum Porträt des Kaisers. Austria wird von Putti begleitet, die Kränze flechten sowie Kronen und ein Zepter schmieden. Die irdische Szene findet in einem Palmenhain statt. Die Palmen, in denen zweiköpfige Adler nisten, sind mit vierzehn gekrönten Ovalen versehen. In den Ovalen stellte Calin die Icones von den Devisen der Habsburger dar, wobei er heraldisch rechts die Devisen Rudolfs I. (UTRUM LUBET), Albrechts I. (FUGAM VICTORIA NESCIT), Friedrichs des Schönen (ADHUC STAT), Albrechts II. (TOLLE MORAS), Friedrichs III. (HIC REGIT ILLE TUETUR), Maximilians I. (PER TOT DISCRIMINA) und Ferdinands I. (CHRISTO DUCE) darstellte. Heraldisch links sind die 


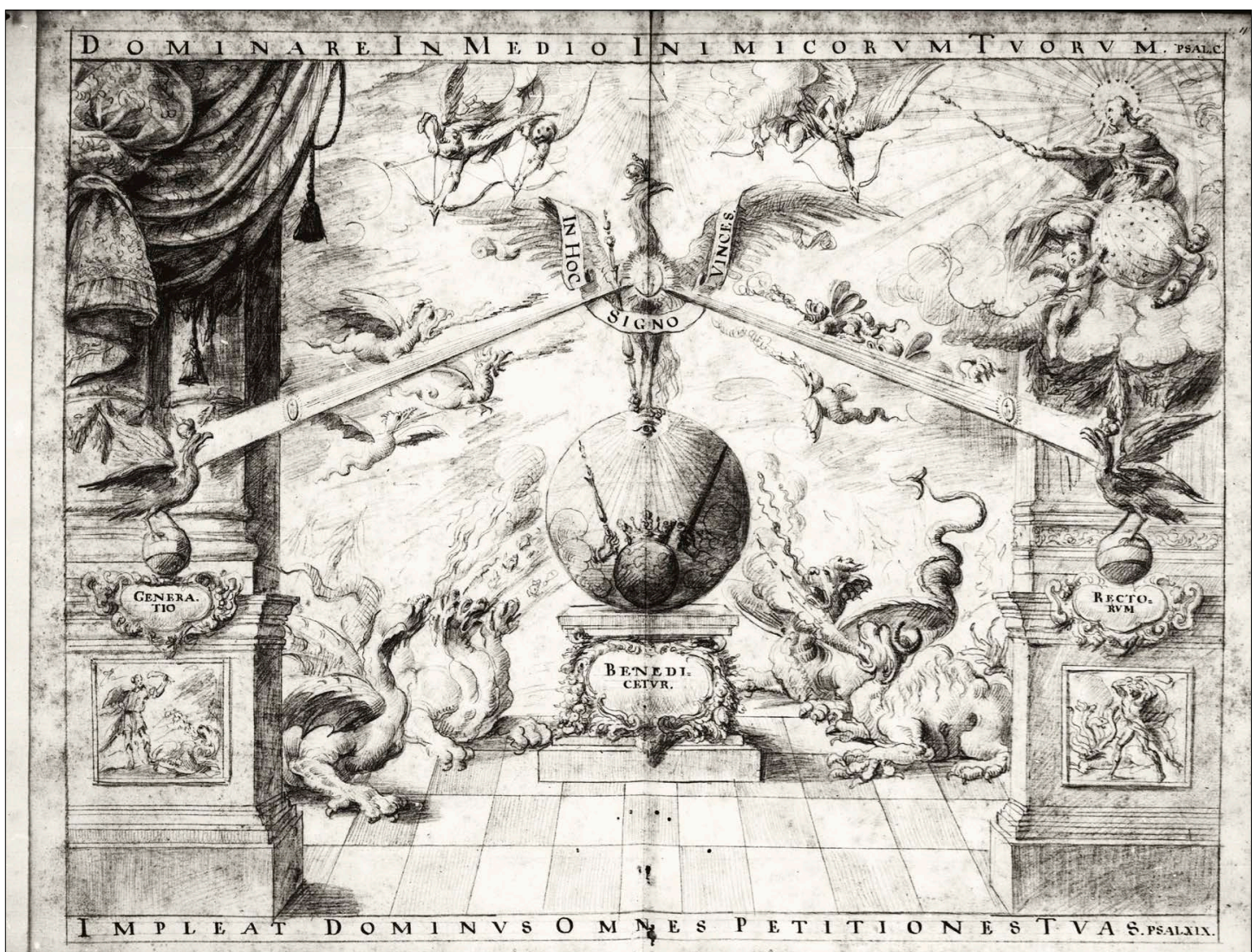

20. Dominik Franz Calin: In hoc signo vinces, 1682, Österreichische Nationalbibliothek, HAD, Cod. 8321, Fol. 11r

Devisen Albrechts II. (TOLLE MORAS), Karls V. (PLUS ULTRA), Maximilians II. (FATA VIAM INVENIENT), Rudolfs II. (ADSIT), Matthias (FIRMATUM COELITS OMEN), Ferdinands II. (LEGITIME CERTANTIBUS) und Ferdinands IV. (PRO DEO ET POPULO) dargestellt. Die Devise des ehemaligen Thronfolgers Ferdinand IV. ist als einzige mit der Reichskrone gekrönt. In der himmlischen Zone halten vier lorbeerbekrönte Putti das Medaillon mit dem Porträt Leopolds. Calin stellte den Kaiser als römischen Imperator dar. Die Darstellung im Profil und als Herme war für die zeitgenössischen Medaillen charakteristisch, wie zum Beispiel für die einige Jahre jüngere Medaille zur Krönung Josephs I. zum Römischen König, auf der das Brustbild Leopolds I. von den Porträts aller Kaiser aus dem Haus Habsburg umgeben ist. ${ }^{124}$ Das gekrönte Medaillon ist von Oliven- und Palmenzweigen umgeben und schwebt unmittelbar unter der strahlenden Sonne, auf der das astrologische Zeichen der Zwillinge dargestellt ist, in dem sowohl Kaiser Leopold I. als auch sein zweiter Sohn Leopold Joseph geboren wurden. Die Darstellung wird theatralisch durch einen betressten Vorhang - einen Ehrenbaldachin - überhöht.

Die personifizierte Austria und das Porträt des Kaisers bildeten zugleich die Bekrönung der größeren Darstellung, mit der Calin die zentrale Achse der Fassade im ersten Geschoss verzierte (Abb. 20). Die beiden Inschriften entnahm Calin den Psalmen: DoMINARE IN MEDIo INIMICORVM TVorvm. Psal. C. (Psalm 110,2) und Impleat Dominvs OmNes Petitiones TVas. Psal. Xix. (Psalm

${ }^{124}$ Zur Medaille siehe SCHUMANN 2003 (Anm. 45), S. 330, 531, 568, Abb. 40. 
19,7). Mit Herrsche inmitten deiner Feinde! wird auf Frankreich und das Osmanische Reich Bezug genommen, während Der Herr möge alle deine Bitten erfüllen nicht nur politisch verstanden werden kann, sondern auch als Geburtstagsgruß. Die Inschrift GENERATIO RECTORVUM BENEDICETVR (das Geschlecht der Redlichen wird gesegnet), die auf drei Kartuschen verteilt ist, wurde dem Psalm 112,2 entnommen. Die Kartusche mit Generatio ist auf dem linken Postament befestigt, über einem Relief, das Simson mit dem Eselskinnbacken darstellt; er triumphiert jedoch nicht über tausend tote Philister (Richter, 15,15-7), sondern über einen Löwen (Richter, 14,6). Auf dem gegenüberliegenden Relief ist unter der Kartusche mit RECTORVM Herkules im Kampf mit der Lernäischen Hydra dargestellt. Die Kartusche mit BENEDICETVR ist auf einem Postament in der Mitte der Darstellung befestigt, auf dem die Weltkugel mit dem Icon der Devise Leopolds CONSILIO ET INDUSTRIA dargestellt ist. Auf der Kugel steht ein gekrönter Adler mit einem Zepter, der strahlenden heiligen Hostie auf der Brust und der Inschrift IN Hoc SIGNo VINCES. Die heilige Hostie bestrahlt zwei kleinere gekrönte Adler, die auf Weltkugeln mit Bindenschildern stehen. Die Devise Kaiser Leopolds wird von vier Drachen bedroht. Der durch den Halbmond als Osmanisches Reich gekennzeichnete Drache speit Pfeile, während aus dem Maul des durch den Hahnenkamm als Frankreich gekennzeichneten Drachen Schlangen hervorkriechen. Kleine fliegende Drachen, von denen einige durch den Hahnenkamm als Franzosen identifiziert werden können, bedrohen den gekrönten Adler. Die Drachen werden von Engeln beschossen, die von Maria Immaculata befehligt werden. Calin hat die Immaculata zur Seite versetzt, um zu verhindern, dass die personifizierte Austria und das Porträt des Kaisers des oberen Emblems bedeutender erscheinen würden als Maria.

\section{Die Stammbäume der Habsburger}

Nach seiner mutmaßlichen Übersiedlung aus München nach Wien in den Jahren 1665/1666 widmete sich Calin genealogischen Studien und der Visualisierung der genealogischen Daten in der Form großformatiger Stammbäume. ${ }^{125}$

Mit 1666 ist der prächtige, 2950 x $1622 \mathrm{~mm}$ große, mit Tempera und Goldfarbe ausgeführte Stammbaum datiert, auf dem das Geschlecht der Habsburger von dem Frankenkönig Pharamundus von Troja und Sicambrien hergeleitet wird. ${ }^{26}$ Die ausgezeichnete Erhaltung bezeugt, dass der aus 21 Blättern bestehende Stammbaum nie auf eine Unterlage geklebt und aufgehängt wurde. Die Genealogie ist oben Genealogia HabspVrgo-Avstriaca, et Avstriaco-Hispanica, a Xit. et PLVS SACVLIS HANC IN FORMAM REDACTA betitelt. In der Signatur bezeichnete sich Calin als Bibliothekar und Sekretär des bayerischen Kurfürsten: Studio et Zelo Ser: ${ }^{\text {mi }}$ Bavarice Elect. Bibliothecarij et Secretarij Dominici Francisci Calin Goritiensis An: MDCLXVI. In einer der Inschriften nennt Calin die Historiographen, auf deren Ausführungen er sich bei der Erstellung des Stammbaumes stützte: Ioannes Trithemius, Gvillimannus, Wolfgangus Lazius, Henningius, Gebvillerus, Menlius,

\footnotetext{
125 Siehe LEITNER 1989 (Anm. 1), S. 626-627, Nr. 7-8, 10, 12, 14.

${ }^{126}$ Wien, Albertina, Inv. Nr. 44230. Zu den Theorien über die Abstammung der Habsburger von Pharamundus von Troja siehe Alphons LHOTSKY, Apis Colonna. Fabeln und Theorien über die Abkunft der Habsburger. Ein Exkurs zur Chronica Austrie des Thomas Ebendorfer, Mitteilungen des Instituts für Geschichtsforschung und Archivwissenschaft in Wien, 60, 1944, S. 203-222; CORETH 1950 (Anm. 8), S. 32-35; VOCELKA, HELLER 1997 (Anm. 45), S. 117-120; 134-136.
} 


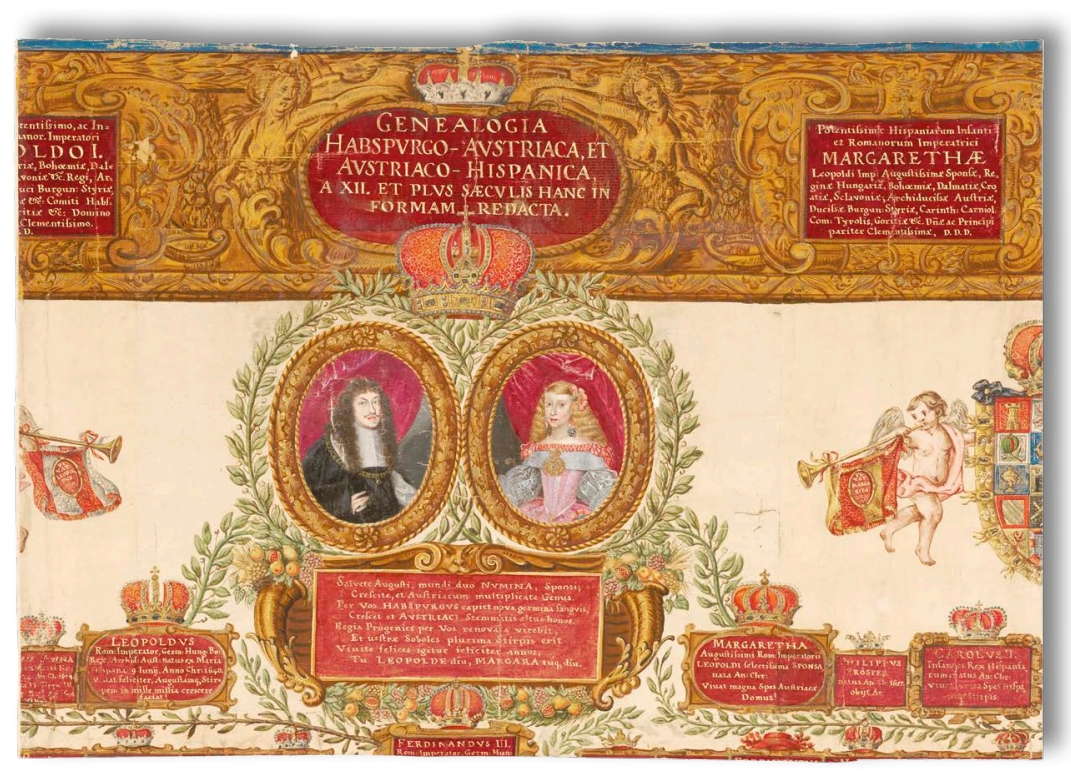

21. Dominik Franz Calin: Genealogia HabspurgoAustriaca et AustriacoHispanica, 1666, Albertina, Wien, Inv. Nr. 44230/2

Reusnerus, Piespordius, et alij quàm plurimi fide dignissimi Scriptores. ${ }^{127}$ Die genannten Gelehrten vertraten die Meinung, dass die Habsburger von den Trojanern abstammten, wozu Alphons Lhotsky bemerkte: „Die Troja-Habsburg-Sage ist von allen Vermutungen über die Herkunft des Hauses Österreich die künstlerisch fruchtbarste geworden: Handschriften- und Wandmalerei, Dichtung und Bühne, Kunstfertigkeit aller Art - sogar die Alchimie sind im Bunde mit ihr anzutreffen. ${ }^{\text {"128 }}$

In der Mitte unten stellte Calin einen Sarkophag dar, dessen Vorderseite er für eine Inschrift über König Pharamundus († 430) und seine Taten verwendete. Zwei Sirenen halten das gekrönte Wappen von Pharamundus mit drei Fröschen. ${ }^{129}$ Auf den Sarkophag ist ein kleinerer Sarkophag als Postament für den Stammbaum gestellt, mit einer Clodius Crinitus († 445) gewidmeten Inschrift und einem gekrönten bärtigen Männerkopf. Seitlich befinden sich die Wappen der Könige von Troja und Sicambrien. Der Stamm und die Lorbeerzweige des Baumes sind mit rechteckigen Tafeln versehen, auf denen mit Goldschrift die Namen der Könige und ihrer Gemahlinnen, die Todesdaten und bei einigen ihre Taten angeführt sind. Für die Wichtigeren bereitete Calin größere Kartuschen vor, wie für den fünften König der Franken Clodoveus Magnus († 514), der sich nach Calin 493 mit seinem Volk taufen ließ und als erster drei heraldische Lilien im Wappen benutzte

$127 \mathrm{Zu}$ den Werken von Johannes Trithemius, Franz Guilliman, Wolfgang Lazius, Hieronymus Henninges, Hieronymus Gebwiller, Jakob Mennel, Elias Reusner und Theoderic (Thierry) Piespord siehe LHOTSKY 1944 (Anm. 126), S. 205-208, 212-213, 220-221, 226-227, 238-243; CORETH 1950 (Anm. 8), S. 33 25, 50-51, 156.

${ }^{128}$ Mit Alchimie ist das Medaillon gemeint, für das Calin den Entwurf beisteuerte und das im Folgenden behandelt wird; LHOTSKY 1944 (Anm. 126), S. 217.

${ }^{129}$ Das Wappen von Pharamundus mit drei Fröschen kommt auch bei Thiery Piespord vor, den Calin als eine seiner Quellen nannte; siehe Theodoricus PIESPORD, Serenissimorum potentissimorumque principum Habsburgi-Austriacorum stemma, origo, res gestae. Quatuor schematibus à Pharamundo Francorum rege ad haec usque tempora deductae. Iconibus, emblematibus, insignibus illustratae, Bruxellae 1616, Pag. 1. Das Wappen mit drei Fröschen wurde spätestens von den Humanisten der Maximilianischen Zeit erfunden, da es auch auf den Jörg Kölderer zugeschriebenen aquarellierten Federzeichnungen vorkommt, die die Ahnen Kaiser Maximilians I. darstellen; siehe dazu Veronika SANDBICHLER, Jörg Kölderer (?), Die Ahnen Kaiser Maximilians I., Kaiser Maximilian I. und die Kunst der Dürerzeit (Hrsg. Eva Michel, Maria Luise Sternath), Albertina, Wien, München-London-New York 2012, S. 170-171, Kat. Nr. 21. 
(trium Liliorum Insignia usurpauit). ${ }^{130}$ Nach der Teilung in die Könige von Frankreich und die von Austrasien sind Clodoveus II. ( $†$ 662) und Sigisbertus I. ( $† 635)$, mit dem die Reihe der Grafen von Habsburg beginnt, ${ }^{131}$ auf größeren Tafeln angeführt. Die Tafel mit dem Namen von Hatopertus, der als erster Graf von Habsburg angeführt wird, Dux Super: Alemannioe, Primus Comes Habspurgi, quod Castellum ipse fundavit unà cum Altenburgo, ist nicht besonders hervorgehoben. Die ovale Kartusche mit dem Namen seines Urenkels Hettopertus ist mit Mischwesen verziert, die aus geflügelten Frauenoberkörpern und Fischen bestehen. Die nächsten hervorgehobenen Tafeln gehören dem Grafen Luitfridvs I., den Heiligen Bischöfen Ulrich von Augsburg († 973) und Gebhard von Konstanz († 885), dem Papst Leo IX. und dem Burgunderkönig Rudolf III. Wegen der Reihenfolge und Namensformen der legendären Ahnen darf man annehmen, dass Calin den Stich Genealogia Habsbvrgica à Pharamvndo Francioe Orientalis Duce, usque ad Rudolphum I. Rom. Imp. als Quelle verwendete, der von Wolfgang Kilian ausgeführt und 1623 in Augsburg publiziert wurde, ${ }^{132}$ der lateinischen Ausgabe folgte die 1629 veröffentlichte deutsche Übersetzung von Elias Ehinger. ${ }^{133}$

Die bekrönte ovale Kartusche mit Namen und Taten des ersten Habsburger Kaisers (Königs) Rudolf I. († 1291) ist unten mit zwei Löwen, die den Reichsapfel halten, und oben mit zwei Adlern, die Zepter und Schwert tragen, verziert. Am Baumstamm folgen Rudolf I. die Kaiser Albert I. $(\dagger$ 1368) und Friedrich III. ( $\dagger$ 1315), Erzherzog Ernst der Eiserne ( $\dagger$ 1424), Kaiser Friedrich IV. († 1493), Kaiser Maximilian I. († 1519) und Erzherzog Philipp I. († 1506), dem die größte Kartusche nach Rudolf I. gewidmet ist, um die Folgen seiner Eheverbindung mit Johanna von Kastilien hervorzuheben. Die Kaiser von Karl V. bis Matthias kommen an den Zweigen vor, während am Baumstamm Philipp dem Schönen die Tafel mit dem Namen Erzherzog Karls II. von Innerösterreich ( $\dagger$ 1570) folgt sowie die Kaiser Ferdinand II. ( $†$ 1637) und Ferdinand III. ( $†$ 1657). Während die Tafeln mit den Namen des aktuellen Kaisers Leopold I. und seiner Gemahlin Margarita Teresa zur Seite an die Zweige gerückt sind, ist die zentrale Kartusche aus Füllhörnern geformt. Sie wird zur Gratulation verwendet und drückt den Wunsch nach zahlreicher Nachkommenschaft aus (Abb. 21). Die Porträts des Kaiserpaars sind mit Lorbeerzweigen umgeben, über ihnen schwebt die Kaiserkrone. Die Gesichtszüge Margarita Teresas, ihre Haartracht, Schmuck und Kragen bezeugen, dass Calin als Vorlage das ganzfigurige, von Gérard Duchâteau 1664 in Madrid gemalte Verlobungsporträt verwendete, das auch den Frontispiz seines im selben Jahr (1666) erschienenen Buches In optatissimo Natalis Diei recursu (Abb. 12) ziert. ${ }^{134}$ Calin übernahm den Schnitt des Kleides der zukünftigen Kaiserin, nicht aber seine dunkle Farbe mit der Goldstickerei und dem Muster aus Doppeladlern.

\footnotetext{
${ }^{130}$ Auf der Jörg Kölderer zugeschriebenen aquarellierten Zeichnung der Ahnen Maximimilians I. führt Clodoveus ein gespaltenes Wappen mit drei Fröschen und drei Lilien sowie den trojanischen Löwen als Herzschild; siehe SANDBICHLER 2012 (Anm. 129), S. 170.

${ }^{131}$ Vgl. LHOTSKY 1944 (Anm. 126), S. 225-226, 240-242.

${ }^{132}$ Wolfgang KILIAN, Serenissimorum Austriae Ducum, Archiducum, Regum, Imperatorum Genealogia, à Rudolpho I. Habsburgensi, Caesare, ad Ferdinandum II. Rom. Imp. semper Augustum, \&ُc. Aeri incisa à Wolfgango Kiliano, Eiconographo Augustano, Augustae Vindelicorum 1623.

${ }^{133}$ Elias EHINGER, Deß aller Durchleüchtigsten Haus Osterreichs Herzogen, Ertzhertzogen, König vnd Kayser Eigentliche Contrafacturen, samt historischer beschreibung der Geburt register vnd geschlecht, von Rudolpho an, deß namens dem ersten Römischen Kä̈ser biß auff Ferdinandum II. anitzo regirenden Römischen Kaÿser \& c. In vnsere Teütsche Sprach versetzt vnd von Wolfgang Kilian Bürger und Kupferstecher in Augspurg in Kupfer gestochen, Augsburg 1629.

${ }^{134}$ Zum Porträt siehe HEINZ, SCHÜTZ 1976 (Anm. 97), S. 85; POLLEROSS 2003 (Anm. 33), S. 223-225.
} 


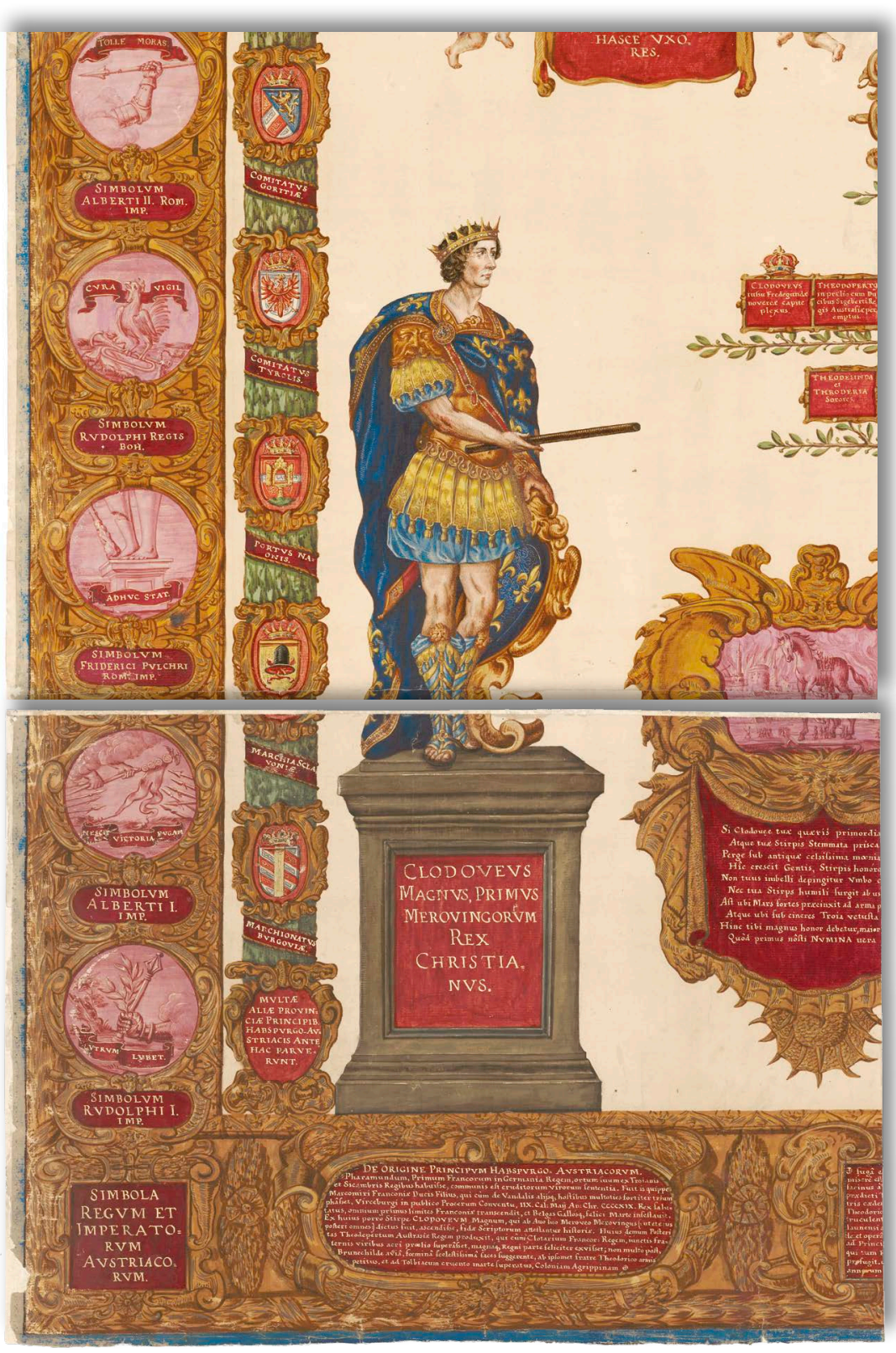

22. Dominik Franz Calin: Genealogia HabspurgoAustriaca et AustriacoHispanica, 1666, Albertina, Wien, Inv. Nr. 44230/16

\section{Dominik Franz Calin:} Genealogia HabspurgoAustriaca et AustriacoHispanica, 1666, Albertina, Wien, Inv. Nr. 44230/19

In der Höhe von Pharamundus bis Chlodwig I. stellte Calin zwei aus Muschelformen bestehende Kartuschen dar, die teilweise für Inschriften über Chlodwig I. und Rudolf I. verwendet wurden, während er im oberen Teil heraldisch rechts das Trojanische Pferd im brennenden Troja und heraldisch links Äneas, der Anchises aus der brennenden Stadt trägt, darstellte. Neben der heraldisch rechten Kartusche befindet sich die ganzfigurige Darstellung Chlodwigs auf einem Postament mit der Inschrift Clodovevs Magnvs, Primvs Merovingorvm Rex Christianvs (Abb. 22, 23). Der erste Merowingerkönig ist als junger Mann mit einfacher Zackenkrone und in einer antikisierenden Rüstung mit nackten Oberschenkeln und Stiefeln dargestellt. In der Rechten hält er einen Kommandostab, sein blauer Umhang ist wie der französische Krönungsmantel mit goldenen fleur-de-lis bestickt, drei Lilien erscheinen auch auf dem Wappenschild, auf den sich Chlodwig stützt. Die Vorlage darf man in einem der Porträtbücher vermuten, wobei zu bemerken ist, dass sich Chlodwig im Buch von Francesco Terzio Austriacae gentis imagines noch auf 
einen gespalteten Schild stützt, der drei Frösche im rechten und drei Lilien im linken Feld trägt. ${ }^{135}$ Gegenüber von Chlodwig I. befindet sich Rudolf I., mit der Inschrift RVDOLPHVS COM. HAPSPVRG. AVSTRIACORVM IMPERATOR befindet. Rudolf trägt eine Rüstung aus der Zeit Kaiser Maximilians I. und die Kaiserkrone, die Verbrämung seines Umhangs ist mit Edelsteinen und einem Doppeladler geschmückt. Er hält einen Kommandostab in seiner Rechten und stützt sich auf den österreichischen Bindenschild. Auf seiner Brust hängt ein mit goldenen Flammen umrahmtes Medaillon mit einer heiligen Hostie, auf die in der Kartusche mit Äneas und Anchises Bezug genommen wird: Austriacce Æneas fons Pietatis erit /.... Tu Pius in summum, Dive Rudolphe, Deum. Hinc tua perpetuos Soboles florebit in annos, Et post hac Natos MILLIA MILLE dabit.

Über dem ersten christlichen König und dem „österreichischen Äneas“ stellte Calin in Lorbeerkartuschen Wappen der Ehepartner der Habsburger und Habsburgerinnen dar (ACCEPERVNT Archidvces, Reges et Imperatores Avstriaci a tempore RVDolphi I. Imp. hasce VXores / Dvxervnt e domo Avstriaca et Hispan. a tempore Rvd. Primi Imp. Exteri Reges et PrinCIPES HASCE VXORES). Das heraldisch rechts aus 59 gekrönten Wappen bestehende Arrangement endet oben mit dem Wappen von Leopold I. und Margarita Teresa, sein aus 57, ebenfalls gekrönten Wappen zusammengesetztes Pendant endet mit dem Wappen von Ludwig XIV. von Frankreich und Maria Teresa von Spanien. Über den Wappen und in der Höhe der heiliggesprochenen Bischöfe Ulrich und Gebhart tragen fünf Putti die päpstlichen Insignien zur Kartusche des Papstes Leo IX.; darüber schwebt das Bibelzitat VALDE SPECIOSVS EST IN SPLENDORE SVO. ECCL. CAP. 4.3. Als Pendant dazu und unter der Inschrift GLORIficavit eVM in ConspeCtV RegVM. ECCL. Cap. 4.5. tragen fünf Putti eine Königskrone und ein Zepter zur Kartusche des Burgunderkönigs Rudolf III. Im oberen Teil des Stammbaumes gibt es weniger Platz für Darstellungen. In der Höhe von Philipp dem Schönen stellte Calin reichverzierte, von Putti getragene Kartuschen dar, die aus Füllhörnern gebildet sind, aus denen Kaiser- und Königskronen, Herzogs- und Kardinalshüte sowie eine Tiara, Mitren, Zepter und ein Reichsapfel fallen. Die Inschriften beziehen sich auf die Söhne Philipps des Schönen und ihre Rolle: Ferdinandvs Primvs, Rom. Imperator Stemmatis Avstriacorvm Caes. Propagator und Carolvs V. Rom. Imperator Stemmatis Regvm Hispaniar. PropagaTOR. Um die österreichische gegenüber der spanischen Linie der Habsburger hervorzuheben, stellte Calin die Kartusche des jüngeren Ferdinand I. heraldisch rechts und die des älteren Karl V. heraldisch links dar. ${ }^{136}$ Neben den Porträts Leopolds I. und Margarita Teresas malte Calin ihre Wappen, von posaunenblasenden Putti getragenen, auf deren Fahnen die Jubelrufe VIVAT AVSTRIA, Vivat Leopoldvis, Vivat Margarita und Vivat Hispania geschrieben sind.

Der Stammbaum wird links von einer aus Lorbeerblättern gebildeten Leiste mit 21 Wappenkartuschen umrahmt, die die Potentia Domvs Avstriaca bezeugen und oben mit dem Reichswappen beginnen, während am Leistenfuß MvLte alie ProvinCIA PrinCipib. HabSPVRGo-Avstriacis ante haC PARVERVNT steht. Als Pendant ist rechts eine Leiste mit ebenfalls 21 Wappenkartuschen dargestellt, die die Potentia Corona Hispanic ze zeigt, die mit dem Wappen

${ }^{135}$ Francesco TERZIO, Francisci Tertii Bergomatis Serenissimi Ferdinandi Archiducis Austriae Ducis Burgundiae Comitis Tirolis etc. pictoris aulici Austriacae gentis Imaginum, 1-5, Innsbruck 1569-1573, Fol. 35. Zu den Porträts siehe Elisabeth SCHEICHER, Die »Imagines Gentis Austriacae« des Francesco Terzio, Jahrbuch der Kunsthistorischen Sammlungen in Wien, 79, 1983, S. 43-92; Tina KOŠAK, Between Uniformity and Uniqueness. Depictions of Benefactors of Stična Cistercian Abbey, Acta historiae artis Slovenica, 25/2, 2020, S. 176-177.

${ }^{136}$ Umgekehrt als auf dem Stich Genealogia Habsburgica à Pharamundo Franciae Orientalis Duce, usque ad Rudolphum I. Rom. Imp. von Wolfgang Kilian in KILIAN 1623 (Anm. 132) und EHINGER 1629 (Anm. 133). 
des Königreichs Kastilien beginnt und unten mit der Bemerkung MVlta alia RegNa et PRINCIPATVS HISPANICA CORONA ETIAM NUM PARENT vervollständigt ist.

Die Bordüre des Stammbaums ist reich mit monochrom gemalten Lorbeerkränzen, Knorpelund Ohrmuschelwerk sowie grotesken Masken und Tierköpfen verziert. ${ }^{137}$ Die Bordüre ist oben und unten mit Inschriftenkartuschen versehen, während beiderseits in jeweils achtzehn Kartuschen die Impresen der Kaiser und Könige (Simbola Regvm et Imperatorvm Avstriacorvm) heraldisch rechts und der Grafen (Simbola Generosissimorvm Comitvm Habspvrgiorvm) heraldisch links dargestellt sind. Die Grafenreihe beginnt rechts oben mit Simbolvm SigISBERTi I. ExVLIS, das aus einem von der Sonne umstrahlten Weinstock und dem Motto AT SALTEM ILLVSTROR besteht. Die Devise mit der Darstellung des Weinstocks und der Sonne kommt spätestens 1570 bei Francesco Terzio vor, ${ }^{138}$ als Vorbild benutzte Calin jedoch die Darstellung, die 1616 von Thierry Piespord publiziert wurde. ${ }^{139}$ Dasselbe gilt für die anderen 17 Impresen der Grafen von Habsburg von Sigisbertus II. bis Albertus III. ${ }^{140}$ Die Reihe der Impresen der Könige und Kaiser beginnt links unten mit SIMBOLVM RVDOLPHI I. IMP. und SIMBOLVM ALBERTI I. IMP., die ebenfalls aus Piespords Buch kopiert wurden. ${ }^{141}$ Für die weiteren 16 Impresen von (Gegen)König Friedrich dem Schönen bis Kaiser Leopold I. wurden die Stiche von Terzio und andere Vorbilder verwendet. ${ }^{142}$ Die monochrome malerische Ausführung mit Goldhöhungen in Muschelgoldtechnik erinnert an die Darstellungen von Maria Anna Sibylla Calin und lässt die Annahme zu, dass sie ihrem Ehemann bei der Ausführung des Stammbaumes geholfen hat. Als Hinweis auf ihre Beteiligung können die beiden Sibyllen gedeutet werden, die oben in der Mitte die Kartusche mit dem Titel GENEALOGIA HABSPVRGO-AVSTRIACA halten.

1666, im selben Jahr wie die Genealogia Habsprrgo-Avstriaca, fertigte Calin mit Tempera und Goldfarbe eine 2900 x 1620 mm große Darstellung mit Porträts aller römischen, römisch-deutschen und byzantinischen Kaiser sowie osmanischen Sultane an ${ }^{143}$ Die aus 21 Blättern bestehende Darstellung ist als Pendant zur Genealogia Habspvrgo-Avstriaca zu verstehen, ein Huldigungswerk, das Calin dem Kaiser vermutlich ebenfalls anlässlich seiner Eheschließung schenkte, obwohl Margarita Teresa in den Texten nicht genannt wird. Betitelt ist die Darstellung oben in der Mitte mit ICONOLOGIA et Series omnium, quotquot â Iulio Cesare fuerunt, Imperatorum Romanorum, Byzantinorum, Germanicorum, Turcicorum; quibus inserti omnes utriusque Statûs Sac: Rom. Imperij Principes Electores: omniúmque Imperij Principatuum Insignia. Calin signierte das Werk unten in der Mitte mit Serenissimi Bavariae Electoris Secretarius et Bibliothecar: DomINICvs FRANCISCVS CALIN de Sancta Cruce ex Comitatu Goritio; invenit, et humillimè dedicauit; Anno Christi MDCLXVI.

${ }^{137}$ Zur Bemerkung, dass Calin noch manieristisch anmutendes Rollwerk und retardiertes, ohrenförmiges Rollwerk zur Ornamentierung verwendete, siehe LEITNER 1989 (Anm. 1), S. 534.

138 TERZIO 1569-1573 (Anm. 135); vgl. LHOTSKY 1944 (Anm. 126), S. 240.

139 PIESPORD 1616 (Anm. 129), Pag. 3.

${ }^{140}$ Vgl. PIESPORD 1616 (Anm. 129), Pag. 3, 5. Reihenfolge und Namesformen der legendären Grafen von Habsburg (Sigisbertus I. Exul, Sigisbertus II., Ottobertus I., Babo, Rotherius, Hettoprechtus, Ramprechtus, Guntramus I., Leuthardus, Luitofridus, Hunifridus, Guntramus II., Kancellinus, Rapato, Wernerus I., Otto, Wernerus II. und Albertus III.) sind mit Reihenfolge und Namen vergleichbar, die bei Francesco Terzio vorkommen und vermutlich von Jacopo da Strada entworfen wurden; siehe dazu LHOTSKY 1944 (Anm. 126), S. 240.

${ }^{141}$ PIESPORD 1616 (Anm. 129), Pag. 5.

${ }^{142}$ In Frage kommen vor allem die Stiche von Wolfgang Kilian, publiziert in KILIAN 1623 (Anm. 132) und EHINGER 1629 (Anm. 133).

${ }^{143}$ Wien, Albertina, Inv. Nr. 44231. 
24. Dominik Franz Calin: Iconologia et Series omnium, quotquot $\hat{a}$ Iulio Caesare fuerunt, Imperatorum Romanorum, Byzantinorum, Germanicorum, Turcicorum, 1666, Albertina, Wien, Inv. Nr. 44231/17

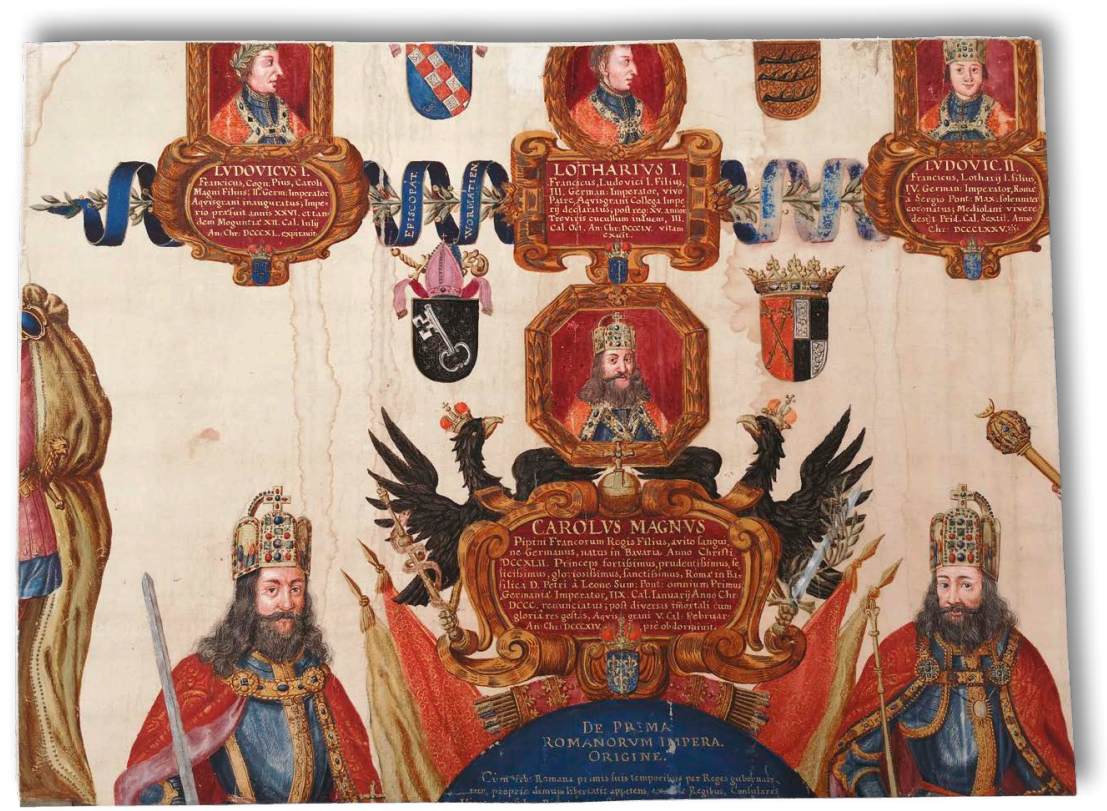

In der Mitte unten stellte Calin ein Postament dar, auf dessen Vorderseite eine Kartusche mit dem Reichswappen hängt, während die seitlichen Inschriften die Porträtierten auf dem Postament identifizieren: Carolvs Magnvs Conditor Imperatorvm Germanicorvm und RVDolphys Prim. Conditor Imperatorvm Avstriacorvm (Abb. 24). Über dem Reichswappen postierte Calin eine Weltkugel, die durch Waffentrophäen gestützt wird und als Hintergrund einer Inschrift dient, in der Calin eine kurze Zusammenfassung der Geschichte seit der Römischen Republik über Julius Caesar, Kaiser Konstantin, die byzantinischen Kaiser bis zur osmanischen Eroberung Konstantinopels skizziert. Der Text endet mit dem ersten Kaiser in Germania, Karl dem Großen. Die Weltkugel ist durch eine Karl dem Großen gewidmete Kartusche bekrönt, die von zwei Adlern gehalten wird, die ein mit einer Schlange umwundenes Zepter und ein mit Lorbeer umgebenes Schwert halten. Die Kartusche steht auf dem gekrönten Wappen mit drei Lilien und ist oben mit dem Reichsapfel versehen. Die Karl dem Großen gewidmete Huldigungsbeschreibung (Princeps fortissimus, prudentissimus, felicissimus, gloriosissimus, sanctissimus) würde man eher für den aktuellen Kaiser erwarten. Für die ganzfigurige Darstellung Karl des Großen heraldisch rechts von der Weltkugel benutzte Calin als Vorlage wahrscheinlich eine Kopie von Albrecht Dürers Idealbildnis des Kaisers, mit dem die ottonische Reichskrone, das Reichsschwert, der Reichsapfel und der Krönungsmantel übereinstimmen, während Calin ihn etwas jünger und in der Rüstung darstellte. In Rüstung und Krönungsmantel und mit den gleichen Attributen stellt Calin auch Rudolf I. von Habsburg dar, jedoch mit einem Zepter statt Schwert in der rechten Hand. Die Gesichtszüge Rudolfs I. erinnern an Philipp Kilians Kupferstich, der in Sigmund von Birkens Überarbeitung von Johann Jakob Fuggers Spiegel der Ehren des Höchstlöblichen Kayser- und Königlichen Ertzhauses Oesterreich erst 1668 in Nürnberg publiziert wurde. ${ }^{144}$ Durch das Medaillon mit der Heiligen

\footnotetext{
${ }^{144}$ Johann Jakob FUGGER, Spiegel der Ehren des Höchstlöblichsten Kayser- und Königlichen Erzhauses Oesterreich oder Ausführliche GeschichtSchrift von Desselben, und derer durch Erwählungs- Heurat- Erb- und Glücks-Fälle ihm zugewandter Kayserlichen HöchstWürde, Königreiche, Fürstentümer, Graf- und Herrschaften, Erster Ankunft, Aufnahme, Fortstammung und hoher Befreundung mit Kayser- König-Chur- und Fürstlichen Häusern /.../, Nürnberg
} 
Hostie, das an Rudolfs Brust hängt, betonte Calin die Pietas Austriaca. Bei dem zentralen unteren Motiv ist vor allem die betonte Darstellung der französischen heraldischen Lilien bemerkenswert, die sich nicht nur unter der Karl dem Großen gewidmeten Kartusche finden, sondern auch heraldisch rechts von dem Postament, auf der Brustplatte des Waffentropaions, das mit einem gallischen Helm und einem Hahn als Schwertknauf zusätzlich an Frankreich erinnert, während das Tropaion mit dem Bindenschild heraldisch links dargestellt ist. Man darf annehmen, dass die Hervorhebung Frankreichs nicht erwünscht war in einer Zeit, in der Ludwig XIV. nach der Kaiserkrone strebte und sich die Habsburger darum bemühten, durch den Nachweis der altehrwürdigen Abstammung des Hauses Habsburg von Karl dem Großen dessen Vorrang und Ehrenstellung innerhalb der Herrscherhäuser Europas zu legitimieren. ${ }^{145}$

Heraldisch rechts sind Postamente mit ganzfigurigen Bildnissen von Kaiser Konstantin dem Großen (Constantinvs Magnvs, Conditor Imperatorvm Byzantinorvm) und Julius Caesar (Caivs Ivlivs, Conditor Imperatorvm Romanorvm) dargestellt. Als Vorlage für den ersten christlichen Kaiser verwendete Calin das Bildnis von Kaiser Maximilian I., das von Dominicus Custos verfertigt und 1601 in Innsbruck publiziert wurde. ${ }^{146}$ Der obere Teil der Rüstung, der mit Gold und Edelsteinen verbrämte Umhang, der Reichsapfel, der Kommandostab und der zu seinen Füßen liegende Helm, wurden fast unverändert übernommen, jedoch vervollständigte Calin die Brustplatte mit einem großen Kreuz, während die rosafarbenen Strümpfe und die goldenen Stiefel an die Antike erinnern sollten. Eine überzeugendere antikisierende Wirkung erzielte Calin mit dem Bildnis von Julius Caesar mit rosafarbener Rüstung, goldenem Umhang und einem Lorbeerkranz. Gesichtszüge und Rüstung erinnern an das Titelkupfer des 1650 in Amsterdam erschienenen Buchs Caius Suetonius Tranquillus, ${ }^{147}$ doch dürften Calin auch andere Darstellungen von Julius Caesar bekannt gewesen sein. Auf den heraldisch linken Postamenten stellte Calin ganzfigurige Bildnisse von Osman I., Gründer der osmanischen Dynastie und des Osmanischen Reichs (ОTtomanvs Conditor Imperatorvm TVRCicor.), sowie des byzantinischen Kaisers Nikephoros I. (Nicephorvs Logotheta Propagator Imperatorvm Byzantinorvm) dar. Für die Darstellung Osmans I. kopierte Calin das Bildnis des Sultans Suleiman II. von Dominicus Custos. ${ }^{148}$ Die Vorlage für Kaiser Nikephoros konnte nicht eruiert werden; Calin stellte ihn mit einer antikisierenden Rüstung, Umhang, Zepter, Weltkugel und einer Krone, die die Form einer Mitra hat, dar.

1668, S. 1. Zum Ehrenspiegel des Hauses Österreich siehe CORETH 1950 (Anm. 8), S. 53; Inge FRIEDHUBER, Der 'Fuggerische Ehrenspiegel' als Quelle zur Geschichte Maximilians I. Ein Beitrag zur Kritik der Geschichtswerke Clemens Jägers und Sigmund von Birkens, Mitteilungen des Instituts für Österreichische Geschichtsforschung, 81, 1973, S. 101-138; zur These, dass das Titelblatt, die lateinischen Widmungen und das Titelkupfer direkt vom Hof konzipiert wurden, siehe SCHUMANN 2003 (Anm. 45), S. 291; POLLEROSS 2003 (Anm. 33), S. 271.

${ }^{145}$ Vgl. Friedrich POLLEROSS, Habsburgische Kaiserreihe, Welt des Barock 1986 (Anm. 6), S. 66, Kat. Nr. 1.18.

${ }^{146}$ Jacob SCHRENCK VON NOTZING, Augustissimorum Imperatorum, Serenissimorum Regum atque Archiducum, Illustrissimorum Principum, nec non Comitum, Baronum, Nobilium, aliorumque Clarissimorum Virorum, qui aut ipsi cum imperio bellorum Ducem fuerunt, aut in iisdem praefecturis insignioribus laudabiliter functi sunt, verissimae imagines, /.../. Opus Praelibati Serenissimi Archiducis jussu in vita inchoatum \& ab ejusdem Serenitatis Consiliario \& Secretario Jacobo Schrenkio a Nozingen continuatum \& absolutum, Oeniponti 1601, Abb. 4.

${ }^{147}$ Caius Suetonius Tranquillus. Cum annotationibus diversorum, Amsterdam 1650. Zum Exemplar in der Bibliothek der Salzburger Erzbischöfe, auf das sich das inhaltliche Konzept des Salzburger Caesar-Zyklus stützen soll, siehe Christoph BRANDHUBER, Caesare Duce. Zur Ikonographie des Caesar-Zyklus in der Residenzgalerie Salzburg, Residenzgalerie Salzburg. Gesamtverzeichnis der Gemälde (Hrsg. Roswitha Juffinger), Salzburg 2010, S. 406-407.

${ }^{148}$ SCHRENCK VON NOTZING 1601 (Anm. 146), Abb. 6. 


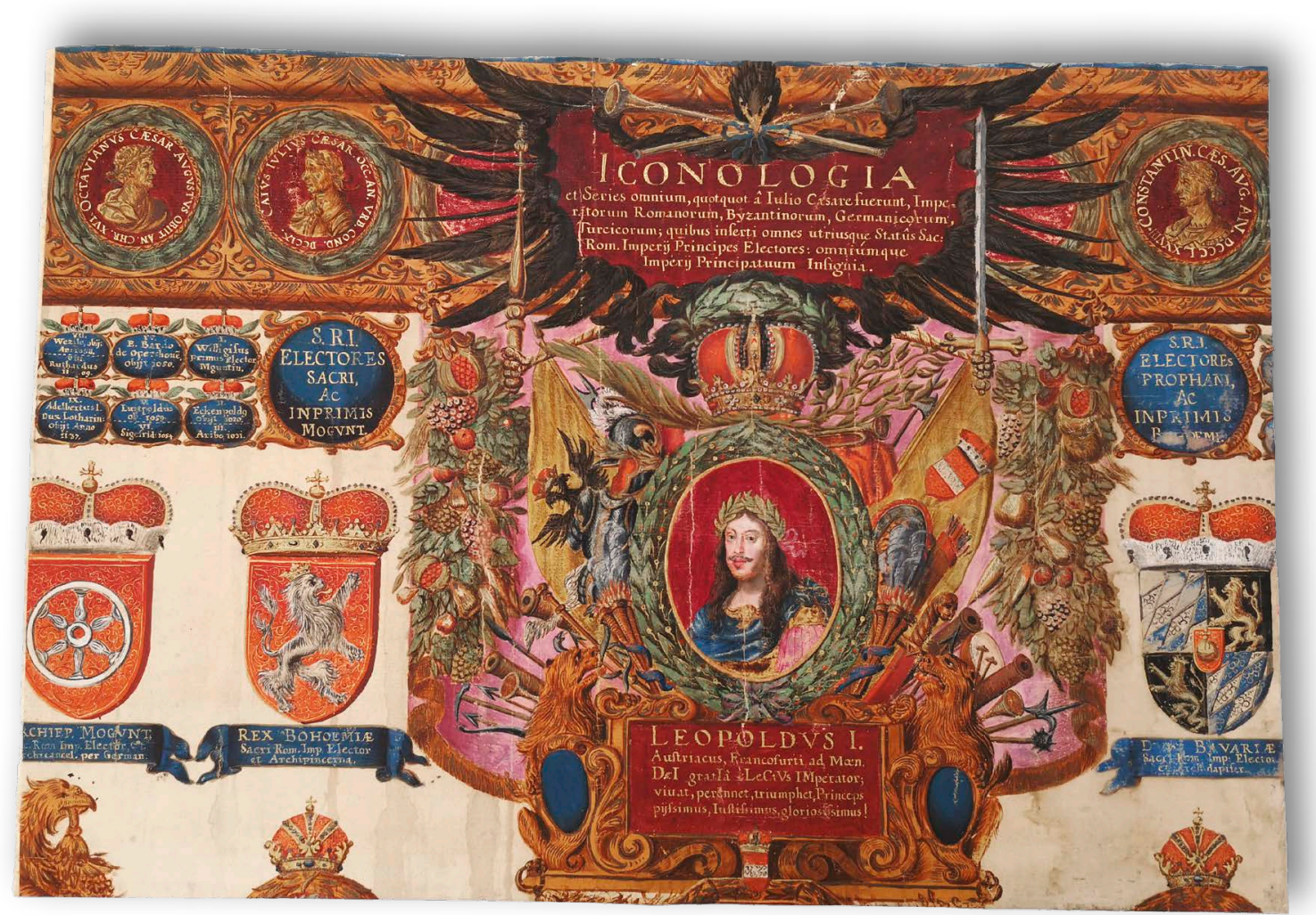

25. Dominik Franz Calin: Iconologia et Series omnium, quotquot â Iulio Caesare fuerunt, Imperatorum Romanorum, Byzantinorum, Germanicorum, Turcicorum, 1666, Albertina, Wien, Inv. Nr. 44231/2

Im zentralen Feld der Darstellung befinden sich 52 römisch-deutschen Kaiser von Karl dem Großen bis Leopold I. ${ }^{149}$ Sie sind nicht in Form eines Stammbaums visualisiert, sondern als gerahmte ovale oder achteckige Brustbilder mit Inschriftenkartuschen, die mit Lorbeerzweigen verbunden und in 14 horizontale Streifen gegliedert sind. Die chronologische Reihung erfolgt in jedem Streifen von links nach rechts, mit Ausnahme des vorletzten, wo Calin Ferdinand III. vor Ferdinand II. stellen musste, um Leopold I. über seinem Vater in der Mitte darstellen zu können. Obwohl sich Calin darum bemühte, so viele Habsburger wie möglich in der Mittelachse (am „Baumstamm“) zu zeigen, gelang es ihm bei aller Kombinatorik nur für Friedrich den Schönen, Ferdinand I., Ferdinand III. und Leopold I. Dennoch erzielte er den Eindruck, als sei der aktuelle Kaiser ein direkter Nachfolger von Karl dem Großen. Calin alternierte auch die Reichs- und Hauskrone der Habsburger sowie Lorbeerkränze, wobei die letzten fünf Kaiser seit Rudolf II. mit Lorbeer bekrönt sind. Als Vorlage für die Bildnisse verwendete Calin die in Porträtbüchern publizierten Stiche, für einige Habsburger (Friedrich den Schönen, Albrecht II., Friedrich III., Maximilian I., Rudolf II., Matthias und Ferdinand II.) darf man annehmen, dass Calin die Stiche von Wolfgang Kilian als Vorlage nahm. ${ }^{150}$ Das Porträt Leopolds I. als römischer Imperator ist mit Lorbeer gerahmt und von einer prächtigen Kartusche umgeben (Abb. 25). Zwei Löwen flankieren die Tafel mit der Inschrift LEOPOLDVS

${ }^{149}$ Als Vorbild dürften Gerhard Bouttats' Illustrationen im Werk Nicolaus AVANCINI, Imperium Romano-Germanicum, sive quinquaginta imperatorum ac Germaniae regum Elogia: Augustissimo Romanorum Imperatori Leopoldo, Ab Antiquissima ac Celeberrima Universitate Viennensi oblata /.../, Viennae 1658, dienen. Der Verfasser wurde erst in der Ausgabe von 1663 genannt.

${ }^{150}$ KILIAN 1623 (Anm. 132); vgl. EHINGER 1629 (Anm. 133). 
I. Austriacus, Francofurti ad Mon. DeI gratIà èLeCtVs IMperator; viuat, perennet, triumphet, Princeps pijssimus, Iustissimus, gloriosissimus! Die Waffen und Fahnen sollen militärische Erfolge und die Fruchtgirlanden die Prosperität andeuten. Erfindungsreich ist der Adler mit zwei Posaunen der Fama im Schnabel und mit Zepter und Schwert in den Krallen dargestellt, während er mit seinem Schwanz die Kaiserkrone über Leopold mit dem Lorbeerkranz krönt.

In den freien Feldern zwischen den Kaiserporträts hat Calin heraldisch rechts die Wappen der kirchlichen Fürstentümer (S. R. I. PRINCIPATvs ECCLESIASTICI) und links die Wappen der weltlichen Fürstentümer (S. R. I. PRINCIPATVs SACULARES) dargestellt, wobei die größeren Wappen der Kurfürsten in höchster Stellung neben Leopold I. dargestellt sind. Das zentrale Feld rahmte er mit blauen, ovalen und mit Kurfürstenhüten bekrönten Schildchen, auf die er die Namen der Kurfürsten und ihre Sterbedaten schrieb. Die Reihe der S. R. I. ELECTORES SACRI beginnt heraldisch rechts oben mit 46 Erzbischöfen von Mainz und wird mit 40 Erzbischöfen von Trier und 47 Erzbischöfen von Köln fortgesetzt. Die Reihe der S. R. I. ELECTORES PROPHANI beginnt oben mit 27 Königen von Böhmen, gefolgt von 28 Kurfürsten von Bayern, 27 Kurfürsten von Sachsen und 37 Kurfürsten von Brandenburg.

Die Bildnisse der römischen und byzantinischen Kaiser und der osmanischen Sultane stellte Calin in einer prächtigen, mit Palmetten geschmückten Bordüre sowie in zwei vertikalen Leisten dar. Die Brustbildnisse in der Bordüre sind mit Lorbeerkränzen umrahmt, die goldenen Darstellungen sind wie auf antiken Münzen und Medaillen mit Umschriften versehen. Auf beiden vertikalen Leisten befinden sich ebenfalls Brustbildnisse, jedoch kleiner, in ovalen Kartuschen und mit einer Inschrift unter der Kartusche. Die Reihe beginnt heraldisch rechts oben mit CaIvs IvLIVS CÆSAR, der nach Calin im Jahr 709 nach der Gründung Roms ermordet worden war. Das Sterbejahr wird auch bei allen anderen Porträtierten angeführt, jedoch in üblicher Jahreszählung. In der heraldisch rechten Bordüre sind 43 Kaiser bis Diokletian (abdizierte 304) dargestellt, in der heraldisch linken ebenfalls 43, von Constantius I. († 306) bis Konstantin, bei dem Calin das Todesjahr 878 anführt. Dies ist vermutlich ein Fehler, da die Reihe der byzantinischen Kaiser mit Nikephoros I. († 811) weitergeführt wird. In der heraldisch rechten vertikalen Leiste kommen neben Nikephoros I. noch 38 byzantinische Kaiser vor, wobei die Reihe in der heraldisch linken Leiste von unten nach oben mit 14 Bildnissen fortgesetzt wird, von Balduin I. (BALD. FLANDER Anno MCCV) bis Konstantin XI. (Constantin Vlt. Anno 1453). Damit die Reihenfolge mit den 24 osmanischen Sultanen übereinstimmte, musste Calin zwischen Konstantin XI. und Osman I. die Darstellung eines Mannes mit Turban und die Inschrift SEQUITVR Monarchia Turcica einfügen. Die Reihe endet mit ACMETES II. regn: An: MDCXLVIII, womit der aktuelle Sultan Mehmed IV. gemeint ist. Als Vorlage für die 163 Bildnisse der Kaiser und Sultane hat Calin wahrscheinlich die Darstellungen der Münzen verwendet, die von Ottavio Strada gesammelt und gezeichnet und 1615 in Frankfurt publiziert wurden; ${ }^{151}$ eine Neuauflage erfolgte 1664 in Leiden. ${ }^{152}$ Da die Reihenfolge

${ }^{151}$ Octavio DE STRADA À ROSBERG, De Vitis imperatorum et caesarum romanorum, tam occidentalium quam orientalium, nec non uxorum et liberorum eorum, item tyrannorum omnium, qui diversis temporibus Romanum Imperium attentare \& occupare conti sunt, inde à C. Iulio Caesare, primo Monarcha ad D. N. Imperatorem, Caesarem Matthiam, unà cum eorum effigiebus \& symbolis; /.../ olim Incredibili labore, sumptu magno, peregrinationibus multis, ijsque periculosis Octavii de Strada à Rosberg, civis Romani, S. C. Mtis, Rudolphi sanctissimae memoriae Nobilis Aulici \& Antiquarij ordinatij congestum \& adornatum /.../, Francofurti ad Moenum 1615.

152 Octavio DE STRADA À ROSBERG, Genealogia et series Serenissimorum \& Potentissimorum Austriaae ducum, archiducum, regum, imperatorum; eorumque illustriss. Conjugum, Et Liberorum utriusque sexus a Rudolpho I. Habspurgensi imperatore Ad Invictissimum Ferdinandum II. Rom. Imper. Semper Augustum, \&c. Authore Octavio 
der Kaiser nicht völlig übereinstimmt, wäre es möglich, dass Calin auch andere Bücher, in denen die Münzen reproduziert wurden, nutzte. Überdies ist anzunehmen, dass er einige Bildnisse nach seiner Phantasie malte, um die Serie einheitlich darstellen zu können. Auch die Bildnisse zweier byzantinischen Kaiserinnen (THEODORA Imper: An: 1056 und EVDOCIA IMP. An: MLXVIII) konnte Calin nicht aus Ottavio Stradas Buch übernommen haben.

Die 1666 entstandenen großformatigen Stammbäume Genealogia Habspvrgo-Avstriaca und Iconologia gehören zu den ambitioniertesten und prächtigsten Werken Calins. Sie bezeugen seine guten Kenntnisse der historiographischen und genealogischen Studien des 16. und 17. Jahrhunderts sowie verschiedener illustrierter Bücher mit Bildnissen der Herrscher und uomini illustri. Der Grund dafür, dass sie nie ausgestellt wurden und unbekannt geblieben sind, dürfte in dem Widerspruch zwischen Monumentalität des Formats und Zierlichkeit der Details zu finden sein. Während man das Ganze aus einer gewissen Distanz betrachten soll, kann man die Inschriften nur aus nächster Nähe lesen. Auch die Feinheit der gemalten Details eignet sich eher für die Buchmalerei als für große Formate. Vermutlich war eine graphische Vervielfältigung der gemalten Stammbäume vorgesehen, wurde jedoch nicht verwirklicht. Man darf annehmen, dass eines der Vorbilder für die Stammbäume Calins die Ehrenpforte von Kaiser Maximilian I. war, die jedoch mit $3410 \mathrm{x}$ 2920 mm und 36 Papierbögen Calins Werke im Format übertrifft, so dass der Widerspruch zwischen Monumentalität und minuziöser Ausführung noch stärker zum Ausdruck kommt. ${ }^{153}$ Das von Johannes Stabius entworfene Programm für die Ehrenpforte ist komplexer, da er zusätzlich die militärischen Heldentaten und die vortrefflichen Kenntnisse und Charaktereigenschaften Maximilians I. miteinbezieht, gemeinsam sind jedoch die Betonung des Stammbaums, die ursprüngliche Abstammung der Habsburger von den Trojanern und ihre Verschwägerung mit europäischen Herrscherhäusern, die Reihen der kaiserlichen Amtsvorgänger seit Julius Caesar und die Wappendarstellungen als Beleg für die Territorien, die das Haus Habsburg besaß oder beanspruchte. ${ }^{154}$

$\mathrm{Ob}$ auch Calins dritter, in der Albertina verwahrter Stammbaum so prächtig ausgeführt ist, ${ }^{155}$ konnte nicht eruiert werden, da er aus konservatorischen Gründen nicht angeschaut werden durfte. Calin verfertigte 1667 mit schwarzer Tinte, Tempera, Goldfarbe und Silberfarbe auf Pergament einen 750 x 2870 mm großen Stammbaum der Habsburger von Rudolf I. bis Leopold I. mit dem Titel Opus genealogicum in quo demonstratur, quod omnes Potentissimi totius Christianitatis Reges et Principes ex Augustissimo Austriaco sanguine per contracta Matrimonia promanarint. ${ }^{156}$ In der Mitte unten befindet sich Calins Widmung Ita vovet Operis huius Genealogici Auctor. Serenissimi Bavariae Electoris Bibliothecarius, Dominicus Franciscus Calin. 1667.

Anlässlich der Geburt von Erzherzog Ferdinand Wenzel Joseph entwarf Calin einen Stammbaum des Hauses Habsburg Genealogia HabspVrgo-AVstrIaCa DoMVs Rvdolfo Primo

de Strada a Rosberg, Civ. Rom. DD. Maximiliani \& Rudolphi II. Caesarr. Nob. Aul. \& Antiquario. Nunc primum aeri incisa, \& publico usui data, Lugduni Batav. 1664.

${ }^{153}$ Vgl. Christian BENEDIK, Le grandi opere xilografiche di Massimiliano I: Corteo Trionfale e l'Arco di Trionfo, Divus Maximilianus. Una contea per i Goriziani 1500-1619 (Hrsg. Silvano Cavazza), Mariano del Friuli 2002, S. 62-63.

${ }^{154}$ Zum Programm der Ehrenpforte siehe Thomas SCHAUERTE, Albrecht Dürer und Mitarbeiter, Albrecht Altdorfer, Die Ehrenpforte, 1515, Kaiser Maximilian I. und die Kunst der Dürerzeit (Hrsg. Eva Michel, Maria Luise Sternath), Albertina, Wien, München-London-New York 2012, S. 373-376, Kat. Nr. 124; vgl. GOLOUBEVA 2000 (Anm. 55), S. 30-35.

${ }^{155}$ Albertina, Wien, Inv. Nr. 44234.

${ }^{156}$ Alle Daten sind dem Inventarbuch entnommen und nicht überprüft; siehe Wien, Albertina, Inv. Nr. 44234. 


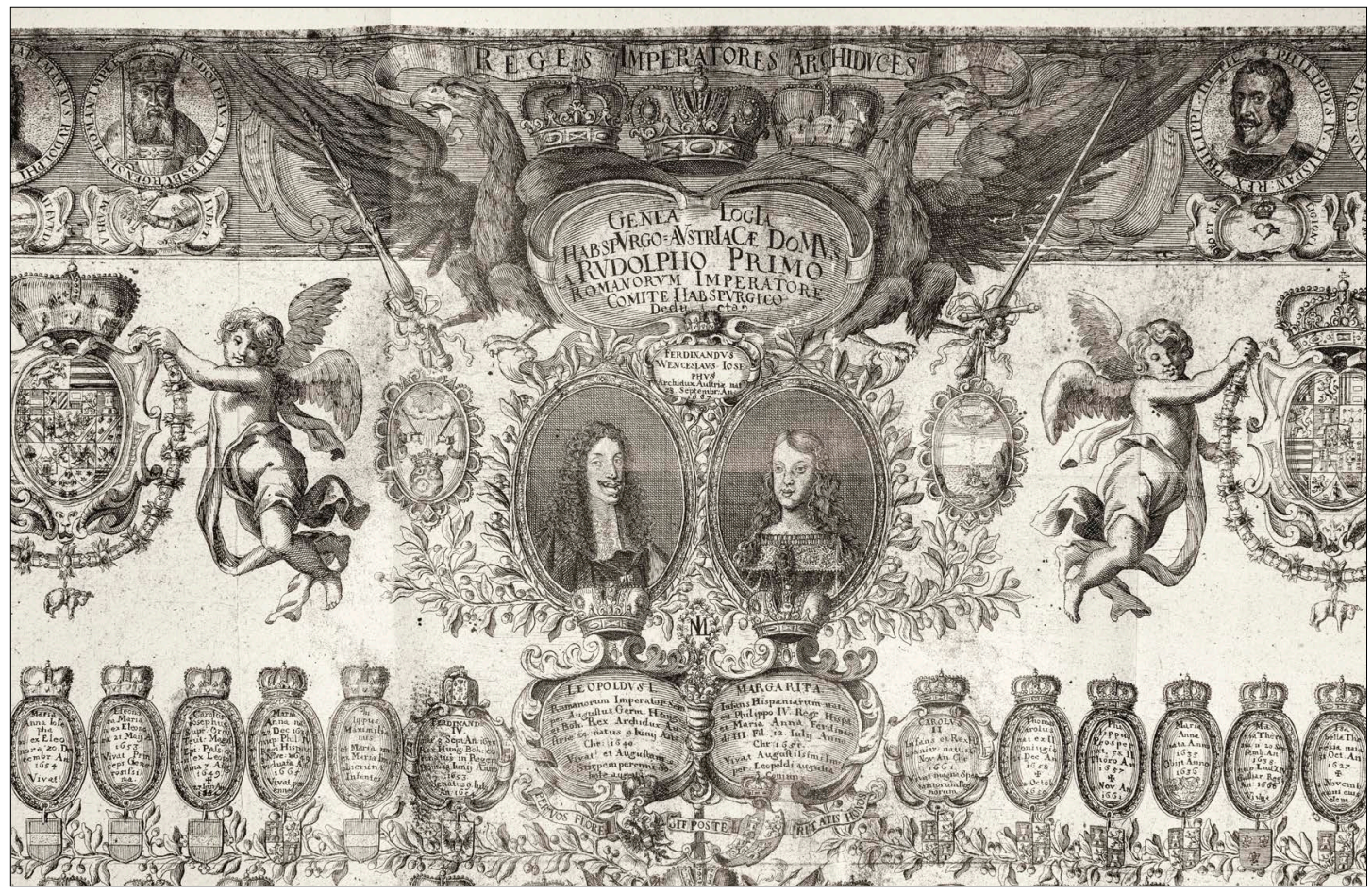

26. Johann Martin Lerch nach Dominik Franz Calin, Genealogia Habspurgo-Austriacae Domus, 1667, in: Vnderschidliche Schild vnd Wappen, 2008

Romanorvm IMPERATORe COMIte HabSPVURgico Deducta (1667), der von Johann Martin Lerch in Wien in Kupfer gestochen wurde (Abb. 26). ${ }^{157} \mathrm{Ob}$ das Original Calins erhalten ist, ist nicht bekannt; ein Exemplar des aus drei Blättern bestehenden großformatigen Kupferstichs ( 1430 x 769 mm) ist in der graphischen Sammlung von Johann Weikhard Valvasor (1641-1693) erhalten. ${ }^{158}$ Nach Meinung von Milan Pelc war der Kupferstich für einen exklusiven adeligen Empfängerkreis bestimmt, der dem Hof und dem Haus Habsburg nahe stand; aufgrund seiner Wiener Verbindungen sollte auch Valvasor ein Exemplar erhalten. ${ }^{159}$ Die Genealogie der Habsburger beginnt in der Mitte unten mit einem Sarkophag, auf dessen Vorderseite Calins Widmung an Leopold I., seine Gemahlin Margarita Teresa und ihre Nachkommen geschrieben steht. ${ }^{160}$ Auf den Sarkophag ist eine Kartusche mit der Widmung an Kaiser und Kaiserin gestellt, die mit Militaria und Wappenfahnen umgeben ist. Auf ihr steht die Inschrifttafel des ersten Kaisers Rudolf I., mit Kaiserkrone und flankiert von zwei bekrönten Adlern, die ein Schwert, ein Zepter und die Inschrift BENEDICAM TIBI ET MULTIPLI/

157 Siehe PELC 2013 (Anm. 12), S. 117.

${ }^{158}$ Vnderschidliche Schild vnd Wappen vnd dergleichen Kupfferstich Welche Von Vnderschidlichen Künstlern gezeichnet ins Kupffer gradirt, vnd gestochen Auch Allerley Geistliche vnd Weltliche Holtzschnid ziehrlich ins Holtz geschnitten Welche Mit Sonderbahren Fleiß zusamben gebracht Durch Johann Weychard Valvasor Freyhernn zu Wagensperg in Crain. Anno 1685 (Hrsg. Lojze Gostiša, Mirna Abaffy), Ljubljana-Zagreb 2008 (Iconotheca Valvasoriana, 16), Kat. Nr. 16-18.

${ }^{159}$ PELC 2013 (Anm. 12), S. 118.

${ }^{160}$ Invictissimo Romanorum Casari Leopoldo I. et Avgustissimo Imperatrici Margaritce Aternum perennature sobolis incrementum. Vovet et dicat consecrátq. Serenissimi Bavariæe Electoris Bibliothecarius Dominicvs Franciscvs Calin de Sancta Cruce, Operis huius Inventor. 
CABO SEMEN TVVM Gen. Cap. 22. V. 17 halten. Kartusche und Inschifttafel sind mit vier Personifikationen auf niedrigen Postamenten umgeben, die aufgrund der Inschriften, Attribute und Embleme als Iustitia, Pietas, Religio und Prudentia erkennbar sind. ${ }^{161}$ Als zusätzliche Attribute halten die Tugenden eine Königs- und eine Kaiserkrone, eine mit Hermelin umrandete Bischofsmitra und einen Herzogshut. Auf den Vorderseiten der Postamente sind Embleme dargestellt.

Hinter der Kartusche wächst der Stammbaum, auf dem die Familienmitglieder mit entsprechender Kaiser- oder Königskrone, Herzogs- oder Kardinalshut versehen sind. Bei den Verheirateten sind auch die Wappen ihrer Gemahlinnen dargestellt. Über Philipp I. dem Schönen fügte Calin ein herzförmiges quadriertes Wappenschild mit dem Wappen des Königreichs KastilienLeón sowie die Inschrift SEMPER AvstriaCA ein. Philipps jüngerer Sohn Ferdinand ist heraldisch rechts als der Begründer der österreichischen (VELLVS AVSTRIACVM), der ältere Karl ist heraldisch links als Begründer der spanischen Linie (VELLVS HISPANICVM) dargestellt. Der Stammbaum endet oben mit den Porträts von Leopold und Margarita in ovalen, mit Lorbeer umgebenen Medaillons, zwischen denen eine kleine Kartusche mit dem Namen ihres ältesten Sohnes Ferdinand Wenzel Joseph dargestellt ist. Anlass für die Anfertigung der Genealogie war die Geburt des Thronfolgers am 28. September 1667. Über den Porträts befindet sich eine von der kaiserlichen und königlichen Krone und einem Herzogshut bekrönte Kartusche mit dem Titel des Werkes, beiderseits der Porträts sind die Wappen des Ehepaars dargestellt, beide werden von einem Engelspaar gehalten.

In der äußeren Randleiste stellte Calin 54 Porträts der Kaiser, Könige und Erzherzöge des Hauses Habsburg dar; unter den Porträts befindet sich jeweils eine Kartusche mit der Devise des Abgebildeten. Die heraldisch rechte Reihe beginnt oben in der Mitte mit Kaiser Rudolf I. und endet mit König (Erzherzog) Philipp dem Schönen. Die 27 Porträts der heraldisch rechten Reihe sind verkleinerte und vereinfachte Kopien der Porträts, die von Wolfgang Kilian gestochen und 1623 in Augsburg publiziert wurden. ${ }^{162}$ Die 1623 erschienene Serie von Wolfgang Kilian diente auch als Vorlage für 18 von 27 Porträts der heraldisch linken Reihe auf Calins Stammbaum, die unten mit Kaiser Karl V. beginnt und oben mit König Philipp IV. von Spanien endet. Calin übernahm fasst alle Porträts aus Kilians Serie, doch er ließ die Porträts des unehelichen Juan d'Austria und des jugendlichen Königs Philipp IV. von Spanien aus und fügte das Porträt von Kardinal Ferdinand, einem Bruder Philipps IV., hinzu. Die Bildnisse von Kardinal Ferdinand, seines Neffen Balthasar Carlos, von König Ferdinand IV., Kaiser Ferdinand III., Erzherzog Leopold Wilhelm, Erzherzog Ferdinand Karl von Tirol, Erzherzog Karl Joseph, Erzherzog Sigismund Franz sowie des spanischen Königs Philipp IV. übernahm Calin von einer anderen Porträtserie.

1673 veränderte Calin den Stammbaum von 1667 nur geringfügig im oberen Teil und machte daraus ein geeignetes Geschenk zur Hochzeit Leopolds I. mit Erzherzogin Claudia Felicitas von Tirol. ${ }^{163}$ Das einzige mir bekannte Exemplar, bei dem die kolorierten Stiche auf eine Barockleinwand geklebt sind $\left(1480\right.$ x $810 \mathrm{~mm}$ ), wird im Landesmuseum Kärnten verwahrt (Abb. 27). ${ }^{164}$ Die

${ }^{161}$ Als Calin 1677 anlässlich der dritten Vermählung Kaiser Leopolds eine Genealogie seiner Gemahlin Eleonore Magdalena Theresia von Pfalz-Neuburg verfasste, erklärte er die Tugenden des Hauses Habsburg folgenderweise: Augustceque Austriace Domui, quam Pietas fundavit, quam Justitia fulcit, \& quam Religio tuetur /.../. Auf Prudentia bezieht sich im Text die Devise Leopolds: /.../ Sacratissimam Majestatem Tuam, à cujus CONSILIO ET INDUSTRIA tot Regnorum Populorumque Salus dependet /.../; siehe CALIN VON MARIENBERG 1677 (Anm. 36).

162 KILIAN 1623 (Anm. 132); vgl. EHINGER 1629 (Anm. 133).

${ }^{163}$ Zum Stammbaum siehe LEITNER 1989 (Anm. 1), S. 627, Nr. 14.

${ }^{164}$ Dem Kollegen Mag. Robert Wlattnig danke ich für seine Hilfe beim Anschauen, Fotografieren und Vermessen des Exemplars sowie für weiterführende Gespräche. Die Genealogie mit der alten Inventarnummer 4341 kam als 


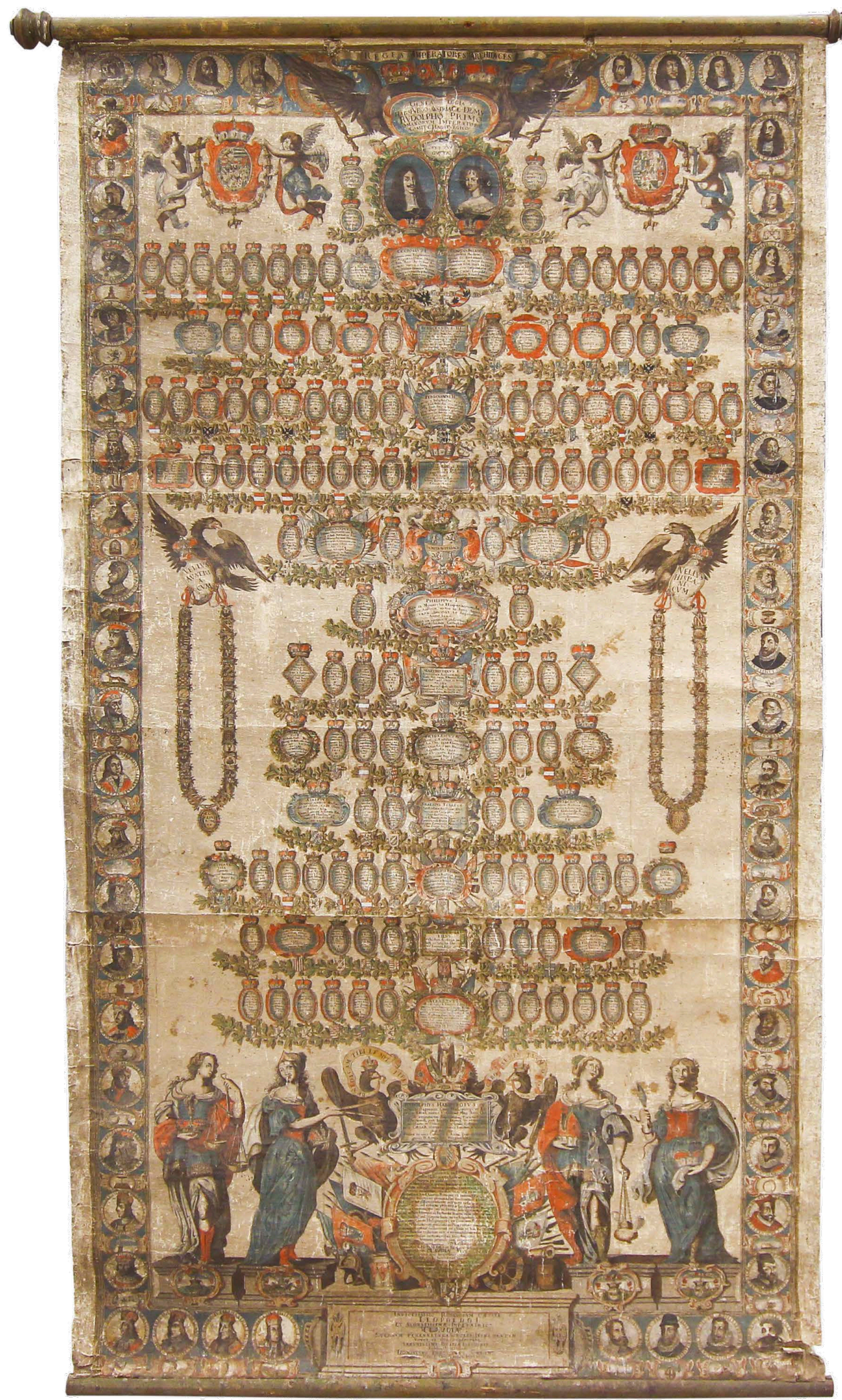

27. Johann Martin Lerch nach Dominik Franz Calin, Genealogia Habspurgo-Austriacae Domus, 1673, Landesmuseum Kärnten, Klagenfurt 


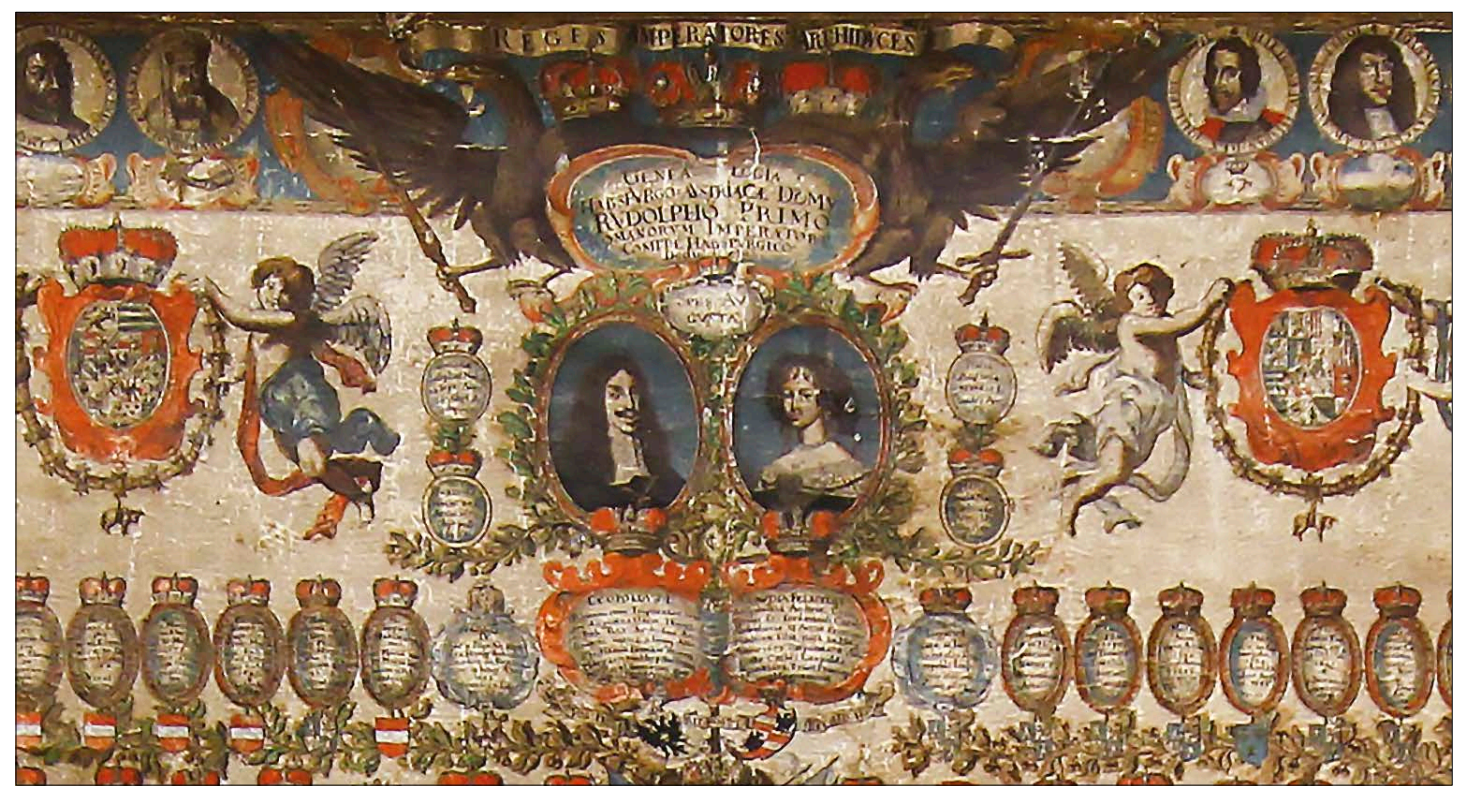

28. Johann Martin Lerch nach Dominik Franz Calin, Genealogia Habspurgo-Austriacae Domus, 1673, Landesmuseum Kärnten, Klagenfurt

feine Kolorierung lässt darauf schließen, dass sie von Calin oder seiner Gemahlin ausgeführt wurde. Der Stecher Johann Martin Lerch wird nicht erwähnt, links unten ist vermutlich die Signatur des Verlegers: Viennoe Austrice Apud Joannem Eicharium Herz. 1673. In der auf dem Sarkophag angebrachten Widmung veränderte Calin nur den Namen der Gemahlin Leopolds (Abb. 28). ${ }^{165}$ Am Stammbaum selbst wurde nichts verändert, in der obersten Reihe kommen neben der großen Kartusche von Claudia Felicitas sogar die gekrönten Kartuschen von Margarita Teresa und ihren sieben Geschwistern vor. Die kleine Namenskartusche von Claudia Felicitas bleibt an derselben Stelle als zweite in der oberen Reihe, Calin veränderte jedoch den Erzherzogshut in die Kaiserkrone. Da auch die Serie der 54 Porträts der Habsburger mit ihren Devisen in der Rahmenleiste nicht verändert wurde, erscheint das Porträt von Erzherzog Ferdinand Karl von Tirol, des Vaters der Braut, in der rechten oberen Ecke des Blattes, zufälligerweise nicht weit vom Porträt seiner Tochter entfernt. Auch das Porträt Kaiser Leopolds blieb unverändert, während das Porträt von Margarita Teresa durch das Porträt von Claudia Felicitas ersetzt wurde. Calin stellte die Kaiserin mit feineren Gesichtszügen dar als der gleichzeitige Kupferstich von Cornelis Meyssens und Johann Martin Lerch, der den kaiserlichen Brautzug in Graz zeigt; die Vorlage für das Porträt des Kaisers dürfte aber dieselbe sein. ${ }^{166}$ Statt der auf die Geburt Ferdinand Wenzels hinweisenden Inschrift führte

Geschenk von Gottlieb Baron Ankershofen in die Sammlungen des Geschichtsvereins für Kärnten (LEITNER 1989 (Anm. 1), S. 521). Nach Meinung von Robert Wlattnig kam es um die Mitte des 19. Jahrhunderts zur Schenkung, wobei man nicht mehr eruieren kann, wie und wo Freiherr von Ankershofen, der damalige Vereinspräsident des Geschichtsvereins für Kärnten, die Genealogie erhielt.

${ }^{165}$ InVictissimo Romanorvm CAesari LEOpoldo I. ET AVgVStissime Imperatici CLAVDIÆ ETERNVM PERENNATVRa SOBOLIS INCREMENTVM. Vovet et dicat consecrátq. Serenissimi BaVARIA ELECTORIs Bibliothecarius Dominicvs Franciscvs Calin de Sancta Cruce, Operis huius Inventor.

${ }^{166}$ Zum Stich, den die „akademischen Kupfferstecher zu Wienn“ Cornelis Meyssens und Johann Martin Lerch Kaiser Leopold I. offerierten, siehe Barbara KAISER, Schloss Eggenberg, Wien 2006, S. 69. Auch der Grazer Kupfer- 


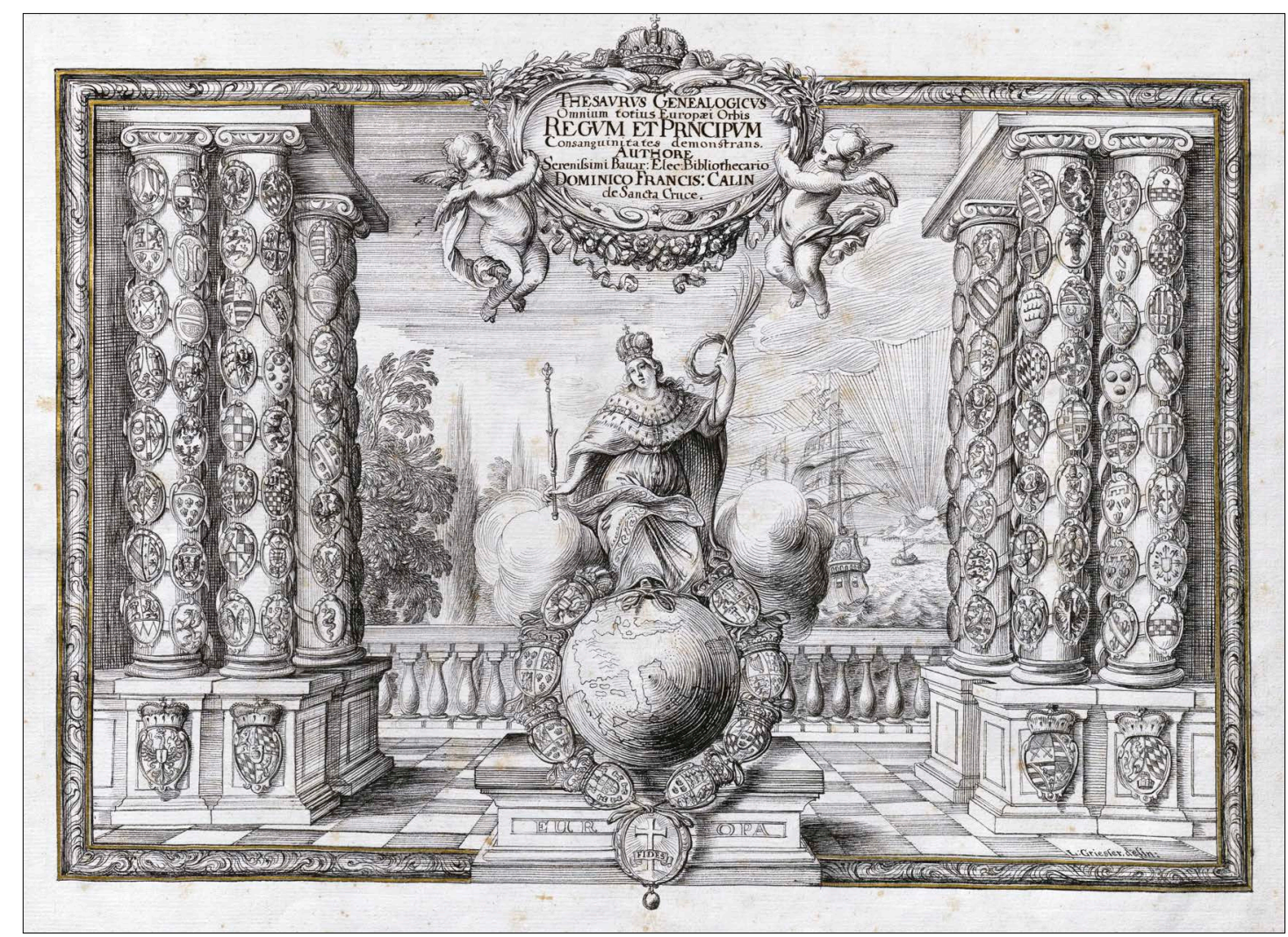

29. Lorenz Griessler und Dominik Franz Calin: Thesaurus Genealogicus, 1671,

Österreichische Nationalbibliothek, HAD, Cod. 9229, Fol. IIIr

Calin nur die kurze Inschrift SPES AVGVSTA an, statt der ineinander verschlungenen Initialen des Brautpaares ML dagegen die Initialen des neuen Brautpaares CL.

1671 legte Calin das prachtvolle Ehrenwerk Thesaurus Genealogicus vor, das 152 Stammbäume der europäischen königlichen und fürstlichen Häuser umfasst und mit einem von Lorenz Griessler (auch Grießler) ${ }^{167}$ gezeichneten Titelblatt (Abb. 29) versehen ist. ${ }^{168}$ Griessler entwarf eine Personifikation Europas, die Kaiserkrone und Hermelinumhang trägt und Zepter, Lorbeerkranz und Palmzweig haltend auf der Weltkugel sitzt. Die Weltkugel ist von acht Wappen des Heiligen Römischen Reichs und der Königreiche Frankreich, Polen, Portugal, Spanien, England und Schottland, Schweden und Dänemark umgeben, die unten mit einem Medaillon, das mit einem Kreuz und der Inschrift Fides versehen ist, verbunden sind. Auf beiden Seiten von Europa sind Säulen mit Wappendarstellungen gezeichnet, auf deren Postamenten sich die Wappen der weltlichen Kurfürstentümer Brandenburg, Bayern, Sachsen und Pfalz befinden. Im Hintergrund links der Europa ist ein Zypressenhain dargestellt, rechts werden ein Schiff und ein Boot auf ruhigem Meer stark von der Sonne bestrahlt. Nach dem Titelblatt folgen die Widmung an Kaiser Leopold I. und das

stecher Johann Caspar Mannasser benutzte ein anderes Vorbild für das Porträt der Kaiserin, als er den Brautzug darstellte; zu Mannassers Stich siehe PELC 2013 (Anm. 12), S. 122, 124.

167 Zum Maler und Vergolder Lorenz Griessler (um 1622-1690) siehe Dankmar TRIER, Grießler (Griessler), Lorenz, Allgemeines Künstler-Lexikon. Die Bildenden Künstler aller Zeiten und Völker, 62, München-Leipzig 2009, S. 77.

${ }^{168}$ CALIN VON MARIENBERG 1671 (Anm. 30). Siehe auch LEITNER 1989 (Anm. 1), S. 627, Nr. 11. 
Gedicht Ad Avgustissimam Domvm Avstriacam, beide von Calin signiert: Dominicus Franciscus Calin de S. Cruce ex Com: Goritioe bzw. Dominicvs Franciscrvs Calin de Sancta Cruce Anno Chr: MDCLXXI. Für die Stammtafeln wurden Kupferstiche in Form einer Ahnenprobe ${ }^{169}$ vorbereitet, mit einer Kartusche für den Namen des regierenden Kaisers, Königs bzw. Fürsten, einer Kartusche für sein Wappen und rechteckigen Feldern für die Namen seiner Eltern, Großeltern, Urgroßeltern und Ururgroßeltern. In die vorbereitete Form werden Namen, Titel und meistens die Geburts- und Sterbedaten mit der Hand geschrieben, die Wappen sind mit Temperafarben und Muschelgold gemalt.

1671 verfertigte Calin mit Tempera und Goldschrift das Theatrum Austriacee Glorioe, einen 840 x 1340 mm großen Stammbaum, der die Abstammung von 162 Kaisern, Kaiserinnen, Königen und Königinnen von Rudolf I. von Habsburg bezeugt. ${ }^{170}$ Er betitelte den Stammbaum THEATRUM Austriace Gloria in quo stemmatographice repraesentatur, qualiter ex RudolPhi I. CAes. Aug. Sanguine cum in Lineâ directa, tum per contracta matrimonia, Centum et Sexaginta Duo Imperatores, Imperatrices, Reges et Regince magnâ cum admiratione profluxerint. Links oben hält ein lorbeerbekrönter Putto die Kaiserkrone, das Zepter und die Inschrift LEOPOLDo InviCTISSIMo RoMANORUM CAESARI, während sein Pendant rechts oben eine Königskrone und die Inschrift $A U$ gusta Posteritatis Perenne Incrementum hält. In der Mitte unten ist die Signatur Serenissimi Bavar. Elect. Bibliothecarius Dominicvs Franciscus Calin de S. Cruce Composvit, et Humillime Dedicavit Viennae Anno Chr. MDCLXXI angebracht. Der Stammbaum ist auf zwei Pergamentblätter gemalt, die in der Mittelachse aneinanderstoßen sollen. Die Lösung wirkt unbefriedigend, da die mittleren zwölf Inschrifttäfelchen, die den Habsburgern von Rudolf I. bis Leopold I. gewidmet sind (Rudolf I., Albrecht I., Albrecht II., Leopold III., Ernst der Eiserne, Friedrich III., Philipp der Schöne, Karl von Innerösterreich, Ferdinand I., Ferdinand II., Ferdinand III. und Leopold I.), geteilt werden mussten und nur schwer lesbar sind.

Die Kartusche mit der Inschrift Rudolphus I. Dei Gratia eleCtvs Rom. Imperator, Comes

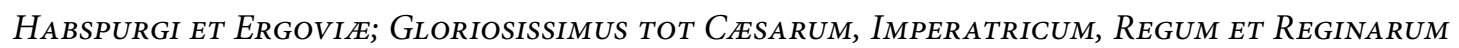
ex Anna Comite Hohenbergica Progenitor deCessit Anno Christi MCCXCI befindet sich auf dem Boden. Hinter der Kartusche wächst ein Lorbeerbaum mit weitverzweigten Ästen, auf denen Calin bekrönte Inschriftäfelchen verteilte, bei denen er verschiedene Kronenformen berücksichtigte. Beiderseits wird ein Heiliger in einem strahlenden Medaillon hervorgehoben; links Sanctus BERNARDVs Marchio Badensis (Bernhard von Baden wurde erst 1769 seliggesprochen) und rechts Sanctus Casimirvs Princeps Lithvan, der 1602 heiliggesprochene Sohn des polnischen Königs Kasimir IV. und der Elisabeth von Habsburg. Eine große Kartusche ist nur noch dem aktuellen Kaiser gewidmet: LEOPOLDVs Romanor: Imperator Semper Augustus, Germ: Hungarioe, Bohœmice Rex, Archidux Austrio; Vivat, et Augustum Sangvinem augeat!

Calins letztes bekanntes Werk für Leopold I. ist der Entwurf für die Porträts von Leopold I., seiner Gemahlin Eleonore und seiner 40 Ahnen für das Alchimistische Medaillon, das der Wiener Wachsbossierer Johann Permann fertigte und Johann Wenzel Sailer von Reinburg dem Kaiser schenkte. ${ }^{171}$ In der Mitte des Medaillons ist das kaiserliche Paar dargestellt, das von Ahnenbildnissen

\footnotetext{
${ }^{169} \mathrm{Zu}$ den Formen der visuellen Darstellung der genealogischen Daten siehe Stefan SEITSCHEK, Adel und Genealogie in der Frühen Neuzeit, Adel im 18. Jahrhundert. Umrisse einer sozialen Gruppe in der Krise (Hrsg. Gerhard Ammerer, Elisabeth Lobenwein, Martin Scheutz), Innsbruck-Wien-Bozen 2015, S. 58-61.

${ }^{170}$ Wien, Albertina, Inv. Nr. 44233.

${ }^{171}$ Friedrich POLLEROSS, Mythischer Stammbaum, Welt des Barock 1986 (Anm. 6), S. 66, Kat. Nr. 1.17; siehe auch
} 
in drei konzentrischen Kreisen umgeben ist, die chronologisch und spiralförmig vom äußeren Rand zur Mitte verlaufen. Die Ahnenreihe beginnt oben in der Mitte mit dem Frankenkönig Pharamundus von Troja und wird rechts mit fünf Frankenkönigen und drei Königen Austrasiens fortgeführt. Dann folgen die alemannischen Fürsten Sigisbertus I. und Sigisbertus II.; Ottobertus I. wird als Gründer des Hauses Habsburg beschrieben. Ihm folgen sechzehn Grafen von Habsburg. Die Reihenfolge der legendären Ahnen folgt weitgehend dem Stammbaum, den Calin 1666 ausgeführt hat. Zwölf Habsburger von Rudolf I. bis Ferdinand III. sind dieselben, die Calin 1671 für das Theatrum Austriacae Glorice wählte, nur fügte er Friedrich den Schönen hinzu. Die Dargestellten sind vor allem durch die Kopfbedeckungen differenziert. Nur Leopold I. und seine beiden unmittelbaren Vorgänger sind mit einem Lorbeerkranz bekrönt, einige Ahnen tragen Kaiser- oder Königskronen, die Grafen von Habsburg meist Helme, während Pharamundus einen Turban trägt. Die kreisförmige Anordnung der Ahnen um das Porträt Leopolds I. kommt auf Medaillen vor, ${ }^{172}$ näher verwandt ist aber ein Stich von Christian Adam Widmann und Gerard de Groos, der im 1673 in Prag publizierten Fürstenspiegel von Johann Jacob Weingarten veröffentlicht wurde. ${ }^{173}$ Auf dem Stich sind die Bildnisse, beginnend mit Sigisbertus Graf von Habsburg, nur in zwei Kreisen um das Porträt Leopolds I. in der Mitte angeordnet.

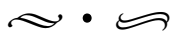

Im Gegensatz zu den Werken seines Zeitgenossen Johann Ludwig Schönleben (1618-1681), der vorwiegend in Ljubljana (Laibach) tätig war und sich der Genealogie der Habsburger und der adeligen Familien, der Geschichte Krains, rhetorischen, theologisch-mariologischen, dramatischen und philosophischen Werken widmete, ${ }^{174}$ haben die Werke Calins kaum die Aufmerksamkeit der Forscher geweckt. Die Kritik von Anna Coreth, dass Dominik Franz Calin ein „nicht sehr erfolgreicher kaiserlicher Historiograph “ gewesen sei, gründete in der Tatsache, dass sein ambitionierter Plan einer Ausgabe des "Genealogischen Ehrenwerkes" nicht realisiert wurde ${ }^{175}$ wohl aber auch in der Unkenntnis der zahlreichen ausgeführten Werke Calins. Aufgrund der Angaben zu Calins Einkommen - 1677 erhielt er von der Hoffinanzkammer die beträchtliche Summe von 2150 Gulden ${ }^{176}$ - darf man Calin zu den bestbezahlten Gelehrten am Kaiserhof zählen. ${ }^{177}$ Die im Beitrag

POLLEROSS 2003 (Anm. 33), S. 240-241.

${ }^{172}$ Siehe die Medaille anlässlich der Krönung Josephs I. zum Römischen König, auf der ein Brustbild Leopolds I. von den Porträts aller Kaiser aus dem Haus Habsburg umgeben ist, beginnend mit Rudolf I. in der Mitte unten; SCHUMANN 2003 (Anm. 45), S. 330, 531, 568.

${ }^{173}$ Johann Jacob WEINGARTEN, Fürsten=Spiegel Oder Monarchia Deß hochlöblichen Ertz=Hauses Oesterreich. Worinnen Im Ersten Theil Nit allein alle Römische Kayser und Könige von Rudolpho I. sondern auch alle Hertzog=Ertzherzog= und Graffen auß dem hochlöblichen Ertz=Hauss Oesterreich / so viel deren bießhero von denen Historicis vorgebracht worden / bieß auff die Jetzt Glorwürdig Regierende Maytt: Leopoldum I. /.../, Prag 1673.

${ }^{174} \mathrm{Zu}$ den Werken Schönlebens siehe zuletzt Monika DEŽELAK TROJAR, Janez Ludvik Schönleben (1681-1681). Oris življenja in dela, Ljubljana 2017 (Apes academicae, 1), S. 201-246 (mit älterer Bibliographie).

175 CORETH 1950 (Anm. 8), S. 40.

176 LEITNER 1989 (Anm. 1), S. 527.

177 Graf Galeazzo Gualdo Priorato wurde 1664 als Hofhistoriker mit einem Jahresgehalt von 1500 Gulden angestellt, erhielt jedoch von 1666 bis 1669 mindestens 12.200 Gulden an Honoraren für die Recherche zu dem dreibändigen Werk Historia di Leopoldo Cesare; siehe POLLEROSS 2003 (Anm. 33), S. 271-272. Die höchsten Jahresgehälter um die 1500/2000 Gulden erhielten die Inhaber der obersten Hofämter, wie der Obersthofmarschall und der Oberstallmeister sowie die Kapellmeister, die Hofarchitekten Fischer von Erlach und Hildebrandt und manche Sänger; siehe POLLEROSS 2003 (Anm. 33), S. 197. 
vorgestellten Arbeiten dokumentieren Calins Wirken als Poet, Librettist, Historiograph, Genealoge, Schöpfer von Emblemen, Zeichner und Maler. Die Erstellung eines kompletten Werkkatalogs wird durch die weite Verstreuung seiner Werke, die als Unikate oder Drucke in geringer Auflage in verschiedenen öffentlichen Institutionen und in Privatbesitz erhalten sind, erschwert. ${ }^{178}$ Zur unzureichenden Kenntnis von Calins Werken trug auch die Tatsache bei, dass seine prächtigen, für das Haus Habsburg gemalten Stammbäume nie ausgestellt wurden. Angesichts des heutigen Forschungsstands darf man schließen, dass die Stärke des malerisch begabten Gelehrten Dominik Franz Calin vor allem in Wort-Bild-Kombinationen lag, was sowohl in seinen emblematischen als auch in den genealogischen Werken zum Ausdruck kommt. ${ }^{179}$

${ }^{178} \mathrm{Zu}$ den 30 Werken, die Friedrich W. Leitner bekannt waren (LEITNER 1989 (Anm. 1), S. 625-630), kann man mindestens noch die emblematische Gratulationsschrift In optatissimo Natalis Diei recursu, die Geschichtswerke über die Grafen Sinzendorff und die Grafen Serényi, fünf großformatige gemalte Stammbäume der Familien Auersperg, Dietrichstein, Harrach und Kuenburg sowie den Entwurf für den Stammbaum der Familie Esterhazy rechnen; siehe VIDMAR 2019 (Anm. 3), S. 50-61; Polona VIDMAR, Rodovnik Auerspergov s Turjaka ter rodovniki genealoga in historiografa Dominika Frančiška Kalina von Marienberga za dvorno plemstvo, Kronika, 69/2, 2021, S. 239-266.

179 Dieser Beitrag entstand im Rahmen des Forschungsprogramms Slovenian Artistic Identity in European Context (Slovenian Research Agency, P6-0061). 


\section{Bibliographie}

AMANN-BUBENIK, Johannes, Kaiserserien und Habsburger-Genealogien. Die Entwicklung einer Gattung poetischer Habsburgerpanegyrik vom 16. bis zum 18. Jahrhundert, Wien 2013 (ungedruckte Dissertation).

ANDRITSCH, Johann, Die Matrikeln der Universität Graz 1630-1662, 6/2, Graz 1980.

APPUHN-RADTKE, Sibylle, Das Thesenblatt im Hochbarock. Studien zu einer graphischen Gattung am Beispiel der Werke Bartholomäus Kilians, Weißenhorn 1988.

APPUHN-RADTKE, Sibylle, Allegorie und Emblem, Quellenkunde der Habsburgermonarchie (16.-18. Jahrhundert). Ein exemplarisches Handbuch (Hrsg. Josef Pauser, Martin Scheutz, Thomas Winkelbauer), Wien-München 2004 (= Mitteilungen des Instituts für Österreichische Geschichtsforschung, 44), S. 898-915.

APPUHN-RADTKE, Sibylle, Sol oder Phaeton? Invention und Imitation barocker Bildpropaganda in Wien und Paris, Kunst und Macht. Politik und Herrschaft im Medium der bildenden Kunst (Hrsg. Wilhelm Hofmann, Hans-Otto Mühleisen), Münster 2005 (Studien zur visuellen Politik, 2), S. 94-127.

AVANCINI, Nicolaus, Imperium Romano-Germanicum, sive quinquaginta imperatorum ac Germaniae regum Elogia: Augustissimo Romanorum Imperatori Leopoldo, Ab Antiquissima ac Celeberrima Universitate Viennensi oblata /.../, Viennae 1658.

BENEDIK, Christian, Le grandi opere xilografiche di Massimiliano I: Corteo Trionfale e l'Arco di Trionfo, Divus Maximilianus. Una contea per i Goriziani 1500-1619 (Hrsg. Silvano Cavazza), Mariano del Friuli 2002, S. 51-65.

BRANDHUBER, Christoph, Caesare Duce. Zur Ikonographie des Caesar-Zyklus in der Residenzgalerie Salzburg, Residenzgalerie Salzburg. Gesamtverzeichnis der Gemälde (Hrsg. Roswitha Juffinger), Salzburg 2010, S. 400-433.

BRANDHUBER, Christoph, Trias colossea. Max Gandolphs Familie, Fürsterzbischof Maximilian Gandolph Graf von Kuenburg. Regisseur auf vielen Bühnen 1668-1687 (Hrsg. Christoph Brandhuber, Reinhard Gratz), Salzburg 2018, S. 17-21.

Caius Suetonius Tranquillus. Cum annotationibus diversorum, Amsterdam 1650.

CALIN, Maria Anna Sibylla, Corona Immortalis Gloriae in Leopoldi Augusti Caesaris Praeclaris Virtutibus effigiata; Eiusdemque Sacratissimae Maiestati Humillimo Calamo consecrata â Maria Anna Sibylla Calina. Anno Chr. MDCLXXI, Österreichische Nationalbibliothek, Sammlung von Handschriften und alten Drucken, Cod. 10176.

CALIN VON MARIENBERG, Dominicus Franciscus, Corona Austriacorum Caesarum, nec non Ungariae, Boemiaeque Regum elogia. Annexo panegyrico, et luctu Austriae, ob tristissimum obitum Divi Ferdinandi Tertii, Caesaris Augusti, justi, pii s. Serenissimo ac potentissimo Principi, Domino, Domino Leopoldo, Ungariae, Boemiaeque Regi s. Archiduci Austriae, Duci Burgundiae, Styriae, Carinthiae, Carnioliae etc. Comiti Habspurgi, Tyrolis, et Goritiae etc. Domino, Domino clementissimo, humillime submisissimeque dedicata a Dominico Kalyno ex comitatu Goritiensi, 1657, Österreichische Nationalbibliothek, Sammlung von Handschriften und alten Drucken, Cod. 10210.

CALIN VON MARIENBERG, Dominicus Franciscus, Aurora exorta. Hoc est Serenissima princeps Maria Anna Christina Iosepha Theresia Caietana Antonia Francisca Felix Hyacinta Victoria serenissimis Bavariae principibus Ferdinando Mariae et Adelaidae Henrietae anno quo GratIa De CoeLIs BoIas ManaVIt In oras felicissime progenita. Cuius Auspicatissimos Exortus Carmine atque Emblemate Dominicus Franciscus Calin de sancta Cruce ex Comitatu Goritioe representauit, Monachii 1660.

CALIN VON MARIENBERG, Dominicus Franciscus, Sol Oriens. In Serenissimo Principe ac Domino, Domino Maximiliano Emmanuele Ludovico Maria Iosepho Caietano Antonio Nicolao Francisco Ignatio Felice, Serenissimi et Potentissimi Principis ac Domini, Domini Ferdinandi Mariae, 
Utr. Bauariae \& Sup. Palat. Ducis, Com. Pal. Rheni, S.R.I. Archidap. \& Electoris, Landgrauij Leichtenbergae, nec non Serenissimae Principis ac Dominae, Dominae Mariae Henrietae Adelaidae, Utriusq; Bauariae \& Sup. Palat. Ducis. Com. Pal. Rh. Electr. Landgraviae Leichtenbergensis, Natae Regiae Principis Sabaudiae \& cr. Dilectissimo filio effigiatus â Dominico Francisco Calin, de Sancta Cruce ex Comitatu Goritiae, Monachij 1662.

CALIN VON MARIENBERG, Dominicus Franciscus, In optatissimo Natalis Diei recursu Augustissimi, potentissimi ac invictissimi Romanorum Imperatoris Leopoldi, Germaniae, Hungariae, Bohoemiae Regis; Archiducis Austriae; Ducis Burgundiae, Styriae, Carinthiae, Carniolae; \&c. \&c. Comitis Habspurgi, Tyrolis \& Goritiae \& c. Eidem Sacrat. ${ }^{\text {mae }}$ Majestati, nec non Pro communi totius Patriae applausu \& congratulatione, inclytis utr. Austriae statibus ac deputatis; humillimo et devotissimo animo dedicata â Serenissimi Bavariae Electoris Bibliothecario \& c. Dominico Francisco Calin, de Sancta Cruce ex Comitatu Goritiae, Viennae 1666.

CALIN VON MARIENBERG, Dominicus Franciscus, Thesaurus Genealogicus Omnium totius Europaei Orbis Regum et Principum Consanguinitates demonstrans. Authore Serenissimi Bauar: Elec: Bibliothecario Dominico Francis: Calin de Sancta Cruce /.../, 1671, Österreichische Nationalbibliothek, Sammlung von Handschriften und alten Drucken, Cod. 9229.

CALIN VON MARIENBERG, Dominicus Franciscus, Copia della Semplicissima Inventione sopra le Quattro Monarchie del Mondo, Humillissim ${ }^{\text {te }}$ Dedicata in Poesia e Musica con un Dissegno di Gran Amfiteatro, a Sua Sacra Cesarea Real Maesta, L’Anno 1675. Domenico Francesco Calin etc. Dove si scuopre, che l'Opera essibita nel Gran Theatro, col Titolo La Monarchia Latina Trionfante per solenizzare la Gloriosissima Nascita del Serenissimo Arciduca Gioseppe etc. Sij stata tutta cavata da quella, ò al meno aplicata nel medemo tenore, Österreichische Nationalbibliothek, Sammlung von Handschriften und alten Drucken, Cod. 10109, Fol. 9r-25r.

CALIN VON MARIENBERG, Dominicus Franciscus, Gentilitius Honos Serenissimae Neoburgicae Prosapiae Duodecim Regiis Coronis Exornatus. Hoc est Opus Genealogico-Historicum In quo per succedentes Generationes stemmatographicé repraesentantur, qualiter Augustissima Neo-Imperatrix Eleonora Magdalena Theresia, Leopoldi Ter Justi, Ter Pii, Terque Magni Caes. Tertia Conjunx, Nata Com: Palatina Rheni in Neuburg, Ducissa Bavariae, Juliaci, Cliviae, Montium etc. Inter festivos Germaniae Applausus publicae luci expositus A Dominoco Francisco Calin de Marienberg, Equite Aurato, Comite Palatino \& Historiographo Cosareo. Anno, quo Austriaca Domus Augusta prole beabitur, Viennae [1677].

CALIN VON MARIENBERG, Dominicus Franciscus, Provocatio Humanissima Dominici Francisci Calin de Marienberg, Historiographi Caesarei etc. Scripta ad Danielem Nesselium Caesareum Bibliothecarium etc. XXVI. Septembris, Anno Salutis MDCLXXX. Concernens primam Serenissimae Habspurgo-Austriae Gentis originem, Österreichische Nationalbibliothek, Sammlung von Handschriften und alten Drucken, Cod. 10109, Fol. 26r-26v.

CALIN VON MARIENBERG, Dominicus Franciscus, Trionfo riportato dall'Invidia. Rappresentatione d'un Gran Torneo à Cavallo, introdotto da Dodieci superbissime Comparse sopra tanti Carri Trionfanti, per solennizzare le Gran Glorie dell'Avgustissima Casa d'Austria. Inventione semplicissima Humillißim. Dedicata à Sua Sacra Cesarea Real Maesta di Leopoldo Imperatore de Romani \&c. Da Domenico Fran: Calin di Marienberg \& c. L’Anno 1680, Österreichische Nationalbibliothek, Sammlung von Handschriften und alten Drucken, Cod. 10109, Fol. 1r-8v.

CALIN VON MARIENBERG, Dominicus Franciscus, Congratulatoria Emblemata, et Luminaria ad Auspicatissimas Cunas Serenissimi Neogeniti Archiducis Leopoldi \& c. Inter Festivos Applausus Publice Repraesentata â Dominico Francisco Calin de Marienberg, Equite Aurato, Com. Palat., et Histor. Caesareo, Viennae Austriae, Anno Chr. MDCLXXXII, Mense Iunio, Österreichische Nationalbibliothek, Sammlung von Handschriften und alten Drucken, Cod. 8321.

CALIN VON MARIENBERG, Dominicus Franciscus, Specification der Genealogischen Ehrnwerkh, welche, sofern Ihro Kä̈s: Mä̈s: allergnädigist beliebig wäre, khundten in Vier sonderliche Theil, der nachkhomenden Posteritet zu einem angedenkhen, forderist aber Zu Ihr Kä̈s: Mä̈s: immerwehrender 
Ehr, Von mir Dominico Francisco Calin gemacht und aufgesezt werden, Österreichische Nationalbibliothek, Sammlung von Handschriften und alten Drucken, Cod. 4014.

CHMEL, Joseph, Die Handschriften in der k. k. Hofbibliothek in Wien, 1, Wien 1840.

CORETH, Anna, Österreichische Geschichtsschreibung in der Barockzeit (1620-1740), Wien 1950

(Veröffentlichungen der Kommission für Neuere Geschichte Österreichs, 37).

CORETH, Anna, Pietas Austriaca. Ursprung und Entwicklung barocker Frömmigkeit in Österreich, Wien 1959.

DE STRADA À ROSBERG, Octavio, De Vitis imperatorum et caesarum romanorum, tam occidentalium quam orientalium, nec non uxorum et liberorum eorum, item tyrannorum omnium, qui diversis temporibus Romanum Imperium attentare \& occupare conti sunt, inde à C. Iulio Caesare, primo Monarcha ad D. N. Imperatorem, Caesarem Matthiam, vnà cum eorum effigiebus \& symbolis; /.../ olim Incredibili labore, sumptu magno, peregrinationibus multis, ijsque periculosis Octavii de Strada à Rosberg, civis Romani, S. C. Mtis, Rudolphi sanctissimae memoriae Nobilis Aulici \& Antiquarij ordinatij congestum \& adornatum /.../, Francofurti ad Moenum 1615.

DE STRADA À ROSBERG, Octavio, Genealogia et series Serenissimorum \& Potentissimorum Austriae ducum, archiducum, regum, imperatorum; eorumque illustriss. Conjugum, Et Liberorum utriusque sexus a Rudolpho I. Habspurgensi imperatore Ad Invictissimum Ferdinandum II. Rom. Imper. Semper Augustum, \&c. Authore Octavio de Strada a Rosberg, Civ. Rom. DD. Maximiliani \& Rudolphi II. Caesarr. Nob. Aul. \& Antiquario. Nunc primum aeri incisa, \& publico usui data, Lugduni Batav. 1664.

DEŽELAK TROJAR, Monika, Janez Ludvik Schönleben (1618 - 1681). Oris življenja in dela, Ljubljana 2017 (Apes academicae, 1).

DIMITZ, August, Geschichte Krains von der ältesten Zeit bis auf das Jahr 1814, 4, Laibach 1876.

EHINGER, Elias, Deß aller Durchleüchtigsten Haus Osterreichs Herzogen, Ertzhertzogen, König vnd Kayser Eigentliche Contrafacturen, samt historischer beschreibung der Geburt register vnd geschlecht, von Rudolpho an, deß namens dem ersten Römischen Kaÿser biß auff Ferdinandum II. anitzo regirenden Römischen Kä̈ser \& c. In unsere Teütsche Sprach versetzt vnd von Wolfgang Kilian Bürger und Kupferstecher in Augspurg in Kupfer gestochen, Augsburg 1629.

Franckreich / Die neuen Conjuncturen Werden dir den Compass gewaltig verrücken / Benebenst vielen remarquablen Begebenheiten, Leipzig 1686.

FRIEDHUBER, Inge, Der 'Fuggerische Ehrenspiegel' als Quelle zur Geschichte Maximilians I. Ein Beitrag zur Kritik der Geschichtswerke Clemens Jägers und Sigmund von Birkens, Mitteilungen des Instituts für Österreichische Geschichtsforschung, 81, 1973, S. 101-138.

FUGGER, Johann Jakob, Spiegel der Ehren des Höchstlöblichsten Kayser- und Königlichen Erzhauses Oesterreich oder Ausführliche GeschichtSchrift von Desselben, und derer durch Erwählungs- HeuratErb- und Glücks-Fälle ihm zugewandter Kayserlichen HöchstWürde, Königreiche, Fürstentümer, Grafund Herrschaften, Erster Ankunft, Aufnahme, Fortstammung und hoher Befreundung mit KayserKönig- Chur- und Fürstlichen Häusern /.../, Nürnberg 1668.

Genealogia Serenissimae Domus Austriacae a Philippo Primo rege Hispaniarum, altero Austriacae magnitudinis fundatore ad augustissimos caesares Leopoldum, et Margaretham deducta, et eisdem augustissimis, dum felici, et toto orbe desiderato hymenaeo jungerentur. Submississime dedicata ab Archiducali Collegio Graecensi Societatis Jesu, Graecii 1666.

GLAVINICH, Sebastian, Deplua charitum Aurora Augustissimi Phoebi Leopoldi Augusto Rore in Margaritam resoluta: Auspicatissimis Toris Augustissimi, Potentissimi, Inuictissimi \& c. \& c. Leopoldi, et Augustissimae Margaritae affectu pio, et aeternum devoto oblata Ab humillimo subdito, ac Capellano Sebastiano Glauinich, Viennae 1666.

GOLOUBEVA, Maria, The Glorification of Emperor Leopold I in Image, Spectacle and Text, Mainz 2000 (Veröffentlichungen des Instituts für europäische Geschichte Mainz, 184).

HAMANN, Brigitte, Die Habsburger. Ein biographisches Lexikon, Wien 1988.

HEINZ, Günther, SCHÜTZ, Karl, Porträtgalerie zur Geschichte Österreichs von 1400 bis 1800, Wien 1976 (Führer durch das Kunsthistorische Museum, 23).

KAISER, Barbara, Schloss Eggenberg, Wien 2006. 
KARNER, Herbert, Pietas Mariana und die Heilung der Städte. Sakralität des Herrschers im öffentlichen Raum, Sakralisierungen des Herrschers an europäischen Höfen. Bau - Bild - Ritual - Musik (16481740), Regensburg 2019, S. 131-156.

KILIAN, Wolfgang, Serenissimorum Austriae Ducum, Archiducum, Regum, Imperatorum Genealogia, à Rudolpho I. Habsburgensi, Caesare, ad Ferdinandum II. Rom. Imp. semper Augustum, \&c. Aeri incisa à Wolfgango Kiliano, Eiconographo Augustano, Augustae Vindelicorum 1623.

KOŠAK, Tina, Between Uniformity and Uniqueness. Depictions of Benefactors of Stična Cistercian Abbey, Acta historiae artis Slovenica, 25/2, 2020, S. 173-202.

KOVÁCS, Elisabeth, Die Apotheose des Hauses Österreich. Repräsentation und politischer Anspruch, Welt des Barock (Hrsg. Rupert Feuchtmüller, Elisabeth Kovács), Wien-Freiburg-Basel 1986, S. 53-86.

KOVÁCS, Elisabeth, MAZAL, Otto, Maria Anna Sibylla Calina, Corona immortalis gloriae /.../, Welt des Barock. Katalog, Augustiner-Chorherrenstift St. Florian, Linz 1986, S. 80, Kat. Nr. 3.06.

KUKULJEVIĆ SAKCINSKI, Ivan, Leben südslawischer Künstler, Agram 1868.

LAVRIČ, Ana, Umetnostna dejavnost v konjiški župniji pod župnikom Sebastijanom Glavinićem de Glamoč, Kronika, 66/1, 2018, S. 43-68.

LEITNER, Friedrich W., Ein Kartenwerk des Hofhistorikers Domenicus Franciscus Calin von Marienberg über das Herzogtum Kärnten, Bericht über den dreizehnten österreichischen Historikertag in Klagenfurt, veranstaltet vom Verband Österreichischer Geschichtsvereine in der Zeit vom 18. bis 21. Mai 1976, Wien 1977, S. 239-248.

LEITNER, Friedrich W., Zur Genealogie des fürstlichen Hauses Portia, Archiv für Diplomatik, Schriftgeschichte, Siegel- und Wappenkunde, 35, 1989, S. 519-630.

LHOTSKY, Alphons, Apis Colonna. Fabeln und Theorien über die Abkunft der Habsburger. Ein Exkurs zur Chronica Austrie des Thomas Ebendorfer, Mitteilungen des Instituts für Geschichtsforschung und Archivwissenschaft in Wien, 60, 1944, S. 171-245.

LHOTSKY, Alphons, Die „Devise“ Kaiser Friedrichs III. und sein Notizbuch, Mitteilungen des Instituts für Österreichische Geschichtsforschung, 60, 1952, S. 155-193.

LISAC, Ljubomir Andrej, Kalin (Kalyn, Kalynus, Calin) Dominik Frančišek, Primorski slovenski biografski leksikon, 2/8 (Hrsg. Martin Jevnikar), Gorica 1982, S. 12-13.

The New Hollstein German Engravings, Etchings and Woodcuts 1400-1700. Johann Ulrich Kraus, 5 (Bearb. Jörg Diefenbacher; Hrsg. Eckhard Leuschner), Ouderkerk aan den Ijssel 2019.

PELC, Milan, Theatrum humanum. Ilustrirani letci i grafika 17. stoljeća kao zrcalo vremena. Primjeri iz Valvasorove grafičke zbirke Nadbiskupije zagrebačke, Zagreb 2013.

PELC, Milan, Panegyric Emblem Books, Jesuits and the Habsburg Emperors: Some Examples Related to $17^{\text {th }}$-Century Croatia, Radovi Instituta za povijest umjetnosti, 43, 2019, S. 59-74.

PIESPORD, Theodoricus, Serenissimorum potentissimorumque principum Habsburgi-Austriacorum stemma, origo, res gestae. Quatuor schematibus à Pharamundo Francorum rege ad haec usque tempora deductae. Iconibus, emblematibus, insignibus illustratae, Bruxellae 1616.

POLLEROSS, Friedrich, Mythischer Stammbaum, Welt des Barock. Katalog, Augustiner-Chorherrenstift St. Florian, Linz 1986, S. 66, Kat. Nr. 1.17.

POLLEROSS, Friedrich, Habsburgische Kaiserreihe, Welt des Barock. Katalog, Augustiner-Chorherrenstift St. Florian, Linz 1986, S. 66, Kat. Nr. 1.18.

POLLEROSS, Friedrich, Sonnenkönig und österreichische Sonne. Kunst und Wissenschaft als Fortsetzung des Krieges mit anderen Mitteln, Wiener Jahrbuch für Kunstgeschichte, 40, 1987, S. 239-256.

POLLEROSS, Friedrich, „Sol Austriacus“ und „Roi Soleil“. Amerika in den Auseinandersetzungen der europäischen Mächte, Federschmuck und Kaiserkrone. Das barocke Amerikabild in den habsburgischen Ländern (Hrsg. Friedrich Polleroß, Andrea Sommer-Mathis, Christopher F. Laferl), Schloßhof im Marchfeld 1992, S. 54-84.

POLLEROSS, Friedrich, „Austrie est imperare orbi universo.“ Der Globus als Herrschaftssymbol der 
Habsburger, 1492-1992. Spanien, Österreich und Iberoamerika (Hrsg. Wolfram Krömer), Innsbruck 1993, S. 35-50.

POLLEROSS, Friedrich, „Pro decore Majestatis”. Zur Repräsentation Kaiser Leopolds I. in Architektur, Bildender und Angewandter Kunst, Jahrbuch des Kunsthistorischen Museums Wien, 4/5, 2003, S. 191-295.

POLLEROSS, Friedrich, Architektur und Panegyrik. Eine Allegorie der Jesuiten zur Geburt von Erzherzog Leopold Joseph (1682), Barock in Mitteleuropa. Werke, Phänomene, Analysen. Hellmut Lorenz zum 65. Geburtstag (Hrsg. Martin Engel), Wien 2007 (= Wiener Jahrbuch für Kunstgeschichte, 55/56, 2006/2007), S. 375-391.

POLLEROSS, Friedrich, Die Immaculata, Kaiser Leopold I. und ein römisches Thesenblatt der Laibacher Franziskaner, Acta historiae artis Slovenica, 23/1, 2018, S. 93-111.

PORTEMAN, Karel, Emblematic Exhibitions (affixiones) at the Brussels Jesuit College (1630-1685), Brussels-Turnhout 1996.

RADICS, Peter, Umeteljnost in umeteljna obrtnost Slovencev. Kulturno-zgodovinska študija, Letopis Matice slovenske za leto 1880 (Hrsg. Janez Bleiweis), Ljubljana 1880, S. 1-58.

REISNER, Sonja, Die poetische Habsburg-Panegyrik in lateinischer Sprache als historische Quelle, Quellenkunde der Habsburgermonarchie (16.-18. Jahrhundert). Ein exemplarisches Handbuch (Hrsg. Josef Pauser, Martin Scheutz, Thomas Winkelbauer), Wien-München 2004 (= Mitteilungen des Instituts für Österreichische Geschichtsforschung, 44), S. 898-915.

SANDBICHLER, Veronika, Jörg Kölderer (?), Die Ahnen Kaiser Maximilians I., Kaiser Maximilian I. und die Kunst der Dürerzeit (Hrsg. Eva Michel, Maria Luise Sternath), Albertina, Wien, MünchenLondon-New York 2012, S. 170-171, Kat. Nr. 21.

SCHAUERTE, Thomas, Albrecht Dürer und Mitarbeiter, Albrecht Altdorfer, Die Ehrenpforte, 1515, Kaiser Maximilian I. und die Kunst der Dürerzeit (Hrsg. Eva Michel, Maria Luise Sternath), Albertina, Wien, München-London-New York 2012, S. 373-376, Kat. Nr. 124.

SCHEICHER, Elisabeth, Die „Imagines Gentis Austriacae“ des Francesco Terzio, Jahrbuch der Kunsthistorischen Sammlungen in Wien, 79, 1983, S. 43-92.

SCHRENCK VON NOTZING, Jacob, Augustissimorum Imperatorum, Serenissimorum Regum atque Archiducum, Illvstrissimorum Principum, nec non Comitum, Baronum, Nobilium, aliorumque Clarissimorum Virorum, qui aut ipsi cum imperio bellorum Ducem fuerunt, aut in iisdem profecturis insignioribus laudabiliter functi sunt, verissimae imagines, /.../. Opus Praelibati Serenissimi Archiducis jussu in vita inchoatum \& ab ejusdem Serenitatis Consiliario \& Secretario Jacobo Schrenkio a Nozingen continuatum \& absolutum, Oeniponti 1601.

SCHUMANN, Jutta, Die andere Sonne. Kaiserbild und Medienstrategien im Zeitalter Leopolds I., Augsburg 2003 (Colloquia Augustana, 17).

SEELIG, Lorenz, Aspekte des Herrscherlobs - Max Emanuel in Bildnis und Allegorie, Kurfürst Max Emanuel. Bayern und Europa um 1700. 1: Zur Geschichte und Kunstgeschichte der Max-Emanuel-Zeit (Hrsg. Hubert Glaser), München 1976, S. 1-29.

SEELIG, Lorenz, Fama prognostica, Kurfürst Max Emanuel. Bayern und Europa um 1700. 2: Katalog der Ausstellung im Alten und Neuen Schloß Schleißheim (Hrsg. Hubert Glaser, Reinhold Baumstark, Annemarie Seling), München 1976, S. 5-6, Kat. Nr. 6.

SEELIG, Lorenz, Emblematische Huldigung auf die Geburt Max Emanuels, Kurfürst Max Emanuel. Bayern und Europa um 1700. 2: Katalog der Ausstellung im Alten und Neuen Schloß Schleißheim (Hrsg. Hubert Glaser, Reinhold Baumstark, Annemarie Seling), München 1976, S. 6, Kat. Nr. 7.

SEITSCHEK, Stefan, Adel und Genealogie in der Frühen Neuzeit, Adel im 18. Jahrhundert. Umrisse einer sozialen Gruppe in der Krise (Hrsg. Gerhard Ammerer, Elisabeth Lobenwein, Martin Scheutz), Innsbruck-Wien-Bozen 2015, S. 55-90.

SMÍŠEK, Rostislav, Deplua charitum Aurora. Leopold I. a Markéta Tereza Španělská v symbolické řeči 
gratulačního spisu Sebastiana Glaviniće k jejich sňatku roku 1666, Listy filologické/Folia philologica, 137/1-2, 2014, S. 41-71.

SOMMER-MATHIS, Andrea, Das Theater auf der Kurtine, Die Wiener Hofburg 1521-1705. Baugeschichte, Funktion und Etablierung als Kaiserresidenz (Hrsg. Herbert Karner), Wien 2014, S. 422-427.

STANIČ, Stanko, Dominik Franc Kalin, Čas. Znanstvena revija Leonove družbe, 9, 1915, S. 280-283.

STELE, France, Kalin (Calin, Kalynus), Dominik Franz, Allgemeines Lexikon der bildenden Künstler von der Antike bis zur Gegenwart, 19 (Hrsg. Hans Vollmer), Leipzig 1926, S. 467.

STROHMEYER, Arno, Höfische und ständische Geschichtsschreibung, Quellenkunde der Habsburgermonarchie (16.-18. Jahrhundert). Ein exemplarisches Handbuch (Hrsg. Josef Pauser, Martin Scheutz, Thomas Winkelbauer), Wien-München 2004 (= Mitteilungen des Instituts für Österreichische Geschichtsforschung, 44), S. 881-897.

TERZIO, Francesco, Francisci Tertii Bergomatis Serenissimi Ferdinandi Archiducis Austriae Ducis Burgundiae Comitis Tirolis etc. pictoris aulici Austriacae gentis Imaginum, 1-5, Innsbruck 1569-1573.

TRIER, Dankmar, Grießler (Griessler), Lorenz, Allgemeines Künstler-Lexikon. Die Bildenden Künstler aller Zeiten und Völker, 62, München-Leipzig 2009, S. 77.

VIDMAR, Polona, Theatrum genealogicum. Die Stammbäume der Grafen Herberstein und Dietrichstein als Mittel adeliger Repräsentation, Acta historiae artis Slovenica, 24/2, 2019, S. 31-64.

VIDMAR, Polona, Rodovnik Auerspergov s Turjaka ter rodovniki genealoga in historiografa Dominika Frančiška Kalina von Marienberga za dvorno plemstvo, Kronika, 69/2, 2021, S. 239-266.

Vnderschidliche Schild vnd Wappen vnd dergleichen Kupfferstich Welche Von Vnderschidlichen Künstlern gezeichnet ins Kupffer gradirt, vnd gestochen Auch Allerley Geistliche vnd Weltliche Holtzschnid ziehrlich ins Holtz geschnitten Welche Mit Sonderbahren Fleiß zusamben gebracht Durch Johann Weychard Valvasor Freyhernn zu Wagensperg in Crain. Anno 1685 (Hrsg. Lojze Gostiša, Mirna Abaffy), Ljubljana-Zagreb 2008 (Iconotheca Valvasoriana, 16).

VOCELKA, Karl, HELLER, Lynne, Die Lebenswelt der Habsburger. Kultur- und Mentalitätsgeschichte einer Familie, Graz-Wien-Köln 1997.

WEINGARTEN, Johann Jacob, Fürsten=Spiegel Oder Monarchia Deß hochlöblichen Ertz=Hauses Oesterreich. Worinnen Im Ersten Theil Nit allein alle Römische Kayser und Könige von Rudolpho I. sondern auch alle Hertzog=Ertzherzog= und Graffen auß dem hochlöblichen Ertz=Hauss Oesterreich I so viel deren bießhero von denen Historicis vorgebracht worden / bieß auff die Jetzt Glorwürdig Regierende Maytt: Leopoldum I. /.../, Prag 1673.

ZIEGLER, Hendrik, Der Sonnenkönig und seine Feinde. Die Bildpropaganda Ludwigs XIV. in der Kritik, Petersberg 2010 (Studien zur internationalen Architektur- und Kunstgeschichte, 79).

\section{Abbildungsnachweis}

1-7, 15-20, 29: @ Österreichische Nationalbibliothek, Wien.

8-11: Google Books.

12-14: ๑ Herzog August Bibliothek Wolfenbüttel.

21-25, Beilage 1-2: ๑ Albertina, Wien.

26: Vnderschidliche Schild vnd Wappen, Ljubljana-Zagreb 2008.

27-28: @ Landesmuseum Kärnten, Klagenfurt. 


\title{
Emblematična voščila, rodovniki in portreti Dominika Frančiška Kalina von Marienberga za Habsburžane
}

\author{
Povzetek
}

Življenje in delo poeta, libretista, historiografa, genealoga, risarja in slikarja Dominika Frančiška Kalina von Marienberg (1624-1683) iz Svetega Križa v nekdanji goriški grofiji sta slabo preučeni. Seznam tridesetih Kalinovih del, ki ga je leta 1989 sestavil Friedrich W. Leitner, je bilo v zadnjih letih mogoče dopolniti z nekaterimi slikanimi rodovniki, ki so ohranjeni v zasebni lasti, ter s slavilnimi spisi in rodbinskimi genealogijami. O Kalinovem uspehu pričajo ugledni naročniki, med njimi bavarski volilni knez, cesar Leopold I., salzburški nadškof in pripadniki dunajskega dvornega plemstva, znatna izplačila dvorne komore in velika hiša na Dunaju, katere risba je v prispevku prvič objavljena. Za nazive bibliotekarja in sekretarja bavarskega volilnega kneza, cesarskega historiografa in genealoga ter palatinskega grofa $s$ predikatom von Marienberg pa je že Leitner ugotovil, da so bili zgolj častni.

Najstarejše doslej znano Kalinovo delo je rokopis Corona Austriacorum Caesarum s tremi serijami pesmi, posvečenimi cesarjem iz rodbine Habsburžanov ter ogrskim in češkim kraljem, ki ga je Kalin leta 1657 namenil (bodočemu) cesarju Leopoldu I. V naslednjih letih je Kalin verjetno bival v Münchnu, kjer je v zgodnjih šestdesetih letih 17. stoletja izšlo nekaj njegovih del, med njimi leta 1660 priložnostno slavilno voščilo ob rojstvu Marije Ane, najstarejše hčere bavarskega volilnega kneza Ferdinanda Marije, in dve leti pozneje sorodno delo ob rojstvu prestolonaslednika Maksimilijana II. Emanuela. Voščili sta ilustrirani z emblemi, ki so delo drugih avtorjev, vendar jih je Kalin verjetno idejno zasnoval.

Po domnevni selitvi na Dunaj v letih 1665/1666 je Kalin ustvarjal raznolika dela za cesarja. Za nelaskavo oceno Kalinove uspešnosti, ki jo je leta 1950 podala Anna Coreth, je zaslužna zlasti Kalinova nedatirana napoved cesarju, da bo spisal in ilustriral genealoško slavilno delo (Genealogisches Ehrenwerk) v štirih delih, vendar ambicioznega načrta ni uresničil. Izvedel pa je delo Thesaurus Genealogicus s stodvainpetdesetimi rodovniki evropskih kraljevskih in knežjih rodbin in ga leta 1671 predložil cesarju. Alegorično naslovnico je po Kalinovem osnutku narisal Lorenz Griessler. V kodeks 10109 v Avstrijski nacionalni biblioteki so vezana tri krajša Kalinova besedila $z$ dvema ilustracijama. V enem od njih je Kalin s cesarskim bibliotekarjem Danielom Nesslom polemiziral o izvoru Habsburžanov, ki po Kalinu ne izhajajo iz rimskih Pierleonijev, temveč iz Trojancev, Sikambrijcev in Merovingov. Drugo besedilo je scenarij za slavilni turnir, ki ga je Kalin 1680 posvetil cesarju, tretje pa libreto, s katerim je Kalin cesarju dokazoval, da je libretist Nicolò Minato za slavnostno opero La Monarchia latina trionfante, ki so jo izvedli ob rojstvu prestolonaslednika Jožefa leta 1678, kopiral tri leta starejšo Kalinovo idejo.

Leta 1671 je Kalinova soproga Marija Ana Sibila cesarju podarila rokopis Corona Immortalis Gloriae. Kalinovo besedilo je prepisala v kaligrafski zlati pisavi in ilustrirala z osmimi emblemi, ki kažejo Leopoldove vladarske kreposti. Nekateri emblemi vključujejo aktualne motive, kot so izgon Judov z Dunaja, zmaga nad turško vojsko in nova postavitev Marijinega stebra na dunajskem trgu Am Hof. Domnevati smemo, da je Marija Ana Sibila s soprogom sodelovala tudi pri slikanju drugih emblematičnih in genealoških del, ki nosijo samo njegov podpis.

Ob poroki cesarja Leopolda z Margareto Terezijo leta 1666 je Kalin objavil slavilno delo In optantissimo natalis diei recursu, ki je ilustrirano s frontispicem in desetimi emblemi. Frontispic je signiral dunajski bakrorezec Johann Martin Lerch, ki je s Kalinom sodeloval tudi pri bakrorezih habsburških rodovnikov. Risar ni podpisan, vendar domnevamo, da je risbe Lerchu pripravil Kalin. Da je tudi sam risal embleme, je razvidno iz emblematičnega slavilnega spisa, ki ga je podaril cesarju po rojstvu drugega 
sina, nadvojvode Leopolda Jožefa leta 1682, in je ostal v rokopisu. S sedmimi risbami ilustrirano besedilo je bilo odgovor na provokacijo francoskega veleposlanika, ki si je drznil kralja Ludvika XIV. sredi Dunaja predstaviti kot pomembnejšega od cesarja.

Ob poroki cesarja Leopolda I. z Margareto Terezijo leta 1666 je Kalin zasnoval in naslikal reprezentativen rodovnik velikega formata Genealogia Habspurgo-Austriaca, et Austriaco-Hispanica, na katerem je izvor Habsburžanov izpeljal iz frankovskega kralja Faramunda iz Troje in rodovnik zaključil s portretoma aktualnega cesarja in njegove soproge. Genealoške podatke je dopolnil s portreti, rodbinskimi in deželnimi grbi, devizami in mitološkima prizoroma. Istega leta je verjetno kot pendant $\mathrm{k}$ rodovniku za cesarja naslikal tudi reprezentativno upodobitev Iconologia et Series omnium, quotquot â Iulio Coesare fuerunt, Imperatorum Romanorum, Byzantinorum, Germanicorum, Turcicorum s portreti dvainpetdesetih cesarjev Svetega rimskega cesarstva od Karla Velikega do Leopolda I., rimskih in bizantinskih cesarjev ter turških sultanov. Pri upodobitvah se je Kalin opiral na portretne knjige 16. in 17. stoletja, za 163 portretov bizantinskih cesarjev in turških sultanov pa smemo domnevati, da se je zgledoval po objavljenih zbirkah novcev.

Ob rojstvu prestolonaslednika Ferdinanda Venclja Jožefa leta 1667 je Kalin pripravil osnutek za rodovnik Habsburžanov Genealogia Habspurgo-Austriacae Domus, ki ga je v baker vrezal Johann Martin Lerch. Edini doslej znani izvod je iz zbirke Janeza Vajkarda Valvasorja. Rodovno deblo se prične z Rudolfom I. Habsburškim in zaključi z aktualnim cesarskim parom, spremljajo pa ga personifikacije kreposti, upodobitve grbov in 54 portretov Habsburžanov z njihovimi devizami. Večina portretov je posneta po bakrorezih Wolfganga Kiliana. Ob drugi poroki cesarja Leopolda z nadvojvodinjo Klavdijo Felicito leta 1673 je bila matrica minimalno predelana in opremljena $\mathrm{z}$ imenom in portretom nove cesarice. Edini znani odtis bakroreza po predelavi je ohranjen v Koroškem deželnem muzeju v Celovcu.

Ob primerjavi s sodobnikom Janezom Ludvikom Schönlebnom (1618-1681), ki se je posvečal sorodnim temam kot Kalin, ugotovimo, da je Kalinov opus veliko slabše raziskan. Z emblemi ilustrirani priložnostni slavilni spisi razodevajo Kalinovo spretnost v emblematičnem razmišljanju in kombiniranju, kakršno so gojili zlasti na jezuitskih gimnazijah. Pomemben in doslej skoraj spregledan pa je tudi Kalinov prispevek k vizualizaciji genealoških podatkov. Ob dosedanjem poznavanju njegovega opusa bi smeli zaključiti, da je uspeh učenega, razgledanega in slikarsko nadarjenega Kalina temeljil na uspešnem kombiniranju teksta in podobe, ki ga kažejo njegova emblematična in genealoška dela. 